MARIANA BERGMANN DA SILVA

\title{
OTIMIZAÇÃO DE REDES DE DISTRIBUIÇÃO FÍSICA CONSIDERANDO INCENTIVO FISCAL BASEADO NO CRÉDITO PRESUMIDO DE ICMS
}

Dissertação apresentada à Escola

Politécnica da Universidade de São

Paulo para obtenção do Título de Mestre em Engenharia.

São Paulo

2007 
MARIANA BERGMANN DA SILVA

\section{OTIMIZAÇÃO DE REDES DE DISTRIBUIÇÃO FÍSICA CONSIDERANDO INCENTIVO FISCAL BASEADO NO CRÉDITO PRESUMIDO DE ICMS}

Dissertação apresentada à Escola

Politécnica da Universidade de São

Paulo para obtenção do Título de Mestre em Engenharia.

Área de Concentração:

Engenharia de Sistemas Logísticos

Orientador:

Prof. Livre-Docente

Hugo Tsugunobu Yoshida Yoshizaki

São Paulo

2007 
Este exemplar foi revisado e alterado em relação à versão original, sob responsabilidade única do autor e com a anuência de ser orientador.

São Paulo, ..... de de $200 \ldots$.

Assinatura do autor

Assinatura do orientador

FICHA CATALOGRÁFICA

Silva, Mariana Bergmann da

Otimização de redes de distribuição física considerando incentivo fiscal baseado no crédito presumido de ICMS / M.B. da Silva. -- São Paulo, 2007. $115 \mathrm{p}$.

Dissertação (Mestrado) - Escola Politécnica da Universidade de São Paulo. Departamento de Engenharia de Transportes.

1.Logística (Administração de materiais) 2.Modelos (Localização) 3.Imposto sobre circulação de mercadorias e serviços I.Universidade de São Paulo. Escola Politécnica. Departamento de Engenharia de Transportes II.t. 
À minha mãe. 
“... se antes de cada acto nosso nos puséssemos a prever todas as conseqüências dele, a pensar nelas a sério, primeiro as imediatas, depois as prováveis, depois as possíveis, depois as imagináveis, não chegaríamos sequer a mover-nos de onde o primeiro pensamento nos tivesse feito parar. Os bons e os maus resultados dos nossos ditos e obras vão-se distribuindo supõe-se que de uma forma bastante uniforme e equilibrada, por todos os dias do futuro, incluindo aqueles, infindáveis, em que já cá não estaremos para poder comprová-lo, para congratular-nos ou pedir perdão; aliás, há quem diga que isso é que é a imortalidade de que tanto se fala, ..."

José Saramago, em Ensaio sobre a cegueira 


\section{AGRADECIMENTOS}

Ao Prof. Hugo Yoshizaki, pelos ensinamentos, pela experiência compartilhada, pelas oportunidades oferecidas e pela especial atenção dedicada para a orientação deste trabalho.

Aos demais professores do Programa de Mestrado em Engenharia de Sistemas Logísticos, pelos ensinamentos e pela grande oportunidade que me deram.

Ao Celso Mitsuo Hino, por toda a ajuda e dedicação, que foram fundamentais para tornar possível a realização deste trabalho.

Ao Rogério Camargo, pelos valiosos momentos de discussão sobre questões tributárias e pela grande ajuda prestada sempre que solicitado.

Ao Mário Morhy, pelo apoio à realização deste trabalho e pela compreensão das necessárias ausências no ambiente de trabalho.

A todos os amigos e colegas que estiveram ao meu lado e que, de forma direta ou indireta, participaram desta conquista.

À minha família, por ter investido na minha formação.

A todos, meus sinceros agradecimentos. 


\section{RESUMO}

Este trabalho estuda a influência de determinados incentivos fiscais relacionados ao Imposto sobre Circulação de Mercadorias e Serviços na estruturação de projetos de rede de distribuição física. O objetivo consiste em desenvolver um modelo matemático que determine uma logística de menor custo considerando incentivos fiscais com base no crédito presumido, em que a característica do cálculo do incentivo é um crédito proporcional ao valor da base de cálculo das notas fiscais com saídas para venda.

Para tanto, estruturou-se um modelo de Programação Linear Inteira Mista. A função objetivo do modelo foi estruturada para minimizar os custos totais, sendo estes compostos por duas parcelas de custos logísticos (frete e armazenagem) e uma parcela referente ao benefício fiscal, que entra como uma parcela negativa na função objetivo, haja visto que o benefício fiscal auferido equivale ao montante do saldo de impostos devido que se deixa de pagar.

Alguns cenários que contemplam as características dos incentivos analisados foram estudados aplicando-se o modelo matemático a um problema fictício, formulado com base na rede de distribuição física de uma indústria que produz e comercializa bens de consumo não duráveis. Para que os resultados obtidos fossem realísticos, os valores referentes aos custos logísticos (fretes e transbordo) bem como os volumes e a distribuição da demanda foram levantados com base nos dados reais de um ano de operação dessa mesma indústria. 


\begin{abstract}
This research evaluates the influence of some specific fiscal benefits related to current states sale taxes for internal and interstate operations over distribution center location decisions. The objective is to develop a mathematic model that determines a distribution network with lower cost considering fiscal benefits based on presumed credit, which is calculated as a proportional value of sales prices.

To reach this objective a Mixed Integer Linear Programming model was developed. The optimizing function was structured to minimize the total cost, composed by logistics costs (freight and warehousing) and by fiscal benefit, which is a negative cost function due to the fact that the fiscal benefit is related to the tax that won't be paid.

Some scenarios considering these fiscal characteristics were studied. The model was applied on a fictitious problem based on the distribution network of a manufacturer that produces and commercializes non durables consumption products. In order to get realistic results, logistics costs (freight and warehousing) and demand parameters were real data gathered from that manufacturer.
\end{abstract}




\section{SUMÁRIO}

LISTA DE FIGURAS ................................................................................................... ix

LISTA DE TABELAS .....................................................................................................

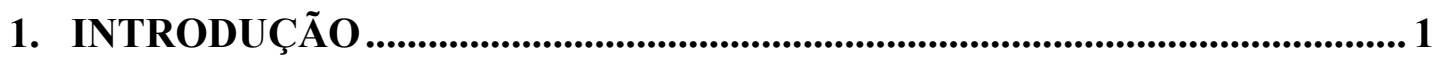

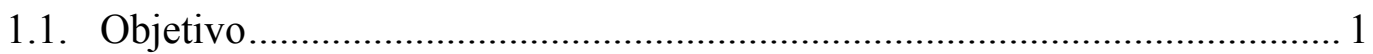

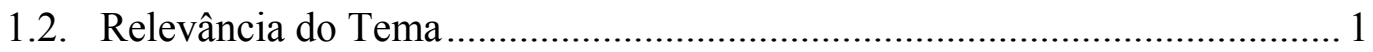

1.3. Organização da Dissertação ...................................................................... 3

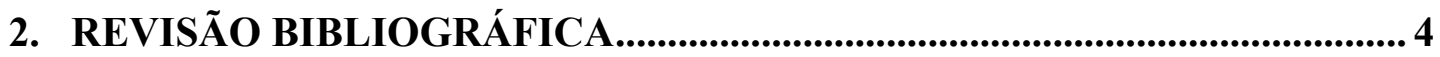

2.1. A Questão Tributária no Brasil ............................................................... 4

2.1.1. Legislação tributária brasileira.................................................... 4

2.1.2. Tributos incidentes em operações logísticas ................................... 8

2.1.3. Incidência do ICMS nas operações logísticas de transferência e venda. 9

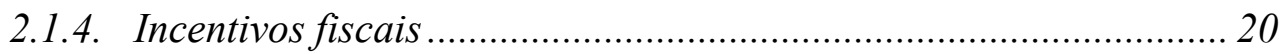

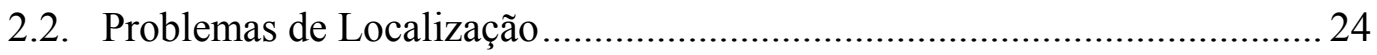

2.2.1. Métodos para configuração da rede logística ………………........ 28

2.2.2. Modelos de localização que consideram a questão fiscal relativa ao ICMS 30

3. MODELAGEM DO PROBLEMA .................................................................39

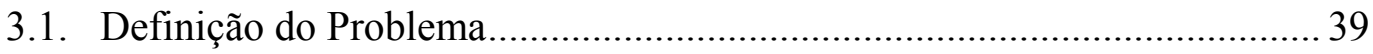

3.2. O Modelo Matemático …………………………………............................ 41



4. DESCRIÇÃO DO CASO ESTUDADO ........................................................... 47

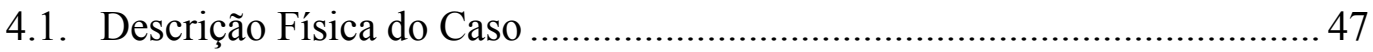

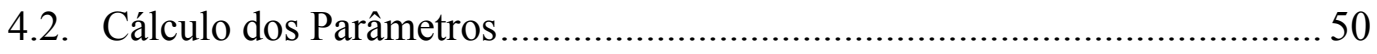

5. APLICACAÇ̃̃O DO MODELO E ANÁLISE DOS RESULTADOS...........56

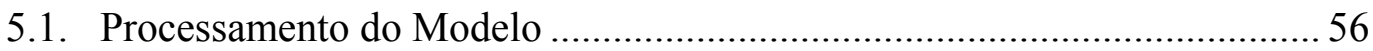

5.2. Cenário Base: Abordagem Logística ........................................................... 58

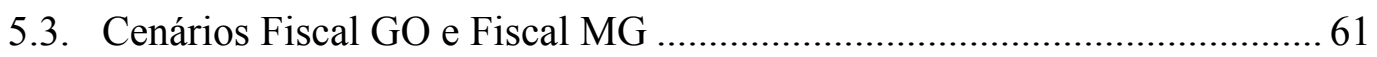

5.4. Conclusões do Capítulo .......................................................................... 70

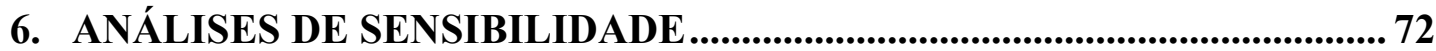

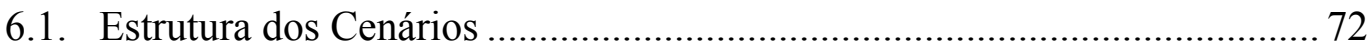

6.2. Grupo de Análise A: tradeoff entre custos logísticos e incentivo fiscal ..... 74

6.3. Grupo de Análise B: tradeoff entre saldo de ICMS e incentivo fiscal........ 80

6.4. Grupo de Análise C: nível de serviço ......................................................... 85 
6.5. Grupo de Análise D: restrição de fluxo mínimo nos CDs

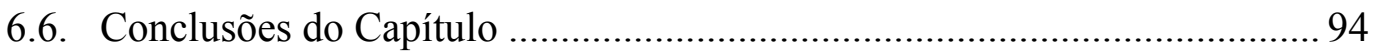

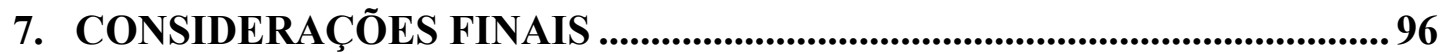

7.1. Sugestões para Estudos Futuros .............................................................. 97

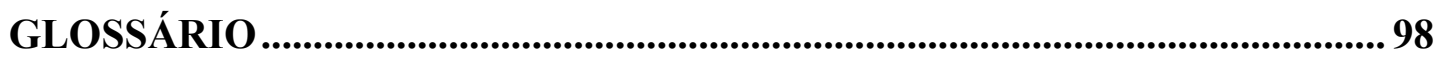

APÊNDICE A. TABELA DE ALÍQUOTAS DE ICMS .................................. 100

APÊNDICE B. TABELA DE DEMANDA POR PRODUTO E POR MERCADO 101

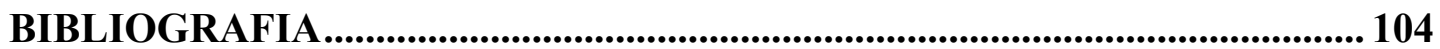




\section{LISTA DE FIGURAS}

Figura 1. Fluxo do ICMS para uma operação transferência/venda entre SE - ES - ES.............. 12

Figura 2. Fluxo do ICMS para uma operação transferência/venda entre BA - ES - RJ. ............ 13

Figura 3. Representação do fluxo gerado pelas três alternativas de localização do CD: Espírito Santo, Bahia e Minas Gerais

Figura 4. Exemplo de incentivo fiscal baseado no Crédito Financeiro e no Crédito Presumido. 22

Figura 5. Exemplo de rede de distribuição. Adaptado de Yoshizaki (2002) e Ballou (2001)... 25

Figura 6. Relação entre o tempo de resposta desejado e a quantidade............................................2

Figura 7. Representação da localização das instalações do problema ...........................................4 48

Figura 8.Distribuição geográfica da demanda dos produtos GO, MG e SP. ................................51

Figura 9. Relatório de solução do What'sBest! referente à solução do Cenário Base. ................57

Figura 10. Fluxos de distribuição do Cenário Base..............................................................................6

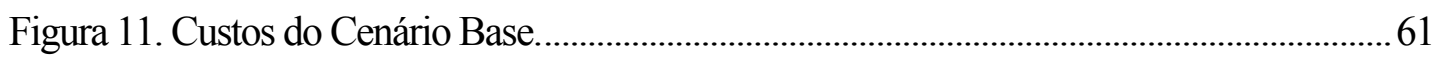

Figura 12. Fluxos de distribuição do Cenário Fiscal GO. ..........................................................62

Figura 13. Fluxos de distribuição do Cenário Fiscal MG..................................................................63

Figura 14. Fluxos de distribuição com origem no CD MG do Cenário Fiscal MG.....................65

Figura 15. Fluxos vs. capacidade nos CDs ativos dos cenários Base, Fiscal GO e Fiscal MG. 66

Figura 16. Custos dos cenários Base, Fiscal GO e Fiscal MG. 68

Figura 17. Fluxos e valores dos saldos de IMCS nos CDs ativos dos cenários Base, Fiscal GO e Fiscal MG. 70

Figura 18. Estrutura dos cenários a serem analisados. 72

Figura 19. Representação das capacidades e fluxos dos CDs ativos nos cenários de variação dos preços dos produtos considerando-se incentivo fiscal fornecido pelo estado de GO. 74

Figura 20. Representação gráfica dos custos dos cenários de variação dos preços dos produtos em relação ao Cenário Fiscal GO. 77

Figura 21. Representação das capacidades e fluxos dos CDs ativos nos cenários de variação dos preços dos produtos considerando-se incentivo fiscal fornecido pelo estado de MG. 78 
Figura 22. Representação das capacidades e fluxos dos CDs ativos nos cenários de variação das margens dos produtos considerando-se incentivo fiscal fornecido pelo estado de GO.

Figura 23. Representação das capacidades e fluxos dos CDs ativos nos cenários de variação das margens dos produtos considerando-se incentivo fiscal fornecido pelo estado de MG.

Figura 24. Distribuição do produto GO em cada um dos CDs abertos nos cenários de variação de margem diante do incentivo fiscal de MG.

Figura 25. Distribuição do produto $\mathrm{MG}$ em cada um dos $\mathrm{CDs}$ abertos nos cenários de variação de margem diante do incentivo fiscal de MG.

Figura 26. Distribuição do produto SP em cada um dos CDs abertos nos cenários de variação de margem diante do incentivo fiscal de $\mathrm{MG}$.

Figura 27. Fluxos de distribuição do Cenário Base com restrição de nível de serviço.

Figura 28. Fluxos de distribuição do Cenário Fiscal GO com restrição de nível de serviço..... 88

Figura 29. Fluxos de distribuição do Cenário Fiscal MG com restrição de nível de serviço. ... 89

Figura 30. Percentual do volume total da demanda entregue por faixa de nível de serviço......91

Figura 31. Comparativo de custos dos cenários Base, Fiscal GO e Fiscal MG com e sem restrições de nível de serviço. 


\section{LISTA DE TABELAS}

Tabela 1. Maiores contribuintes de impostos sobre vendas no Brasil no ano de 2004 ................. 2

Tabela 2. Principais alíquotas estaduais do ICMS ………………………….............................. 10

Tabela 3. Representação dos fluxos relacionados a cada alternativa de localização do CD. .... 17

Tabela 4. Resultados dos fluxos de cada alternativa de localização do CD.................................. 18

Tabela 5. Fatores associados diretamente ao ICMS que podem exercer influência relacionada a este tributo no fluxo de um projeto de rede de distribuição física.

Tabela 6. Exemplos de vantagens fiscais baseadas em crédito presumido oferecidas por diversos estados.

Tabela 7. Relação dos locais candidatos para abertura de centros de distribuição 48

Tabela 8. Regiões de demanda consideradas para as análises da dissertação.

Tabela 9. Parâmetros de custo, preço e margem de venda dos produtos. 50

Tabela 10. Níveis de capacidade e valores de fluxo mínimo nos CDs. .52

Tabela 11. Resultados obtidos pelo Cenário Base: CDs abertos, capacidades, fluxos e saldo de ICMS. 58

Tabela 12. Fluxos de transferência do Cenário Base. 60

Tabela 13. Fluxos de transferência do Cenário Fiscal GO..........................................................62

Tabela 14. Fluxos de transferência do Cenário Fiscal MG.

Tabela 15. Total de cada produto distribuído por cada CD nos cenários Base, Fiscal GO e Fiscal MG.

Tabela 16. Comparativo de custos entre o Cenário Fiscal GO original e com alteração do parâmetro referente à capacidade máxima dos CDs alterado.

Tabela 17. Custos dos cenários Base, Fiscal GO e Fiscal MG.

Tabela 18. Detalhamento dos custos de armazenagem dos Cenários Base, Fiscal GO e Fiscal MG.

Tabela 19. Potencial de incentivo da malha logística proposta pelo Cenário Base nos cenários de variação de preço de $(-75 \%)$ e $(-60 \%)$.

Tabela 20. Custos correspondentes aos cenários de variação dos preços dos produtos considerando-se incentivo fiscal oferecido pelo estado de GO. 
Tabela 21. Fluxos de abastecimento a partir do CD BA nos Cenários Fiscais MG com variação de preço de $-75 \%$ e $-60 \%$

Tabela 22. Custos correspondentes aos cenários de variação dos preços dos produtos considerando-se incentivo fiscal oferecido pelo estado de MG. 80

Tabela 23. Custos correspondentes aos cenários de variação da margem dos produtos considerando-se incentivo fiscal oferecido pelo estado de GO. 84

Tabela 24. Custos correspondentes aos cenários de variação da margem dos produtos considerando-se incentivo fiscal oferecido pelo estado de MG. 84

Tabela 25. Montante de incentivo fiscal, saldo, crédito e débito de ICMS correspondente ao CD MG em cada um dos cenários de variação da margem dos produtos considerando-se incentivo fiscal oferecido pelo estado de MG. 85

Tabela 26. Relação dos mercados aos quais associou-se restrição de nível de serviço. 86

Tabela 27. Fluxos de transferência do Cenário Base com Nível de Serviço.................................90

Tabela 28. Fluxos de transferência do Cenário Fiscal GO com Nível de Serviço. 90

Tabela 29. Fluxos de transferência do Cenário Fiscal MG com Nível de Serviço. 90

Tabela 30. Comparativo de custos dos cenários Base, Fiscal GO e Fiscal MG com e sem restrições de nível de serviço.

Tabela 31. Comparativo da variação dos custos logísticos e do incentivo fiscal capturado nos cenários Base, Fiscal GO e Fiscal MG com e sem restrições de nível de serviço... 93

Tabela 32. Percentual de ocupação dos CDs nos Cenários Base, Fiscal GO e Fiscal MG sem restrição de ocupação mínima nos CDs. .94 


\section{INTRODUÇÃO}

\subsection{OBJETIVO}

O objetivo deste trabalho consiste em desenvolver um modelo matemático que determine uma logística de menor custo considerando incentivos fiscais relacionados ao $\mathrm{ICMS}^{1}$. O tipo de incentivo considerado é baseado no crédito presumido, em que a característica do cálculo do incentivo é um crédito proporcional ao valor da base de cálculo das notas ficais com saídas para venda.

O objetivo do trabalho, portanto, consiste em:

(1) Propor um modelo matemático que avalie o tradeoff entre os custos logísticos (transporte + armazenagem) e a redução no saldo de ICMS a pagar proporcionada pelo benefício fiscal do tipo descrito no parágrafo acima; e

(2) Aplicar este modelo a situações realísticas e com base nos resultados obtidos avaliar os tradeoffs entre logística e os incentivos mencionados.

\subsection{RELEVÂNCIA DO TEMA}

Amaral e Olenike (2003) chamam atenção ao fato de as indústrias estarem sobrecarregadas de tributação em função de incidirem sobre suas atividades ICMS, COFINS, IPI e PIS, além de empregarem cerca de $24,94 \%$ da mão-de-obra formal do país, tendo com isto um alto custo de INSS e FGTS. Os mesmos autores calculam que a tributação média sobre o faturamento das indústrias foi de 35,47\% no ano de 2003.

Ainda segundo esses autores, o ICMS é o tributo que tem a maior arrecadação individual, tendo representado, no ano de 2003, 21,79\% do total arrecadado, ou seja, 7,87\% do PIB. Desse total, os autores informam que $28,66 \%$ foram pagos pelas indústrias.

\footnotetext{
${ }^{1}$ A definição das siglas empregadas ao longo do texto encontra-se no Glossário (página 98).
} 
Conforme pode-se observar na Tabela 1, disponível no banco de dados on line do portal da Revista Exame, entre as 16 empresas que mais pagaram imposto sobre suas vendas no Brasil em 2004, 11 são indústrias.

Tabela 1. Maiores contribuintes de impostos sobre vendas no Brasil no ano de 2004.

\begin{tabular}{llr}
\hline EMPRESA & SETOR & US\$ Milhões \\
\hline TELEMAR & TELECOMUNICAÇÕES & $2.162,20$ \\
TELEFONICA & TELECOMUNICAÇÕES & $1.930,30$ \\
SOUZA CRUZ & INDÚSTRIA DE ALIMENTOS, BEBIDAS E FUMO & $1.598,10$ \\
BRASIL TELECOM & TELECOMUNICAÇÕES & $1.381,30$ \\
VOLKSWAGEN & INDÚSTRIA AUTOMOTIVA & $1.329,10$ \\
GENERAL MOTORS & INDÚSTRIA AUTOMOTIVA & $1.283,20$ \\
BRASKEM & INDÚSTRIA QUÍMICA E PETROQUÍMICA & $1.161,90$ \\
CBB/AMBEV & INDÚSTRIA DE ALIMENTOS, BEBIDAS E FUMO & $1.124,90$ \\
REFAP & INDÚSTRIA QUÍMICA E PETROQUÍMICA & 976,6 \\
FIAT & INDÚSTRIA AUTOMOTIVA & 970,4 \\
GERDAU AÇOMINAS & INDÚSTRIA DE SIDERURGIA E METALURGIA & 915,2 \\
ELETROPAULO METROPOLITANA & SERVIÇOS PÚBLICOS & 854,9 \\
GRUPO PÃO DE AÇÚCAR & COMÉRCIO VAREJISTA & 800,2 \\
CSN & INDÚSTRIA DE SIDERURGIA E METALURGIA & 769,8 \\
USIMINAS & INDÚSTRIA DE SIDERURGIA E METALURGIA & 702,2 \\
COPESUL & INDÚSTRIA QUÍMICA E PETROQUÍMICA & 681,4 \\
\hline
\end{tabular}

Fonte: Revista Exame.

Amaral e Olenike (2003) também observam que os tributos são parte relevante da somatória dos custos e despesas empresariais (cerca de 47,58\% do total) e que, quanto maior a sua incidência, menor é o lucro da atividade.

É interessante observar que, se por um lado os grandes centros de consumo das indústrias de bens de consumo não duráveis encontram-se nos estados da região Sudeste do Brasil, Piancastelli e Perobellli (1996) apontam que os benefícios fiscais são oferecidos com maior intensidade nas regiões Norte e Nordeste do país, o que equivale, no caso de Recife - São Paulo, a uma distância média de 2.660 km.

Tal fato faz com que a análise do tradeoff entre o aumento dos custos de frete e a economia gerada pelo aferimento de benefícios fiscais, objeto do presente estudo, 
seja fundamental para identificar quando as economias geradas pela redução do saldo do ICMS a partir de incentivos fiscais compensam os custos adicionais de frete e armazenagem necessários para o transporte das mercadorias. O modelo matemático desenvolvido nesta dissertação, que consiste em uma contribuição inédita por incluir na modelagem benefícios fiscais baseados no crédito presumido, apresenta grande relevância para auxiliar na realização deste tipo de análise.

\subsection{Organização da Dissertação}

O presente trabalho está subdividido em seis capítulos, a saber:

- Capítulo 1 - Introdução: apresenta o objetivo e o escopo do trabalho, bem como a relevância do tema tratado.

- Capítulo 2 - Revisão bibliográfica: apresenta, comenta e discute os conceitos relacionados aos dois pontos fundamentais relacionados ao problema de pesquisa: a questão tributária no Brasil e o problema logístico de localização.

- Capítulo 3 - Modelagem do problema: apresenta o modelo matemático conceitual e discute os detalhes inerentes aos aspectos da modelagem.

- Capítulo 4 - Descrição do caso estudado: apresenta as características e os parâmetros do problema elaborado para a aplicação do modelo.

- Capítulo 5 - Aplicação do modelo e análise dos resultados: trata sobre a aplicação do modelo, as análises realizadas e os resultados obtidos.

- Capítulo 6 - Análises de sensibilidade: apresenta as análises de sensibilidade realizadas por meio da variação de alguns parâmetros.

- Capítulo 7 - Conclusões e considerações finais: Apresenta as conclusões finais do trabalho, bem como as recomendações para estudos futuros sobre o tema. 


\section{REVISÃO BIBLIOGRÁFICA}

O presente capítulo, dedicado a expor, comentar e discutir conceitos relevantes para o tema da pesquisa, está calcado nos seguintes pontos: a questão tributária no Brasil e o problema logístico de localização.

O estudo referente à questão tributária no Brasil, além de apresentar um panorama geral do contexto tributário brasileiro, relaciona os tributos que incidem em operações logísticas e, após, direciona o foco para a análise do ICMS e dos incentivos fiscais relativos a este tributo.

O problema de localização é tratado na segunda parte, que além de abordar os conceitos, métodos de solução e custos considerados neste tipo de problema, analisa os modelos matemáticos presentes na literatura que consideram a questão tributária, fazendo um paralelo com os aspectos tributários estudados no presente trabalho.

\subsection{A QUESTÃo Tributária nO Brasil}

\subsubsection{Legislação tributária brasileira}

No Brasil, a Constituição de 1.946, com a redação dada pela Emenda Constitucional $\mathrm{n}^{\circ} 18$ de dezembro de 1.965 , estabeleceu a necessidade de uma lei nacional para regular o Sistema Tributário Brasileiro. Em obediência a tal prescrição constitucional, encomendou-se um anteprojeto de lei ao Professor Rubens Gomes de Souza, que após todo um processo de revisão, veio a se tornar o CTN, Lei ${ }^{\circ} 5.172$, de 25 de outubro de 1.966. [Koyama et al, 1996]

Os mesmos autores citados no parágrafo acima colocam que, na ocasião, o CTN consistia em uma Lei Ordinária, e como a Constituição de 1.967 prescreveu que a codificação de nosso Sistema Tributário se desse através de Lei Complementar, passou o CTN, desde então, a ostentar a hierarquia de Lei Complementar, só podendo ser revogado ou modificado por Lei Complementar. A Constituição de 1.988, atualmente em vigor, através de seu Art. 146, continua exigindo uma Lei Complementar para a regulação do Sistema Tributário Brasileiro. Conforme este artigo, cabe à Lei Complementar: 
"I - dispor sobre conflitos de competência, em matéria tributária, entre a União, os Estados, o Distrito Federal e os Municipios;

II - regular as limitações constitucionais ao poder de tributar;

III - estabelecer normas gerais em matéria de legislação tributária, especialmente sobre:

a) definição de tributos e de suas espécies, bem como, em relação aos impostos discriminados nesta Constituição, a dos respectivos fatos geradores, bases de cálculo e contribuinte,

b) obrigação, lançamento, crédito, prescrição e decadência tributários,

c) adequado tratamento tributário ao ato cooperativo praticado pelas sociedades cooperativas."

Para definir e regulamentar o Sistema Tributário Brasileiro existe, além do CTN, uma série de outros documentos regulamentadores que compõem a Legislação Tributária. Conforme coloca Rodrigues (1978), o legislador do CTN procurou definir a expressão "Legislação Tributária" no Art. 96 do CTN, declarando-a compreendida pelas leis, tratados e convenções internacionais, decretos e normas complementares que versem, no todo ou em parte, sobre tributos e relações jurídicas a eles pertinentes. O mesmo autor explica este conjunto normativo conforme o seguinte:

(i) Lei: norma fundamental do direito. No caso do direito tributário, só através dela se pode instituir um tributo, determina a Constituição Federal, consagrando o princípio da legalidade tributária em seus Arts. 19, I e 123 §29.

(ii) Decreto-lei: é o instrumento pelo qual o chefe do poder executivo pode legislar sobre matéria de direito tributário, conforme o Inciso II do Art. 55 da Constituição Federal, faculdade que só deve ser exercida em casos de urgência ou de interesse público relevante.

(iii) Decretos e regulamentos: quando a lei não contenha em seu texto todas as instruções necessárias ao seu cumprimento, compete ao chefe do executivo baixar decretos que explicitem os detalhes que tornem possível a sua execução.

(iv) Normas complementares: dada a complexidade da Legislação Tributária e a multiplicidade de atividades econômicas sobre as quais ela se manifesta, 
surgem discussões entre os interessados - fisco e contribuinte - sobre a interpretação dos diplomas normativos, das quais nascem as normas complementares. O CTN enumera taxativamente, em seu Art. 100, as espécies de normas admitidas:

- Atos normativos: instrumentos através dos quais as autoridades administrativas competentes dirimem as dúvidas de interpretação da lei ou dos regulamentos, particularizando situações ou detalhando procedimentos, de modo a tornar claras e definidas as obrigações dos contribuintes.

- Decisões administrativas: interpretações da Legislação Tributária aplicada a casos concretos, oferecidas por órgãos julgadores, singulares ou coletivos, da administração tributária, para a solução de pendências iniciadas por procedimentos fiscais contestados pelos contribuintes.

- Práticas reiteradas: é uma observância às normas do direito consuetudinário a inclusão, entre as normas complementares, das práticas reiteradamente observadas pelas autoridades administrativas

- Convênios: acordos bilaterais ou multilaterais que sejam celebrados entre a União, os Estados, o Distrito Federal e os municípios; têm muita importância, principalmente em relação o ICMS, pois as isenções relativas a este tributo só podem ser concedidas pelo consenso dos Estados e do Distrito Federal, por determinação do parágrafo $6^{\circ}$ do Art. 23 da Constituição Federal.

Tão importante quanto conhecer a origem e as atribuições do CTN é compreender a definição de tributo apresentada pelo Art. 3 do referido Código, segundo o qual tributo consiste em "toda prestação pecuniária compulsória, em moeda ou cujo valor nela se possa exprimir, que não constitua sanção de ato ilícito, instituída em lei e cobrada mediante atividade administrativa plenamente vinculada".

Conforme Latorraca (1982) e Ferrari (1996), e de acordo com o Art. 5 do CTN e o Art. 145 da Constituição, as espécies tributárias são basicamente três: 
- Imposto: definido de acordo com o Art. 16 do CTN, "é o tributo cuja obrigação tem por fato gerador uma situação independente de qualquer atividade estatal especifica, relativa ao contribuinte".

- Taxa: conforme Art. 77 do CTN, "as taxas cobradas pela União, pelos Estados, pelo Distrito Federal ou pelos Municípios, no âmbito de suas respectivas atribuições, têm como fato gerador o exercício do poder de polícia, ou a utilização, efetiva ou potencial, de serviço público específico e divisivel, prestado ao contribuinte ou posto à sua disposição".

- Contribuição de melhoria: segundo o Art. 81 do CTN "a contribuição de melhoria cobrada pela União, pelos Estados, pelo Distrito Federal ou pelos Municipios, no âmbito de suas respectivas atribuições, é instituida para fazer face ao custo de obras públicas de que decorra valorização imobiliária, tendo como limite total a despesa realizada".

Koyama et al (1996) lembram que na Constituição, contudo, são previstas duas outras figura tributárias que se encaixam perfeitamente na definição de tributo e que são tratadas, portanto, da mesma forma que os tributos, como se tributos fossem: os empréstimos compulsórios e as contribuições especiais. Entretanto, os mesmos autores colocam que os empréstimos compulsórios e as contribuições especiais não possuiriam uma natureza específica autônoma, já que poderiam ser enquadrados em qualquer uma das três categorias de tributos (impostos, taxas ou contribuições), conforme a materialidade de seu fato gerador.

Ainda segundo Koyama et al (1996), fato gerador é uma situação, um evento previsto hipoteticamente em lei, de forma abstrata, mas que, uma vez ocorrido concretamente na vida real, faz surtir para uma determinada pessoa, física ou jurídica, a obrigação de pagar tributo. Yoshizaki (2002) coloca que cada imposto tem fato gerador específico e exemplifica que a posse de um caminhão é o fato gerador do IPVA, enquanto que a operação de venda de um televisor pela indústria para uma loja de departamentos é fato gerador tanto do IPI como do ICMS. 
O ICMS, como o próprio nome já diz, é um imposto que tem como fato gerador operações relativas à circulação de mercadorias, serviços de transporte intermunicipal e interestadual e serviço de comunicação. Melo (2004) dedica o primeiro capítulo de sua obra para explicar em detalhe os fatos geradores do ICMS.

Portanto, as operações logísticas que envolvem transporte de mercadorias, tanto para transferência como para venda, são fato gerador do ICMS e de outros tributos. O tópico seguinte comenta sobre estes tributos e, em seguida, dedica-se um tópico para abordar em detalhes a incidência do ICMS sobre as operações de venda e transferência de mercadorias.

\subsubsection{Tributos incidentes em operações logísticas}

Ribeiro (1999) realizou uma extensa pesquisa sobre a incidência de tributos em operações logísticas. Em seu trabalho, nomeou os tributos que incidem sobre as operações logísticas como tributo sobre transações ou tributos transacionais, e os explicou da seguinte maneira:

"Tais tributos alcançam cada uma das operações realizadas entre a organização e seus fornecedores e clientes. Podem também incidir sobre operaçães realizadas entre estabelecimentos da organização, como as remessas dos bens produzidos para um depósito de triagem, a partir do qual tais bens são comercializados. Por outro lado, os tributos transacionais não agem sobre operações realizadas dentro de um determinado estabelecimento, como a movimentação de materiais de uma linha de produção para outra dentro da mesma fábrica. Em tais operações não ocorre a "exteriorização do fato gerador do imposto" (Cassone, 1995, p. 392) dado que as mercadorias e serviços não ultrapassarem os limites de um estabelecimento fiscal (a fábrica, no caso)."

Uma grande contribuição de Ribeiro (1999) consiste no quadro elaborado pelo autor, que apresenta as relações de operações entre organização, fornecedores e clientes sujeitas aos tributos definidos por ele como transacionais. Para as 27 operações logísticas relacionadas no referido quadro, Ribeiro (1999) associou um ou mais dos seguintes tributos: ICMS, PIS, COFINS, IPI, II e IOF.

Por meio do quadro de Ribeiro (1999) é possível verificar que o ICMS, diferentemente de outros tributos como o PIS e o COFINS, incide em todas as operações logísticas 
relacionadas pelo autor. O item seguinte trata sobre este imposto, abordando suas características e forma de incidência na cadeia de suprimento.

\subsubsection{Incidência do ICMS nas operações logísticas de transferência e venda}

O ICMS é um tributo estadual que incide sobre as operações de circulação de mercadorias e sobre a prestação de serviços de comunicação em geral e de transporte interestadual ou intermunicipal. Caracteriza-se por ser um imposto não-cumulativo e seletivo, com estrutura de débitos e créditos que possibilita que o pagamento do imposto seja apenas sobre o valor agregado e com alíquotas diferenciadas em função da essencialidade dos serviços e mercadorias.

Uma particularidade do ICMS consiste no fato de possuir alíquotas diferenciadas em função do par origem/destino da circulação das mercadorias. Esta configuração foi assim estabelecida para que os estados importadores fossem favorecidos na compra de mercadorias dos estados exportadores.

De acordo com a sistemática vigente do ICMS, a estrutura de alíquotas determina uma tributação de $17 \%, 18 \%$ ou $19 \%$ nas transações intra-estaduais para bens de consumo final - a alíquota de $19 \%$ é aplicada somente para o estado do Rio de Janeiro. Nas transações interestaduais as alíquotas vigentes equivalem a $12 \%$, excetuando-se as realizadas do Sul, São Paulo e Minas Gerais para o Norte, Nordeste, Centro-Oeste e Espírito Santo, as quais são tributadas com alíquota de 7\%; quando o estado de origem da transação é o Rio de Janeiro, há um acréscimo referente a um ponto percentual nessas alíquotas, que passam a ser, portanto, de $13 \%$ e $8 \%$.

Conforme coloca Viol (1999), este diferencial de alíquotas favorece o conjunto de destinos que recebe mercadoria com alíquota de 7\% e 8\%. As alíquotas mais elevadas para as transações que envolvem o Rio de Janeiro são em função do Fundo de Combate e Erradicação da Pobreza, regulamentado pela Lei Complementar $n^{\circ} 111$, de 6 de julho de 2001.

A Tabela 2 abaixo resume a estrutura de alíquotas de ICMS vigente. O Apêndice A apresenta a alíquota aplicada para cada par de estados origem/destino. 
Tabela 2. Principais alíquotas estaduais do ICMS

\begin{tabular}{lc}
\hline Operação & Alíquota \\
\hline - Interna, de importação ou intra-estadual & $17 \%, 18 \%$ ou \\
& $19 \%$. \\
- Interestadual das regiões Sul e Sudeste para as regiões Norte, & $7 \%$ ou 8\%. \\
$\quad$ Nordeste, Centro-Oeste e Espírito Santo & $12 \%$ ou 13\%. \\
- Interestadual nas demais regiões & \\
\hline
\end{tabular}

Sempre que houver operações de transferência ou de venda entre dois estabelecimentos ocorrerá a incidência do ICMS. Nas operações de transferência de mercadorias entre estabelecimentos da mesma empresa as mercadorias são tributadas pelo seu preço de custo, enquanto que nas operações de venda as mercadorias são tributadas pelo seu preço de venda (Yoshizaki, 2002).

Para entender como ocorre a incidência do ICMS, considere-se o exemplo de uma operação de venda em que uma indústria vende seu produto para seu cliente, um estabelecimento varejista. $\mathrm{O}$ valor de venda do produto estabelecido pela indústria equivale a $\mathrm{R} \$ 10,00$ (refere-se aos custos alocados ao produto mais a margem de venda cobrada pela indústria), e a alíquota de ICMS correspondente à operação equivale a $12 \%$. Esta situação é representada a seguir:

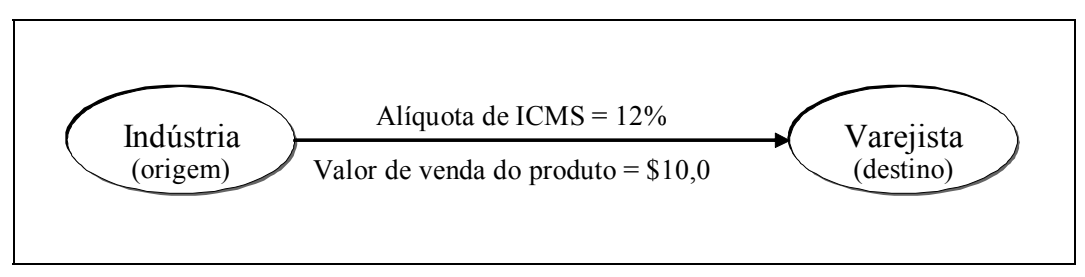

Para calcular o imposto que incidirá sobre essa operação o valor do produto $(\mathrm{R} \$ 10,00)$ deve ser dividido por um menos o valor da alíquota (no caso, $12 \%)$, e do valor obtido a partir dessa operação deverá ser subtraído o valor do produto, conforme o apresentado a seguir:

Cálculo do valor do imposto:

$$
\mathrm{ICMS}=\frac{\text { Valor do produto }}{(1-\text { Alíquota })}-\text { Valor do produto }=\frac{10}{(1-0,12)}-10=11,36-10=1,36
$$


Conhecendo-se o valor do imposto, para saber-se qual o valor da NF correspondente à referida operação de venda, o valor do imposto deve ser acrescido ao valor estipulado para o produto pela indústria $(10+1,36=11,36)$. Assim, o valor da $\mathrm{NF}$, que corresponde ao valor que o estabelecimento varejista irá pagar para a indústria, equivale a R\$11,36. Verifica-se, portanto, que apesar da alíquota nominal do ICMS na operação exemplificada ser de $12 \%$, o valor real que este imposto representa no valor do produto equivale a 13,6\%. Estas informações estão resumidas abaixo:

Valor do produto $=\$ 10,0$

Valor do ICMS (alíquota de 12\%) = \$1,36

Valor da NF (valor a ser pago pelo varejista) $=\$ 11,36$

Representação do ICMS no valor da NF do produto $=13,6 \%$

Conforme os termos do inciso I do $\S 2^{\circ}$ do Art. 155 da Constituição Federal, o ICMS "será não-cumulativo, compensando-se o que for devido em cada operação relativa à circulação de mercadoria ou prestação de serviço com o montante cobrado nas anteriores pelo mesmo ou outro Estado ou pelo Distrito Federal".

Sendo, portanto, o ICMS um imposto não-cumulativo, incidindo somente sobre o valor agregado das mercadorias (apenas o consumidor final paga o valor total do imposto sobre a mercadoria adquirida), a incidência do ICMS sobre os valores de transferência/venda das mercadorias implica na geração de débitos e créditos nos estabelecimentos envolvidos. O valor do imposto calculado no exemplo apresentado na página anterior corresponde ao valor de débito e crédito que ficará nos estabelecimentos de origem (débito) e de destino (crédito) da mercadoria, conforme apresentado a seguir:

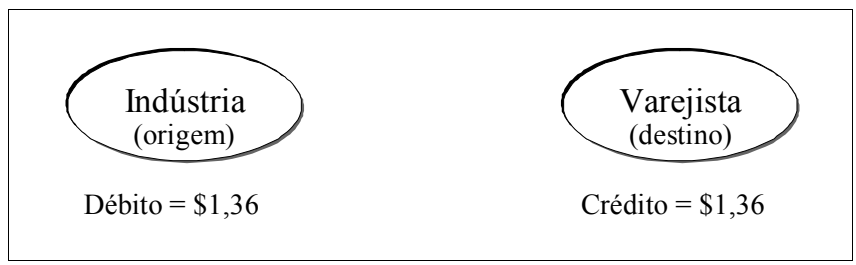


Para melhor compreender a estrutura de incidência do ICMS, considere-se o caso em que uma empresa que possui uma fábrica em Sergipe e um CD no Espírito Santo deva atender um cliente que esteja localizado também no Espírito Santo. O valor de transferência da mercadoria em questão (operação fábrica $\mathrm{CD}$ ) equivale a $\mathrm{R} \$ 100,00$ (valor de custo do produto), enquanto que o valor de venda (operação CD - varejista) equivale a R\$120,00 (valor sem o ICMS). Esse fluxo é representado pela Figura 1 a seguir:

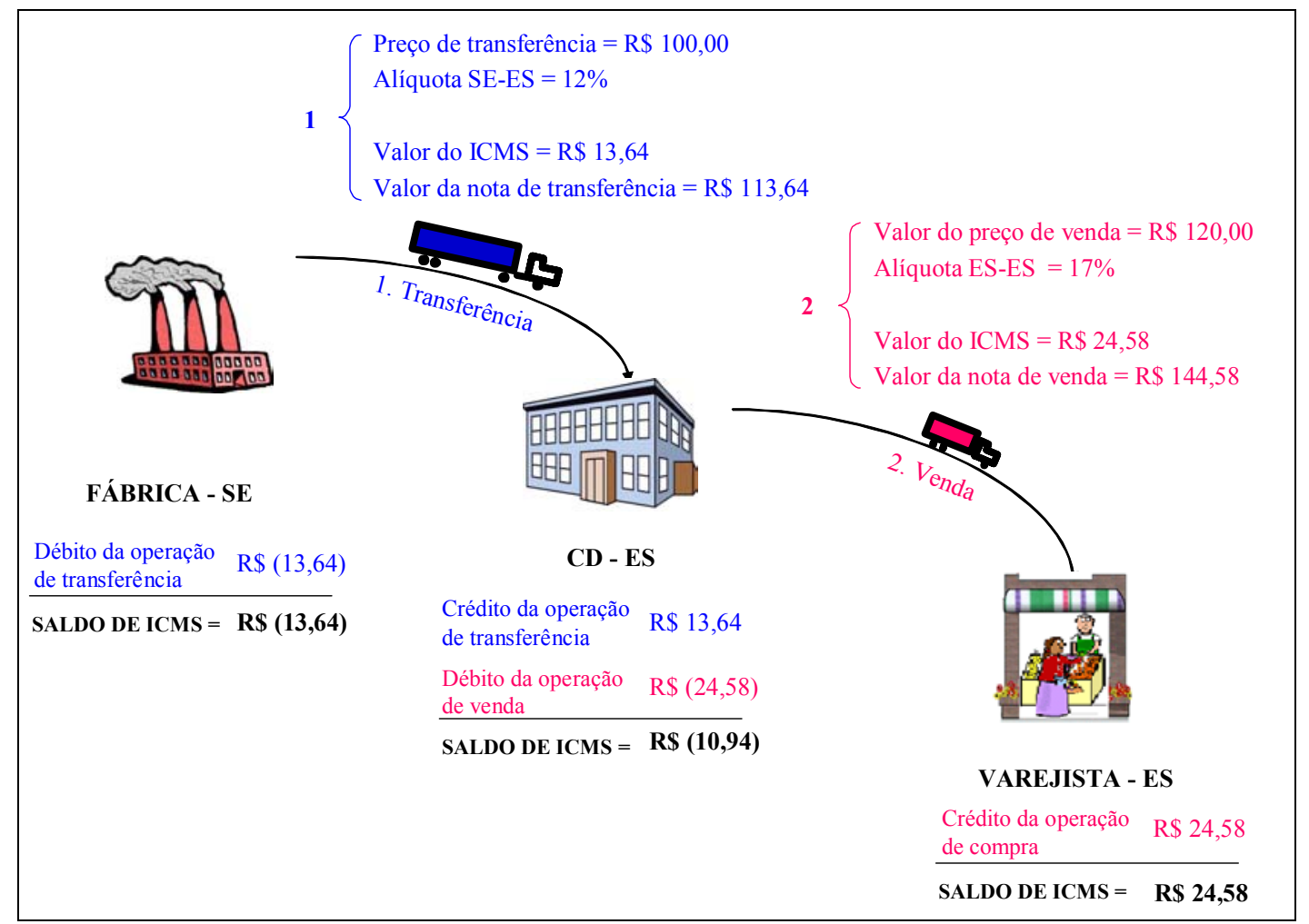

Figura 1. Fluxo do ICMS para uma operação transferência/venda entre SE - ES - ES.

Na transferência da mercadoria da fábrica para o CD (na Figura 1, operação indicada pelo número 1) ao seu preço de custo $\mathrm{R} \$ 100,00$, o valor do imposto que incide na operação equivale a $\mathrm{R} \$ 13,64$, calculado tendo por base a alíquota de $12 \%$. Esse valor consta como um débito na fábrica da empresa e como um crédito em seu CD.

No $\mathrm{CD}$ é acrescida à mercadoria a margem de venda da empresa, que no caso em questão consiste em $20 \%$ de seu valor de custo. Desse modo, na operação de venda da mercadoria (na Figura 1, operação indicada pelo número 2), o preço desta será de $\mathrm{R} \$ 120,00$, e o imposto que incide sobre a operação equivale a $\mathrm{R} \$ 24,58$, calculado 
tendo como base a alíquota de $17 \%$. Como resultado desta operação tem-se no CD um débito de $\mathrm{R} \$ 24,58$ e no varejista um crédito correspondente ao mesmo valor.

Assim, ao final da operação ilustrada na Figura 1, o saldo de imposto a pagar na fábrica será de $\mathrm{R} \$ 13,64$ e no $\mathrm{CD}$ o saldo a pagar será de $\mathrm{R} \$ 10,94(\mathrm{R} \$ 24,58-\mathrm{R} \$$ $13,64)$, de modo que o saldo total de imposto a pagar da indústria será $R \$ 24,58$.

A mesma situação, modificando-se apenas a localização do $\mathrm{CD}$, que agora passa a situar-se no estado de Minas Gerais, é representada na Figura 2 a seguir:

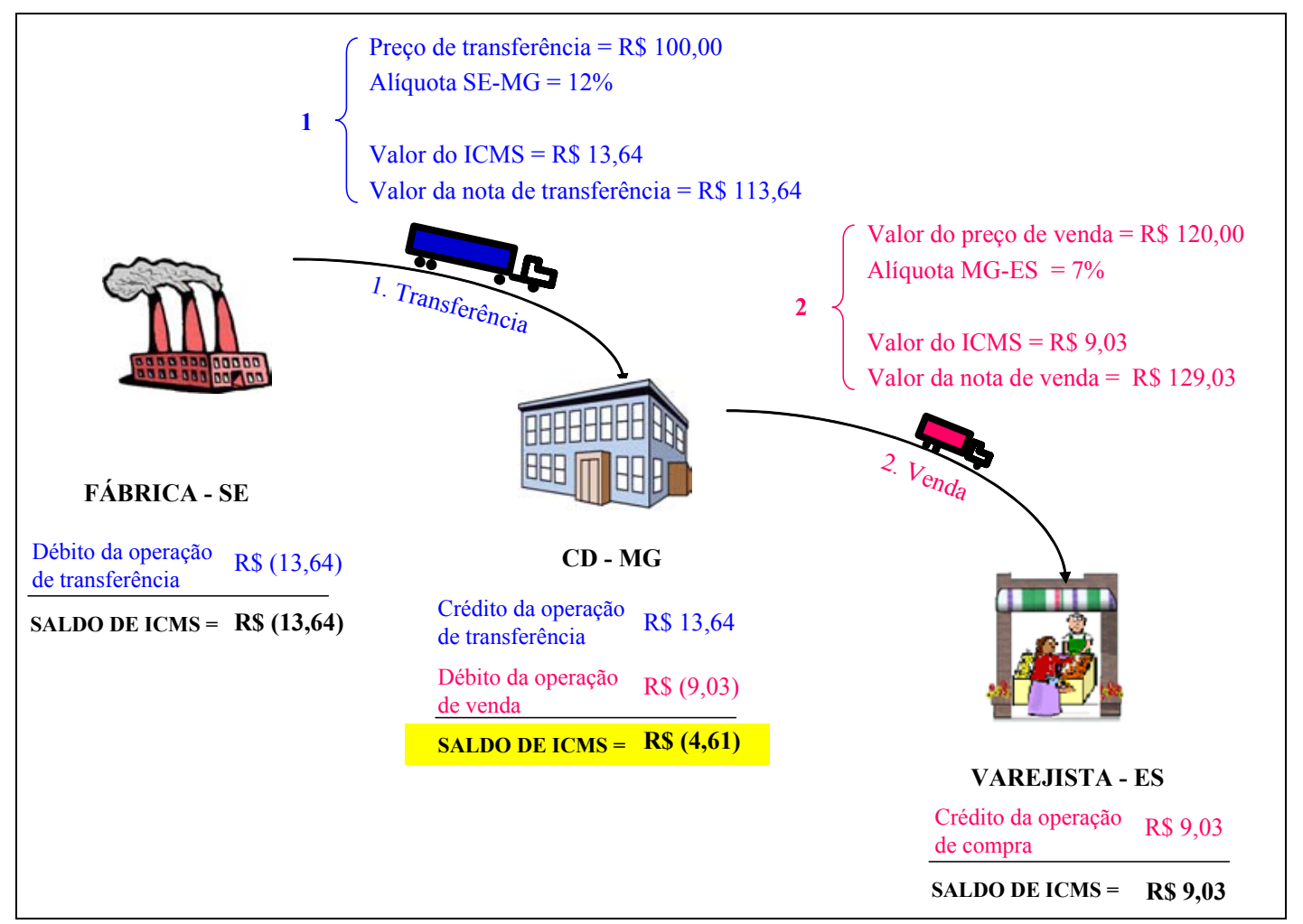

Figura 2. Fluxo do ICMS para uma operação transferência/venda entre BA - ES - RJ.

Verifica-se que a simples alteração da localização do CD do estado do Espírito Santo para o estado de Minas Gerais provocou uma redução de $42 \%$ no valor do saldo de ICMS desta instalação (de R \$ 10,94 para R \$ 4,61). Assim, conforme colocado por Yoshizaki (2002), a impressão que fica ao se olhar as diferenças de alíquotas nas operações interestaduais é que é possível obter-se ganhos, ou seja, reduzir saldo total de ICMS a pagar, quando optamos por realizar a venda de produtos a partir deste ou daquele estado. 
Para verificar se realmente é possível obter-se os ganhos citados, considere-se o caso de uma indústria que produza bens de consumo não duráveis sujeitos às alíquotas padrão de tributação definidas pelo CONFAZ, que estão relacionadas na Tabela 2. Esta indústria possui uma fábrica em Sergipe e tem seu principal mercado, composto por estabelecimentos varejistas, localizado no estado do Espírito Santo.

Suponha-se que a indústria em questão decidiu abrir um CD e está estudando qual a melhor localização para ele. Os locais candidatos para a abertura deste CD situam-se nos seguintes estados: Bahia, Espírito Santo e Minas Gerais.

Para saber se é importante para a indústria considerar a questão fiscal relativa ao ICMS na modelagem de seu problema, as três alternativas de localização do CD dessa indústria serão avaliadas apenas sob a ótica fiscal (sem considerar outros custos), considerando-se para tanto valores arbitrários. Essas alternativas, bem como os fluxos e as alíquotas de ICMS inerentes a elas, estão representadas na Figura 3 a seguir:

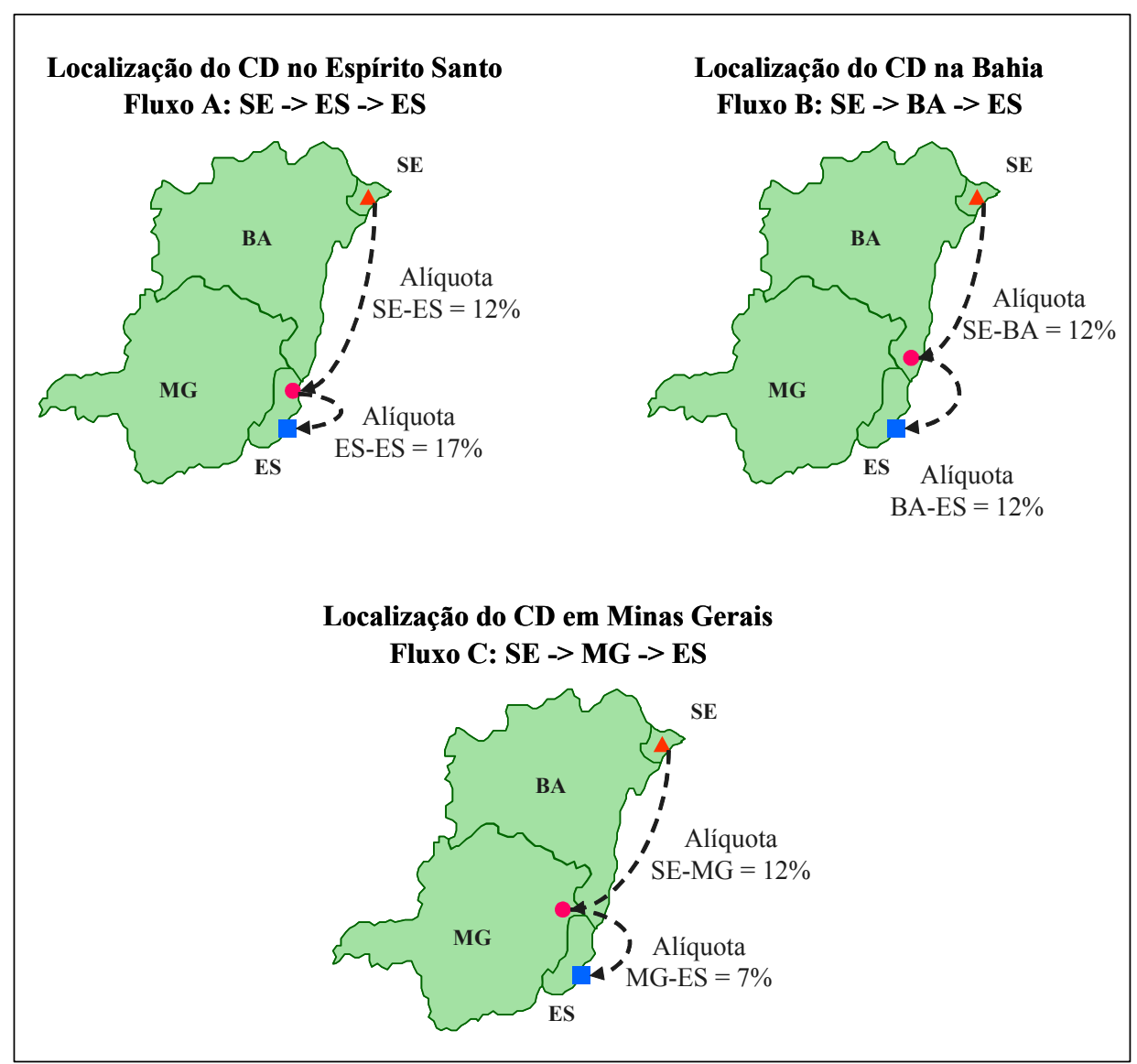

Figura 3. Representação do fluxo gerado pelas três alternativas de localização do CD: Espírito Santo, Bahia e Minas Gerais. 
A avaliação das alternativas de localização do CD representadas nas figuras acima sob o ponto de vista físcal é apresentada na Tabela 3. Nela são apresentadas as seguintes operações comerciais e respectivas informações:

(i) Operação de compra de matéria-prima: fornecedor $\rightarrow$ fábrica da indústria:

- Alíquota de ICMS correspondente à operação (admite-se que o fornecedor está localizado fora do estado do Sergipe).

- Valor da NF, que consiste na soma do valor de compra do produto (matéria-prima) com o valor do ICMS referente à operação.

- Valor do débito e do crédito gerados, respectivamente, no fornecedor e na fábrica da indústria.

(ii) Operação de transferência de produto acabado: fábrica da indústria $\rightarrow$ CD da indústria:

- Alíquota de ICMS correspondente à operação.

- Valor da NF, que consiste na soma do valor de transferência do produto (valor do custo do produto) com o valor do ICMS referente à operação.

- Valor do débito e do crédito gerados, respectivamente, na fábrica e no CD da indústria.

(iii) Operação de venda: CD da indústria $\rightarrow$ varejista:

- Margem de venda da indústria, a ser aplicada sobre o valor de transferência do produto, ou seja, sem o ICMS.

- Alíquota de ICMS correspondente à operação.

- Valor da NF, que consiste na soma do valor de venda do produto (preço de custo + margem) com o valor do imposto referente à operação.

- Valor do débito e do crédito gerados, respectivamente, no CD da indústria e no varejista.

(iv) Operação de venda: Varejista $\rightarrow$ consumidor:

- Margem de venda do varejista, a ser aplicada sobre o valor de compra do produto (sem o ICMS). 
- Alíquota de ICMS correspondente à operação.

- Valor da NF, que consiste na soma do valor do produto a ser vendido (valor de compra do produto + margem) com o valor do imposto referente à operação.

- Valor do débito gerado no varejista.

Os valores apresentados na primeira coluna correspondem ao caso em que o CD está localizado no Espírito Santo, de modo que o fluxo de mercadorias ao longo da cadeia ocorra da seguinte maneira: $\mathbf{S E} \rightarrow \mathbf{E S} \rightarrow \mathbf{E S}$.

A segunda coluna apresenta os valores referentes ao caso em que o atendimento é realizado a partir da Bahia (o CD está localizado neste estado), de modo que o fluxo de mercadorias ao logo da cadeia ocorra da seguinte maneira: $\mathbf{S E} \rightarrow \mathbf{B A} \rightarrow \mathbf{E S}$.

Por fim, a terceira coluna contém os valores referentes ao caso em que o CD está localizado em Minas Gerais, de modo que o fluxo de mercadorias ao longo da cadeia ocorra da seguinte maneira: $\mathbf{S E} \rightarrow \mathbf{M G} \rightarrow \mathbf{E S}$. 
Tabela 3. Representação dos fluxos relacionados a cada alternativa de localização do CD.

\begin{tabular}{|c|c|c|c|}
\hline \multicolumn{4}{|c|}{ FLUXOS DE CADA ALTERNATIVA DE LOCALIZAÇÄO DO CD } \\
\hline & $\begin{array}{c}\text { Fluxo A } \\
\text { SE - ES - ES }\end{array}$ & \begin{tabular}{c|} 
Fluxo B \\
SE - BA - ES
\end{tabular} & $\begin{array}{c}\text { Fluxo C } \\
\text { SE - MG - ES }\end{array}$ \\
\hline \multicolumn{4}{|c|}{ Operaçäo de compra de mercadoria: Fornecedor -> Fábrica } \\
\hline Alíquota de ICMS referente à operaçã̃o & $12 \%$ & $12 \%$ & $12 \%$ \\
\hline Valor da nota fiscal & 39,77 & 39,77 & 39.77 \\
\hline - valor do produto & 35,00 & 35,00 & 35,00 \\
\hline - valor do ICMS & 4,77 & 4,77 & 4,77 \\
\hline Débito gerado no fornecedor & $(4,77)$ & $(4,77)$ & $(4,77)$ \\
\hline Crédito gerado na fábrica & 4,77 & 4,77 & 4,77 \\
\hline \multicolumn{4}{|c|}{ Operaçäo de transferência de produto acabado: Fábrica $\rightarrow$ CD } \\
\hline Alíquota de ICMS referente à operaçẫo & $12 \%$ & $12 \%$ & $12 \%$ \\
\hline Valor da nota fiscal & 113,64 & 113,64 & 113,64 \\
\hline - valor do produto & 100,00 & 100,00 & 100,00 \\
\hline - valor do ICMS & 13,64 & 13,64 & 13,64 \\
\hline Débito gerado na fábrica & $(13,64)$ & $(13,64)$ & $(13,64)$ \\
\hline Crédito gerado no $\mathrm{CD}$ & 13,64 & 13,64 & 13,64 \\
\hline \multicolumn{4}{|l|}{ Operaçäo de venda: $C D$-> Var ejista } \\
\hline Margem da indústria & $25 \%$ & $25 \%$ & $25 \%$ \\
\hline Alíquota de ICMS referente à operaçẫo & $17 \%$ & $12 \%$ & $7 \%$ \\
\hline Valor da nota fiscal & 150,60 & 142,05 & 134,41 \\
\hline - valor do produto & 125,00 & 125,00 & 125,00 \\
\hline - valor do ICMS & 25,60 & 17,05 & 9,41 \\
\hline Débito gerado no CD & $(25,60)$ & $(17,05)$ & $(9,41)$ \\
\hline Crédito gerado no varejista & 25,60 & 17,05 & 9,41 \\
\hline \multicolumn{4}{|l|}{ Operação de venda: Varejista -> Consumidor } \\
\hline Margem do varejista & $20 \%$ & $20 \%$ & $20 \%$ \\
\hline Alíquota de ICMS referente à operaçẫo & $17 \%$ & $17 \%$ & $17 \%$ \\
\hline Valor da nota fiscal & 180,72 & 180,72 & 180,72 \\
\hline - valor do produto & 150,00 & 150,00 & 150,00 \\
\hline - valor do ICMS & 30,72 & 30,72 & 30,72 \\
\hline Débito gerado no varejista & $(30,72)$ & $(30,72)$ & $(30,72)$ \\
\hline
\end{tabular}


A Tabela 4 a seguir apresenta os resultados da indústria e do varejo, bem como o valor final do produto, ou seja, o preço final pago pelo consumidor. É possível observar que, para as três possibilidades de localização do CD avaliadas, não houve qualquer alteração no resultado da indústria e do varejo, e o preço final do produto manteve-se o mesmo para todas as possibilidades.

Tabela 4. Resultados dos fluxos de cada alternativa de localização do CD.

\begin{tabular}{|c|c|c|c|}
\hline \multicolumn{4}{|c|}{ RESULTADO DOS FLUXOS DE CADA ALTERNATIVA DE LOCALIZAÇẪO DO CD } \\
\hline & \begin{tabular}{|c|} 
Fluxo A \\
SE - ES - ES
\end{tabular} & $\begin{array}{c}\text { Fluxo B } \\
\text { SE - BA - ES }\end{array}$ & \begin{tabular}{|c|} 
Fluxo C \\
SE - MG - ES
\end{tabular} \\
\hline \multicolumn{4}{|l|}{ Situaçäo da Indústria (Fábrica + CD) } \\
\hline \multicolumn{4}{|l|}{ Fluxos positivos } \\
\hline Crédito da compra de matéria-prima & 4,77 & 4,77 & 4,77 \\
\hline Crédito de transferência gerado no CD & 13,64 & 13,64 & 13,64 \\
\hline Recebimento pela venda para o varejista & 150,60 & 142,05 & 134,41 \\
\hline \multicolumn{4}{|l|}{ Fluxos negativos } \\
\hline Pagamento de matéria-prima & $(39,77)$ & $(39,77)$ & $(39,77)$ \\
\hline Débito de transferência gerado na Fábrica & $(13,64)$ & $(13,64)$ & $(13,64)$ \\
\hline Débito de venda gerado no CD & $(25,60)$ & $(17,05)$ & $(9,41)$ \\
\hline Balanço do ICMS & $(20,83)$ & $(12,27)$ & $(4,64)$ \\
\hline Resultado total da indústria & 90,00 & 90,00 & 90,00 \\
\hline \multicolumn{4}{|l|}{ Situação do varejista } \\
\hline \multicolumn{4}{|l|}{ Fluxos positivos } \\
\hline Crédito da compra do produto & 25,60 & 17,05 & 9,41 \\
\hline Recebimento pela venda para o cliente final & 180,72 & 180,72 & 180,72 \\
\hline \multicolumn{4}{|l|}{ Fluxos negativos } \\
\hline Pagamento pelo produto & $(150,60)$ & $(142,05)$ & $(134,41)$ \\
\hline Débito da venda para o cliente final & $(30,72)$ & $(30,72)$ & $(30,72)$ \\
\hline Balanço do ICMS & $(5,12)$ & $(13,68)$ & $(21,31)$ \\
\hline Resultado total do varejista & 25,00 & 25,00 & 25,00 \\
\hline \multicolumn{4}{|l|}{ Situaçäo do cliente final } \\
\hline Valor do ICMS pago & $(30,72)$ & $(30,72)$ & $(30,72)$ \\
\hline Valor total pago pelo produto & $(180,72)$ & $(\mathbf{1 8 0 , 7 2 )}$ & $(180,72)$ \\
\hline
\end{tabular}

Nesse caso, portanto, verifica-se que a localização do $\mathrm{CD}$ da indústria não altera o resultado fiscal e financeiro de nenhum membro da cadeia. 
Verifica-se, portanto, que a diferença de alíquotas de ICMS por si só não é capaz de gerar distorções na malha logística de uma empresa. O resultado e saldo final de ICMS a ser pago por cada membro da cadeia permanece sempre o mesmo, independente da localização das unidades produtivas e distribuidoras da indústria.

A impressão da possibilidade de obter-se de ganhos nessa situação é gerada quando os fluxos referentes aos valores pagos e recebidos nas transações das mercadorias não são considerados no cálculo, tal como ilustrado nas Figuras 1 e 2.

\subsubsection{A influência do ICMS no projeto de rede de distribuição física}

O tópico anterior avaliou o impacto da estrutura das alíquotas de ICMS de maneira isolada, ignorando a existência de fatores relacionados ao ICMS que podem exercer algum tipo de influência no que diz respeito a este tributo no fluxo de um projeto de rede de distribuição física. Alguns desses fatores estão relacionados na Tabela 5 a seguir:

Tabela 5. Fatores associados diretamente ao ICMS que podem exercer influência relacionada a este tributo no fluxo de um projeto de rede de distribuição física.

\begin{tabular}{ll}
\hline Sonegação & - Pode haver membros na cadeia de suprimentos que sonegam \\
Fiscal & impostos, como fornecedores, indústrias ou distribuidores, \\
& atacadistas e varejistas... \\
& ...e a presença da sonegação pode acontecer em níveis mais ou \\
& menos intensos. \\
\hline $\begin{array}{l}\text { Concessão de } \\
\text { benefícios }\end{array}$ & - Pode haver concessão de incentivos para determinados \\
& membros da cadeia de suprimento... \\
& ...e os incentivos fornecidos podem ser de diferentes categorias, \\
& como fiscais ou financeiros, por exemplo. \\
\hline $\begin{array}{l}\text { Prazo para } \\
\text { compensação } \\
\text { do saldo }\end{array}$ & A compensação do saldo do ICMS devido pode realizar-se \\
\hline
\end{tabular}

A situação em que pode ocorrer sonegação fiscal é tema do trabalho de Yoshizaki (2002). O caso referente ao prazo da compensação do saldo é estudado no trabalho de Ribeiro (1999). Ambos os autores realizam suas análises considerando o ponto de vista do elo industrial da cadeia de suprimento. 
O presente trabalho contribui ao estudar a influência de incentivos fiscais no projeto de rede de distribuição física de indústrias que podem gozar de tais incentivos, de modo que, tal como fizeram os autores citados no parágrafo anterior, as análises deste estudo serão realizadas considerando-se o ponto de vista da indústria.

O tópico a seguir explora o tema de incentivos fiscais, relaciona alguns dos principais incentivos oferecidos pelos estados e apresenta os incentivos que serão objeto de estudo desta dissertação.

\subsubsection{Incentivos fiscais}

Prado e Cavalcanti (2000) contam sobre a história dos incentivos fiscais no Brasil:

"Remonta pelo menos aos anos 60 a utilização, pelos governos estaduais, de isenções, reduções e diferimentos tributários como recurso para alavancar a industrialização regional. Após um periodo de maior intensidade e evidência, na segunda metade dos anos 60, esse tipo de prática aparentemente perde ímpeto e desaparece dos debates e da mídia, retomando no início dos anos 90, de forma inicialmente tímida, para depois explodir, a partir de 1.993/94, numa grande polêmica nacional. Desde então, o tema vem assumindo importância crescente, ao lado das dimensões inusitadas e por vezes alarmantes causadas pelos beneficios que, num frenético e desordenado processo de disputa, vêm sendo concedidos pelos Estados às grandes empresas, para que se instalem em seus territórios."

Melo (2004) coloca que, embora a lei seja o instrumento competente para dispor sobre as isenções, no âmbito do ICMS está prevista uma sistemática especial, conferindo-se à lei complementar a regulação da forma como, mediante deliberação dos Estados e do Distrito Federal, serão concedidas e revogadas (parágrafo $3^{\circ}$ do Art. 155 da CF), como já era o caso da Lei Complementar $n^{\circ} 24$, de 7 de janeiro de 1.975, que dispôs sobre a celebração de convênios entre as unidades da federação. De acordo com esta lei, a aprovação da concessão de um benefício depende de decisão unânime dos estados representados e pelo Distrito Federal e prevê penalidades em caso de inobservância de seus dispositivos (Varsano, 1996).

Conforme coloca Netto (2003), esse entendimento vem sendo corroborado pela jurisprudência do Supremo Tribunal Federal. Melo (2004) confirma esta afirmativa informando que as unidades federativas têm expedido unilateralmente leis, decretos e 
atos administrativos, outorgando vantagens fiscais, financeiras, creditícias e operacionais que afetam a carga impositiva.

Para Varsano (1996), do ponto de vista de um governo estadual, há claros incentivos econômicos, além dos políticos, para a concessão de benefícios fiscais. Prado e Cavalcanti (2000) lembram que a elaboração de programas voltados para atrair investimentos é prática usual na maior parte dos Estados brasileiros desde os anos 50 (e mais recentemente, também nos grandes municípios).

Apesar de existir incentivos de várias espécies, Netto (2003) identifica que existem dois tipos de benefícios importantes e outros menores, que interferem menos na concorrência negocial entre Estados. $\mathrm{O}$ autor apresenta como os dois mais importantes os seguintes:

(i) Crédito financeiro, que consiste no financiamento subsidiado de parte ou do total do débito do ICMS da empresa; neste caso, um fundo estadual faz o financiamento, em geral de longo prazo, através de uma instituição bancária.

(ii) Crédito presumido, em que o Estado concede uma redução do montante do imposto devido indicado na NF sem alterar esse montante no documento fiscal, de modo que a redução é efetuada no momento do pagamento do imposto, e o comprador recebe o crédito integral indicado na NF.

Netto (2003) explica que o crédito presumido é mais eficaz para atrair investimentos uma vez que sua sistemática reduz o recolhimento do contribuinte, enquanto que no caso do financiamento do ICMS, mesmo o Estado desembolsando o valor do financiamento, a conta de receita não é alterada. A Figura 4, apresentada a seguir, que exemplifica para uma situação hipotética a aplicação do incentivo fiscal baseado no crédito financeiro e no crédito presumido, auxilia na compreensão da afirmativa de Neto (2003). 


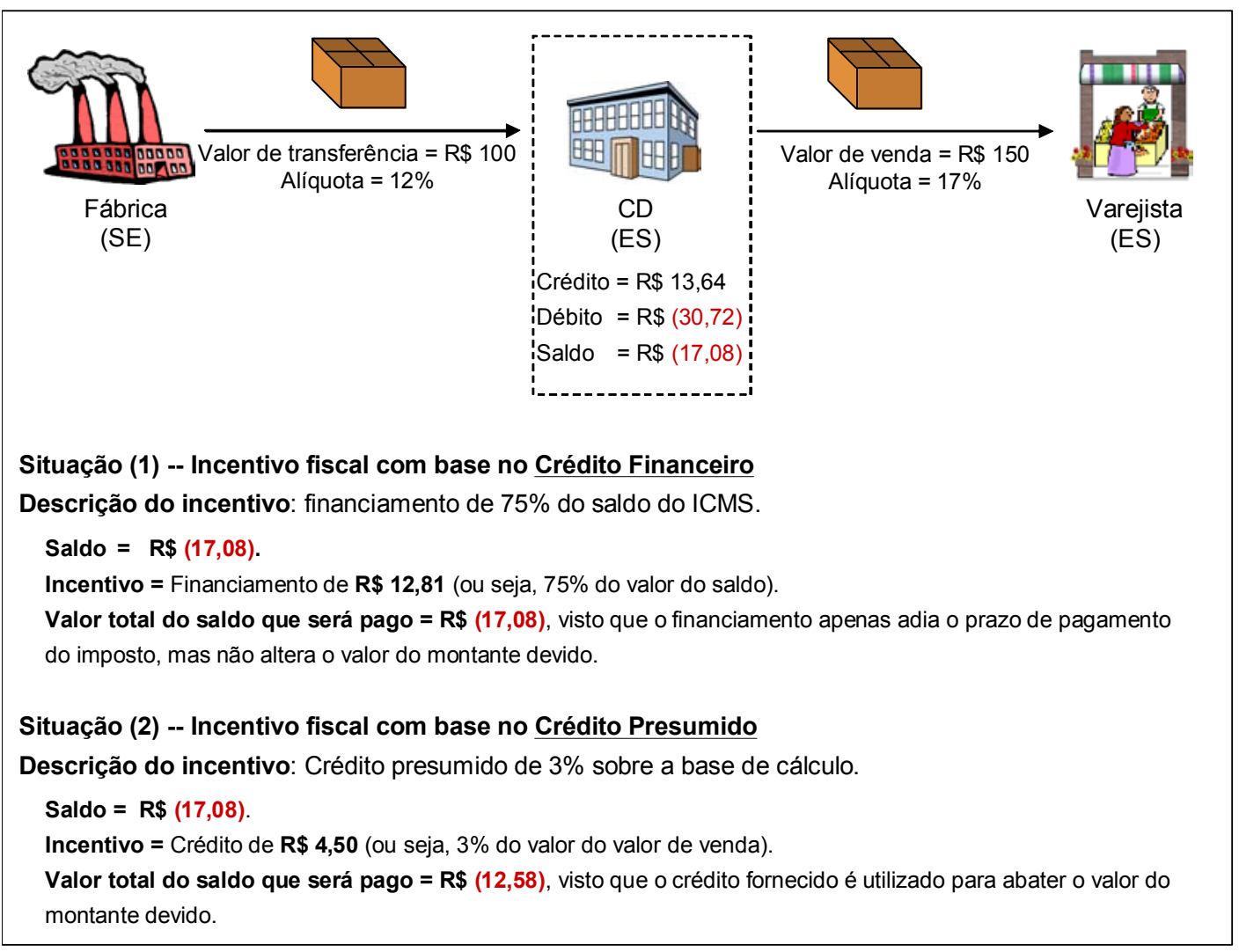

Figura 4. Exemplo de incentivo fiscal baseado no Crédito Financeiro e no Crédito Presumido.

Este trabalho dedica-se aos incentivos baseados no crédito presumido, em que o montante do benefício é um percentual sobre a base de cálculo de todas as notas fiscais de venda independente do destino destas. Espera-se que esses incentivos impactem na decisão da rede de distribuição ótima.

Alguns dos incentivos com base no crédito presumido oferecidos pelos estados de Goiás e Minas Gerais são apresentados na Tabela 6, a seguir. Optou-se por realizar a pesquisa para os estados mencionados para que fosse possível abranger as situações em que há oferta de incentivo (1) por um estado exportador, que emite mercadorias para outros estados sempre com alíquota de $12 \%$, gerando portanto um maior saldo de crédito de ICMS para a apuração do imposto devido e (2) por um estado importador, que emite mercadorias para outros estados importadores com alíquota de $12 \%$ e para estados exportadores com alíquota de $7 \%$, gerando portanto um menor saldo de crédito de ICMS para a apuração do imposto devido. 
Tabela 6. Exemplos de vantagens fiscais baseadas em crédito presumido oferecidas por diversos estados.

\begin{tabular}{|c|c|c|c|}
\hline UF & Mercadoria / Operação & Benefício & Legislação \\
\hline GO & Medicamentos de uso humano. & $\begin{array}{l}\text { Crédito presumido } \\
\text { de } 4 \% \text { sobre a base } \\
\text { de cálculo. }\end{array}$ & $\begin{array}{l}\text { Art. } 11, \text { XXIII do } \\
\text { Anexo IX do Dec. } n^{\circ} \\
4.852 / 97 \text {. }\end{array}$ \\
\hline $\mathrm{GO}$ & $\begin{array}{l}\text { Estabelecimento de comércio atacadista que } \\
\text { destine mercadoria para comercialização, } \\
\text { produção ou industrialização. }\end{array}$ & $\begin{array}{l}\text { Crédito presumido } \\
\text { de } 3 \% \text { sobre a base } \\
\text { de cálculo. }\end{array}$ & $\begin{array}{l}\text { Art. } 11, \mathrm{XV} \text { do } \\
\text { Anexo IX do Dec. } \\
4.852 / 97 \text {. }\end{array}$ \\
\hline GO & Fertilizantes. & $\begin{array}{l}\text { Crédito presumido } \\
\text { de } 5 \% \text { sobre a base } \\
\text { de cálculo. }\end{array}$ & $\begin{array}{l}\text { Art. } 11, \text { IX do Anexo } \\
\text { IX do Dec. } N^{\circ} \\
4.852 / 97 \text {. }\end{array}$ \\
\hline $\mathrm{GO}$ & $\begin{array}{l}\text { Achocolatado em pó, bebida Láctea, creme de } \\
\text { leite, doce de leite, iogurte, leite aromatizado, } \\
\text { leite esterilizado (UHT) ou pasteurizado, } \\
\text { manteiga de leite, queijo, inclusive requeijão, } \\
\text { leite em pó, soro de leite em pó, óleo butírico } \\
\text { de manteiga (butter oil), leite pré-concentrado } \\
\text { integral e leite pré-concentrado desnatado. }\end{array}$ & $\begin{array}{l}\text { Crédito presumido } \\
\text { de } 5 \% \text { sobre a base } \\
\text { de cálculo. }\end{array}$ & $\begin{array}{l}\text { Art. } 11, \text { XXXV do } \\
\text { Anexo IX do Dec. } n^{\circ} \\
4.852 / 97 \text {. }\end{array}$ \\
\hline GO & Derivados da soja. & $\begin{array}{l}\text { Crédito presumido } \\
\text { de } 7 \% \text { sobre a base } \\
\text { de cálculo. }\end{array}$ & $\begin{array}{l}\text { Art. } 11, \text { XXX do } \\
\text { Decreto }{ }^{\circ} 4.852 / 97 .\end{array}$ \\
\hline GO & Feijão. & $\begin{array}{l}\text { Crédito presumido } \\
\text { de } 5 \% \text { sobre a base } \\
\text { de cálculo. }\end{array}$ & $\begin{array}{l}\text { Art. } 11, \mathrm{XXXIV}, \mathrm{b}, \\
\text { Anexo IX do Dec. } \mathrm{n}^{\circ} \\
4.852 / 97\end{array}$ \\
\hline MG & Leite longa vida (UHT). & $\begin{array}{l}\text { Crédito } \\
\text { presumido, de } \\
\text { forma que a carga } \\
\text { tributária seja de } \\
1 \% \text { da base de } \\
\text { cálculo. }\end{array}$ & $\begin{array}{l}\text { Art. } 75, \text { XVI do } \\
\text { RICMS/MG. }\end{array}$ \\
\hline MG & $\begin{array}{l}\text { Produtos industrializados cuja matéria-prima } \\
\text { seja resultante do abate de aves ou de gado } \\
\text { bovino, eqüídeo, bufalino, caprino, ovino ou } \\
\text { suíno, desde que destinados à alimentação } \\
\text { humana. }\end{array}$ & $\begin{array}{l}\text { Crédito presumido } \\
\text { de } 6,9 \% \text { sobre a } \\
\text { base de cálculo. }\end{array}$ & $\begin{array}{l}\text { Art. } 75, \mathrm{IV}, \mathrm{a} \text {, do } \\
\text { RICMS/MG. }\end{array}$ \\
\hline MG & $\begin{array}{l}\text { Mercadorias remetidas por estabelecimento } \\
\text { atacadista ou central de distribuição para } \\
\text { comercialização, produção ou industrialização. }\end{array}$ & $\begin{array}{l}\text { Crédito presumido } \\
\text { de } 9 \% \text { sobre a } \\
\text { base de cálculo. }\end{array}$ & $\begin{array}{l}\text { Art } 75 \text {, inc XIV do } \\
\text { RICMS/MG. }\end{array}$ \\
\hline
\end{tabular}


É possível verificar que estes incentivos abrangem uma grande variedade de produtos, mas que muitos deles são específicos para determinada categoria de produto. Para este estudo serão avaliados os incentivos que são mais abrangentes, por não restringirem-se a determinado tipo de produto. São eles:

- Goiás: oferta de crédito presumido de $3 \%$ da base de cálculo para estabelecimento de comércio atacadista que destine mercadoria para comercialização, produção ou industrialização.

- Minas Gerais: oferta de crédito de 9\% da base de cálculo para mercadorias remetidas por estabelecimento atacadista ou central de distribuição para comercialização, produção ou industrialização.

Esses incentivos serão tratados com maior detalhe na parte referente à modelagem do problema.

\subsection{Problemas de localizaÇão}

A teoria de localização foi formalmente introduzida por Alfred Weber em 1.909, que considerou o problema de localizar um único armazém para minimizar a distância total de viagem entre este armazém e uma série de clientes geograficamente distribuídos (Brandeau; Chiu, 1989). Para uma revisão da literatura associada ao histórico e evolução dos problemas de localização, pode-se consultar Brandeau; Chiu (1989), Martos (2000, Cap.3) ou Klose; Drexl (2005).

As decisões de localização de instalações são um elemento crítico no planejamento estratégico para uma grande variedade de empresas públicas e privadas, haja visto que as ramificações de localizar instalações geram impactos no longo prazo, influenciando inúmeras decisões operacionais e logísticas (Owen; Daskin, 1998).

A Figura 5 apresenta esquematicamente o problema de projeto de rede englobando todo o canal de distribuição física, e oferece uma noção da complexidade diante das inúmeras combinações de soluções possíveis desta categoria de problema logístico. 


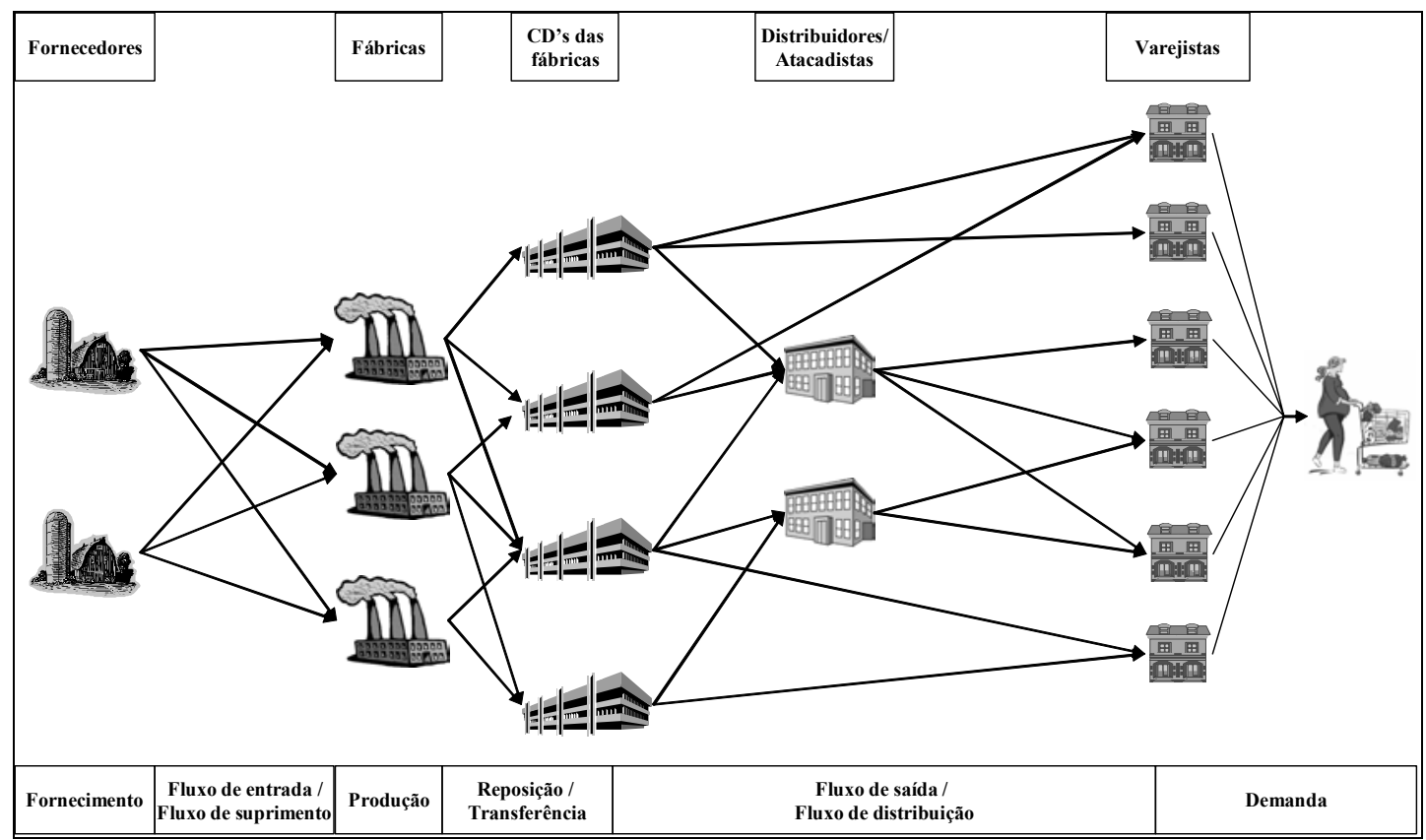

Figura 5. Exemplo de rede de distribuição. Adaptado de Yoshizaki (2002) e Ballou (2001)

Brandeau e Chiu (1989) caracterizam o problema de localização como um problema de alocação espacial de recursos cujas decisões envolvem a determinação do número, da localização e do tamanho das instalações a serem usadas, que incluem pontos nodais na rede, tais como fábricas, portos, fornecedores, armazéns, filiais de varejo e centros de serviço - pontos na rede logística onde os produtos param temporariamente no seu caminho até os consumidores finais.

Owen e Daskin (1998) colocam que o fato de geralmente haver elevados custos associados à aquisição de propriedades e construção de fábricas faz com que a localização ou relocalização de instalações industriais sejam projetos de investimento de longo prazo. Desse modo, para fazer com que tais empreendimentos sejam lucrativos, as empresas devem planejar para que as novas instalações permaneçam em seus locais e em operação por um extenso período de tempo.

Em vista disso, esses mesmos autores sugerem que os tomadores de decisão devam selecionar locais que não apenas apresentem-se como boa opção para o estado atual do sistema, mas que vão continuar a serem lucrativos ao longo de todo tempo de vida da instalação, mesmo que haja alteração dos fatores do entorno, mudanças no perfil da população e que as tendências do mercado evoluam. 
Ballou (2001) coloca que o problema estratégico de localização de múltiplos centros de distribuição é um dos mais comuns e complexos. Dentre as atividades abrangidas pelo problema de localização de centros de distribuição, Ávila (1996) enuncia os seguintes objetivos:

- determinar a quantidade ideal de pontos de distribuição;

- determinar a dimensão adequada para as instalações físicas destes pontos;

- determinar a localização destes pontos;

- determinar a região de atendimento de cada um desses pontos de distribuição;

- determinar como deve ser realizado o abastecimento a partir das fábricas para cada um dos pontos de distribuição; e

- determinar o momento em que a hipótese de fechamento ou abertura de um ponto de distribuição deve ser aventada.

Sobre a complexidade de atingir-se os objetivos dos problemas de localização de múltiplos centros de distribuição, Yoshizaki (2002) aponta o fato de as diversas unidades não poderem ser tratadas como economicamente independentes porque existem diversos tradeoffs logísticos importantes tais como custos de transporte, armazenagem e estoques, além de considerações de nível de serviço.

Chopra (2001) coloca que o desempenho de uma rede de distribuição física deve ser avaliado de acordo com dois fatores: (1) as necessidades dos clientes que devem ser satisfeitas e (2) os custos associados a satisfazer as necessidades dos clientes. Como a qualidade dos serviços oferecidos aos clientes abrange muitos componentes, o autor relaciona aqueles influenciados pela estrutura da rede de distribuição, quais sejam:

- Tempo de resposta: tempo entre a colocação do pedido pelo cliente e o recebimento de seu pedido. 
- Variedade de produtos: número de diferentes configurações de recebimento de produto que um cliente deseja de uma rede de distribuição.

- Disponibilidade de produtos: probabilidade de haver o produto no estoque quando o pedido de um cliente é colocado.

- Experiência dos clientes: facilidade com que o cliente pode colocar e receber seu pedido.

- Visibilidade do pedido: possibilidade do cliente acompanhar a posição de seu pedido desde sua colocação até o seu recebimento.

- Devolução: facilidade de o cliente poder retornar uma mercadoria insatisfatória e a habilidade da rede de distribuição processar esses retornos.

Para examinar particularmente o tradeoff gerado pelo desejo de aumento do tempo de resposta em relação à quantidade necessária de centros de distribuição, Chopra (2001) apresenta o gráfico ilustrado pela Figura 6 a seguir:

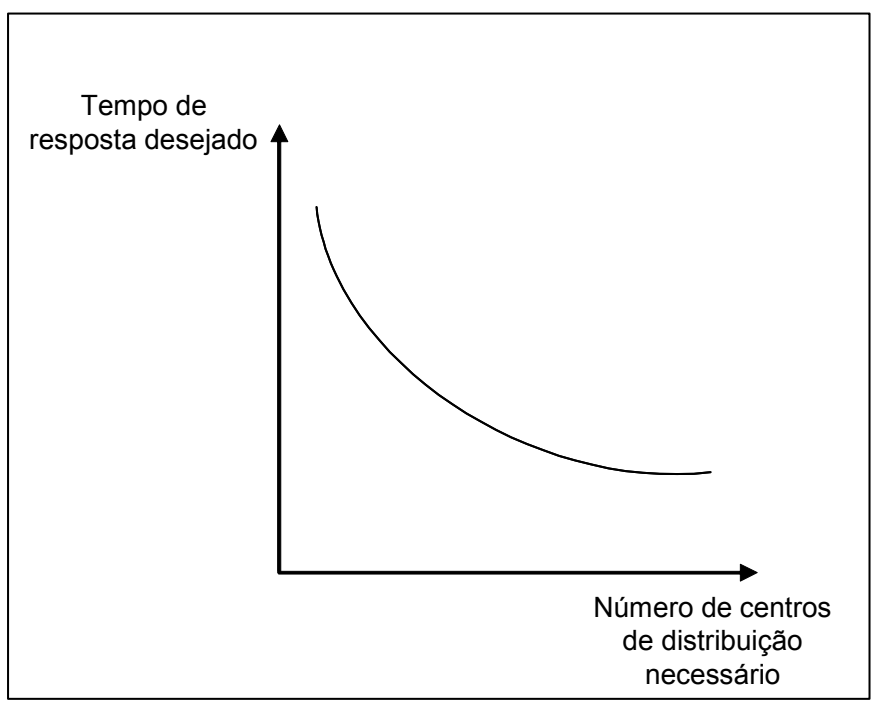

Figura 6. Relação entre o tempo de resposta desejado e a quantidade de centros de distribuição. Adaptado de Chopra, 2001. 
Em seu trabalho, Yoshizaki (2002) considera como proxi do nível de serviço a distância de viagem, medida em quilômetros, entre o centro de distribuição mais próximo até um determinado cliente. Quanto a este aspecto, o autor observa sua particular importância no Brasil, onde é comum haver grandes distâncias entre as cidades, fato que leva as empresas a utilizarem depósitos locais não apenas quando há ganhos em função da diminuição de custos de transporte, mas também para garantir um prazo de entrega satisfatório para o cliente.

Chopra (2001) acredita que cada empresa deva ter o número de instalações que minimize o custo logístico total. Entretanto, ao considerar-se que uma empresa deseja reduzir o tempo de resposta aos seus clientes, Chopra (2001) recomenda que ela aumente o número de instalações em detrimento da minimização dos custos logísticos no caso de os gestores acreditarem que o aumento nos lucros gerados pela melhoria do tempo de resposta será melhor do que o aumento nos custos gerados pelo aumento do número de instalações.

\subsubsection{Métodos para configuração da rede logística}

Para analisar-se um problema de localização, pode-se utilizar uma variedade de métodos. Brandeau; Chiu (1989) classificam esses métodos conforme a técnica empregada para a solução dos modelos. Martos (2000, Cap 3) agrupa-os nas seguintes categorias:

- exatos ou otimizantes: são aqueles que avaliam todas as alternativas e selecionam a melhor, sendo possível demonstrar matematicamente que a solução encontrada é a ótima nas condições definidas pela modelagem.

- heurísticos: esses métodos reduzem o processo de busca de soluções, de acordo com o critério adotado pela heurística desenvolvida, para encontrar uma solução satisfatória do problema com o intuito de reduzir-se o tempo de processamento; não garante, portanto, que a solução encontrada seja a ótima.

- simulação: a utilização deste método permite elaborar um modelo, muitas vezes estocástico, que apresenta as principais características da rede em estudo, o que permite avaliar o desempenho de alternativas propostas, as quais podem ser 
replicadas diversas vezes para gerar estatísticas que poderão ser utilizadas na seleção final.

Geoffrion (1976) e Geoffrion; Powers (1995) acreditam que para o projeto de redes de distribuição física no nível estratégico é mais adequado utilizar métodos otimizadores e apresentam as seguintes razões para isso:

- os métodos otimizadores são tecnicamente viáveis em função da disponibilidade de algoritmos, hardware e software;

- conseguem avaliar simultaneamente todos os complexos tradeoffs logísticos em problemas de grande porte; e

- as empresas têm dados disponíveis para esse tipo de estudos, já que sistemas de bancos de dados automatizados são a regra e não mais a exceção.

Ballou (1999, Cap 13) considera a Programação Linear Inteira Mista - PLIM como o método exato mais promissor para os problemas de localização de múltiplas instalações, uma vez que, ao contrário da maioria dos outros métodos, consegue trabalhar com custos fixos de maneira ótima.

Conforme Ballou (1993) e Masters (1999), há grande quantidade de softwares de localização prontos disponíveis no mercado, sendo que a grande maioria $(90 \%$, de acordo com a pesquisa realizada em 1999) utiliza Programação Linear ou Programação Linear Inteira Mista.

Ballou (2001) coloca que problemas de localização tipicamente envolvem um número muito grande de configurações de projetos de rede a serem avaliados, de modo que para gerenciar o tamanho de um problema prático de localização e obter uma solução, seja em geral necessário usar dados agregados. 
Para Shapiro (2001), a capacidade de poder agregar dados possibilita a resolução dos problemas de localização geográfica por otimização. $\mathrm{O}$ autor dedica parte de um capítulo para tratar sobre como proceder em relação à agregação dos dados referentes aos produtos, instalações, fornecedores e mercados.

Ávila (1996) coloca que, na impossibilidade de captar e modelar todas as variáveis envolvidas, as principais simplificações que se fazem nos modelos de localização, sem que haja perda da qualidade da decisão baseada neles, são:

- tratar a demanda como concentrada em um único ponto;

- não considerar o custo de oportunidade na aquisição de novos equipamentos de movimentação, construção de infra-estrutura e montagem das instalações;

- considerar tarifas proporcionais à distância, quando estas são pequenas;

- considerar as distâncias como lineares e corrigi-las, posteriormente, através de um fator de correção; e

- agregar todos os produtos, tratando-os como se fossem um só.

Em relação à utilização de modelos e métodos de pesquisa operacional para analisar problemas de localização, Shapiro (2001) chama atenção ao fato de os detalhes inerentes a cada problema poderem gerar um grande desafio em definir precisamente um modelo apropriado para cada situação específica.

Para tratar o problema logístico proposto para este trabalho será utilizado um modelo de Programação Linear Inteira Mista. O próximo tópico discorre sobre o trabalho de outros autores que desenvolveram modelos para tratar questões associadas ao ICMS, enfatizando o estudo realizado por Yoshizaki (2002), que foi pioneiro nesse sentido.

\subsubsection{Modelos de localização que consideram a questão fiscal relativa ao ICMS}

Para lidar com o problema de identificar a localização ótima de centros de distribuição intermediários a fábricas e mercados consumidores, Geoffrion e Graves 
(1974) desenvolveram uma versão de um problema de distribuição utilizando programação linear inteira mista.

A versão mais simples do problema modelado pelos autores considera a existência de diversos produtos processados em diversas entidades industriais com capacidade de produção conhecida. Considera ainda que a demanda é conhecida para cada produto em cada uma das zonas de demanda, e que essa demanda é atendida por cargas vindas dos centros de distribuição regionais, de modo que cada zona de demanda deve ser atendida por um único $\mathrm{CD}$.

O problema consiste em determinar quais CD's utilizar, qual o tamanho de cada um dos CD's, que regiões de demanda deverão ser atendidas por qual $\mathrm{CD}$ e qual o arranjo do fluxo de transporte para cada produto. Isso deve ser feito para satisfazer a demanda dada com o menor custo total de distribuição, sujeito à capacidade das plantas e às restrições de fluxo do $\mathrm{CD}$.

Geoffrion e Powers (1995) colocam que o modelo de Geoffrion e Graves é bastante adequado para tratar os problemas de projeto estratégico de redes de distribuição física, sendo utilizado em alguns softwares de localização de instalações.

Yoshizaki (2002) foi pioneiro na abordagem do ICMS como "aspecto estratégico de projeto da rede de distribuição física", em que o tributo é considerado como "aspecto fundamental do gerenciamento da cadeia de suprimentos" (YOSHIZAKI, 2002). Em sua tese o autor comenta os trabalhos anteriormente realizados que de alguma forma trataram ou mencionaram o ICMS, mas identifica que o objeto desses trabalhos não consiste na abordagem do tributo sob o ponto de vista estratégico, que avalia o tradeoff entre o ICMS e os custos logísticos.

Para elaborar o modelo matemático para sua tese, Yoshizaki (2002) partiu do modelo de Geoffrion e Graves, realizando as seguintes adaptações: não restringiu o abastecimento de cada mercado a um único depósito, considerou a questão tributária referente ao ICMS e incorporou o conceito de economia de escala na operação de depósitos no que tange principalmente a custos fixos de amortização de capital, 
depreciação e mão-de-obra direta utilizando para isso variáveis binárias adicionais. $\mathrm{O}$ modelo proposto pelo autor é apresentado a seguir:

\section{Índices}

$i \quad \ldots$ Fábrica [ 4 ]

$j \quad \ldots$ Depósitos [51]

$k \quad \ldots \quad$ Mercados (agregados em meso-regiões) [ 122 ]

$p \quad \ldots$ Produtos (um por fábrica) [4]

$n$... Nível de depósito (indicador para custo fixo e capacidade de depósito) [10]

$S$... Nível de tributação ( $\mathrm{s}=1$ para tributo incorporado na função objetivo cliente indiferente ao crédito de ICMS, pois pode sonegar; e $\mathrm{s}=2$ para tributo fora da função objetivo - cliente quer o crédito, pois não sonega) [2]

\section{Parâmetros}

Dem $M_{k p s} \quad \ldots$ Demanda do produto $p$ no mercado $k$ com tributação ao nível $s(\mathrm{t})$

$\operatorname{CapD}_{j n} \quad \ldots$ Capacidade do depósito $j$ no nível de capacidade $n(\mathrm{t})$

$\mathrm{CapF}_{i p} \quad \ldots$ Capacidade da fábrica $i$ para a classe de produto $p(\mathrm{t})$

$\operatorname{Cus}_{i j} \quad \ldots$ Custo unitário de transferência da fábrica $i$ para o depósito $j(\mathrm{R} \$ / \mathrm{t})$

CusD $D_{j k} \quad \ldots$ Custo unitário de distribuição do depósito $j$ para o mercado $k(\mathrm{R} \$ / \mathrm{t})$

CusF $_{i k} \quad \ldots$ Custo unitário de distribuição da fábrica $i$ para o mercado $k(\mathrm{R} \$ / \mathrm{t})$

$\mathrm{CusB}_{j p} \quad \ldots$ Custo unitário de transbordo da classe de produto $p$ no depósito $j$ $(\mathrm{R} \$ / \mathrm{t})$

Fix $D_{j n} \quad \ldots$ Custo fixo do depósito $j$ com capacidade $n(\mathrm{R} \$ / \mathrm{t})$

CusI $_{j k} \quad \ldots$ Taxa do ICMS na mercadoria na distribuição a partir do depósito $j$ para o mercado $k$

CusIF $_{i k} \quad \ldots$ Taxa do ICMS na mercadoria na distribuição a partir da fábrica $i$ para o mercado $k$

$\operatorname{CusM}_{p} \quad \ldots$ Custo (preço) médio da classe de produto $p$ (no qual incide o ICMS), em R $\$ / t$ 
FICMS $_{k} \quad \ldots \quad$ Fator linear de indicação do nível de tributação $(0 \leq$ FICMS $\leq 1)$

Seja $\operatorname{Dem}_{k p}$ a demanda do produto $p$ no mercado o $k(\mathrm{t})$ com característica fiscal nível $s$, então:

$\operatorname{Dem}_{k, s=1}=\operatorname{Dem}_{k} *$ FICMS

$\operatorname{Dem}_{k, s=2}=\operatorname{Dem}_{k} *(1-$ FICMS $)$

Quando $F I C M S=1$, admite-se que todo o sistema paga 100\% do ICMS; quando FICMS =0, admite-se que todo o sistema sonega este imposto.

\section{Variáveis}

Trnsijps $\quad \ldots$ Quantidade transferida da classe de produto $p$ da fábrica $i$ para o depósito $j$ com nível de tributação $s(\mathrm{t})$

$D s t r D_{j k p s} \quad \ldots$ Quantidade transferida da classe de produto $p$ do depósito $j$ para o mercado $k$ com nível de tributação $s(\mathrm{t})$

$D s t r F_{i k p s} \quad \ldots$ Quantidade transferida da classe de produto $p$ da fábrica $i$ para o mercado $k$ com nível de tributação $s(\mathrm{t})$

$Z_{j n}$

... Assume valor 1 caso o depósito $j$ estiver operando no nível de depósito $n, 0$ em caso contrário

CT $\quad$.. Custo total de operação (R \$/ano)

\section{Função Objetivo}

Minimizar Custo Total (CT)

$$
\begin{aligned}
& \mathrm{CT}=\sum_{i} \sum_{k} \sum_{p}\left\{\left[\left(C u s F_{i k}+C u s I F_{i k} \times C u s M_{p}\right) \times \sum_{s \mid s=1} D s t r F_{i k p s}\right]+\left[C u s F_{i k} \times \sum_{s \mid s=2} D s t r F_{i k p s}\right]\right\} \\
& +\sum_{i} \Sigma_{j} \Sigma_{p}\left(C u s T_{i j} \times \operatorname{Trns}_{i j p}\right) \\
& +\sum_{j} \sum_{k} \Sigma_{p}\left\{\left[\left(C u s D_{j k}+C u s B_{j}+C u s I_{j k} \times C u s M_{p}\right) \times \sum_{s \beta=1} D s t r D_{j l p s}\right]+\left[\left(C u s D_{j k}+C u s B_{j}\right) \times \sum_{s \varsigma=2} D s t r D_{j l q s}\right]\right\} \\
& +\sum_{j} \sum_{n} F i x D_{j n} \times Z_{j n}
\end{aligned}
$$




\section{Restrições}

Restrição de atendimento da demanda da classe de produto $p$ no mercado $k$.

$\operatorname{DemM}_{k p s} \leq \Sigma_{i} D_{s t r} F_{i k p s}+\Sigma_{j} D s t r D_{j k p s} \quad \forall k, \forall p, \forall s$

Restrição de capacidade de produção da classe de produtos $p$ na fábrica $i$.

$\Sigma_{i} \Sigma_{s} \operatorname{DstrD}_{i k p s}+\sum_{j} \Sigma_{s}$ Trnsijps $_{i j \mathrm{CapF}} \leq \quad \forall i, \forall p$

Restrição de capacidade e operação do depósito $j$.

$\Sigma_{i} \Sigma_{p} \Sigma_{s} \operatorname{Trns}_{i j p s} \leq \Sigma_{n} Z_{j n} * \operatorname{CapD}_{j n} \quad \forall j$

Relação entre capacidades de depósitos.

$\Sigma_{n} Z_{j n}=1$

$\forall j$

Balanço de massa da classe de produto $p$ no depósito $j$ com nível de tributação $s$.

$\Sigma_{i} \operatorname{Trns}_{i j p s}=\Sigma_{k} \operatorname{Dstr}_{j k p s} \quad \forall j, \forall p, \forall s$

Não negatividade

$\operatorname{Trns}_{i j p s} \geq 0$

$\forall i, \forall j, \forall p, \forall s$

$\operatorname{DstrD}_{j k p s} \geq 0$

$\forall j, \forall k, \forall p, \forall s$

$\operatorname{DstrF}_{i k p s} \geq 0$

$\forall i, \forall k, \forall p, \forall s$ 
Variáveis binárias

Zjn $=\left\{\begin{array}{l}1, \text { se depósito } j \text { com capacidade } n \text { ficar aberto } \\ 0, \text { em caso contrário }\end{array} \quad \forall j, \forall n\right.$

Yoshizaki (2002) explica que a função objetivo é composta por quatro parcelas, identificadas pelas quatro somatórias, sendo que:

- Parcela 1: considera os custos de distribuição direta a partir da fábrica $i$ para o mercado $k$, que é formado pelo produto de um custo variável pelo fluxo $i k$. Se o cliente desse mercado k quiser o crédito de ICMS, apenas o custo de transporte $\left(C u s F_{i k}\right)$ deve ser considerado no custo variável (referente a segunda parte da somatória, ou seja, $\mathrm{s}=2$ ), isto é, apenas a questão logística vai entrar no cômputo.

- Parcela 2: representa o custo do transporte de transferência fábrica - CD ij .

- Parcela 3: consiste no custo de distribuição a partir do $\operatorname{CD} j$ para o mercado $k$, incluindo o custo variável $C u s B_{j}$ de manuseio (transbordo) no centro de distribuição.

- Parcela 4: representa o custo fixo do CD que for aberto no local $j$, em função de sua capacidade $n$.

Em relação às restrições, o autor do modelo explica que o conjunto de restrições (2) representa o atendimento integral da demanda, de modo que para cada produto $p$ em cada mercado $k$, a demanda deve ser planamente atendida; o conjunto de restrições (3) limita o escoamento de produtos $p$ à capacidade da planta industrial $i$ de fabricálos; as restrições (4) limitam o fluxo nos depósitos $j$ à sua capacidade de movimentação, que está associada ao nível $n$; o grupo de restrições (5) faz com que haja pelo menos um depósito aberto no sítio candidato $j$; para permitir o modelo não abrir nenhuma instalação no local $j$, o nível $n=1$ tem capacidade e custo zero; o conjunto (6) representa o balanço de massa nos depósitos, ou seja, o fluxo de entrada 
é igual ao fluxo de saída; os grupos de restrições (7) a (10) compreendem as usuais exigências de não-negatividade ou valores binários para as variáveis de decisão.

Yoshizaki (2002) coloca ainda que, em relação às restrições do modelo, não há equação para o nível de serviço em função do mesmo ter sido modelado através das distâncias máximas permitidas: os $\operatorname{arcos} i k$ ou $j k$ com distância acima da permitida foram eliminados do modelo.

Para o presente trabalho, desenvolveu-se um modelo matemático a partir do proposto por Yoshizaki (2002). Assim como o modelo matemático elaborado pelo autor, o modelo desenvolvido para o presente trabalho também não restringe o abastecimento de cada mercado a um único depósito. Um outro aspecto incorporado do modelo de Yoshizaki (2002) consiste na modelagem do conceito de economia de escala na operação de depósitos ao que tange principalmente a custos fixos de amortização de capital, depreciação e mão-de-obra direta utilizando para isso variáveis binárias adicionais.

Entretanto, como o presente trabalho aborda a influência do ICMS na cadeia de suprimentos sob uma ótica distinta da abordada por Yoshizaki (2002), naturalmente toda a modelagem de Yoshizaki (2002) referente ao tratamento fiscal do ICMS não pôde ser utilizada para este trabalho.

Dois anos após a publicação do trabalho de Yoshizaki (2002), Pantalena (2004) volta a abordar a questão do ICMS e desenvolve um modelo de localização de CDs para resolver o caso particular de uma indústria química que produz e comercializa produtos sujeitos a uma regulamentação específica quanto às alíquotas de ICMS. Essas alíquotas, regulamentadas pelo Convênio 100/97 do CONFAZ, estão relacionadas a seguir:

- $\quad$ Alíquota de 0\% para vendas dentro do mesmo estado.

- Redução de 60\% na base de cálculo para vendas entre estados, de modo que para vendas interestaduais em que a alíquota base de ICMS é de 7\%, tem-se uma alíquota de $2,8 \%(=7 \% * 0,4)$ e para as regiões em que a alíquota base de ICMS é de $12 \%$, tem-se uma alíquota de $4,8 \%(=12 \% * 0,4)$. 
O objetivo do modelo elaborado por Pantalena (2004) consiste em determinar a localização, capacidade e área de cobertura de CDs de forma a minimizar os custos totais incluindo custos de armazenagem fixos e variáveis (transbordo), custos de frete de transferência e de distribuição e custos de ICMS.

Pantalena (2004) explica que a indústria objeto de seu estudo absorve todos os custos de frete e de ICMS gerados por sua rede de distribuição física, não os repassando, portanto, para seus clientes. Nas palavras da autora: "apesar de diferentes locais de entrega poderem gerar diferentes custos finais (devido à diferença no frete e no ICMS), estes custos não são repassados para o cliente final. Sendo assim, o preço médio praticado é o mesmo em todo país, não havendo possibilidade de "migração" de demanda devido a diferenças de preços ocorridas por mudanças no CD que abastece a região" (PANTALENA, 2004).

Diante disto, Pantalena (2004) incluiu na função objetivo de seu modelo uma parcela de custo de ICMS, correspondente ao débito final de ICMS a ser pago em cada um dos CDs localizados fora do estado de SP: tratam-se dos débitos de ICMS que são gerados na distribuição (vendas) subtraídos dos créditos gerados pelas transferências para cada CD (PANTALENA, 2004). O CD localizado no estado de SP foi excluído pois a autora optou por modelar a particularidade da questão tributária relacionada a esta instalação nas restrições de seu modelo, conforme está explicado nos parágrafos seguintes.

Pantalena (2004) explica que uma conseqüência das alíquotas específicas determinadas pelo Convênio 100/97 do CONFAZ consiste em propiciar a geração de "crédito morto" nos CDs, visto que se toma o crédito de entrada dos produtos nos CDs, mas com alíquotas tão reduzidas para as operações de venda, quase não há débitos na saída das mercadorias destes mesmos CDS. A autora informa ainda que o "crédito morto" gerado na indústria em questão é muito grande e dificilmente consegue ser utilizado, salvo no caso da instalação localizada no estado de SP, visto que a "indústria consegue facilmente "trocar" (o crédito) com seus fornecedores localizados no estado de SP" (PANTALENA, 2004). 
Para que seu modelo matemático também incluísse este problema, Pantalena (2004) incluiu uma restrição que não permite a geração de crédito morto de ICMS nos CDs, salvo no caso da instalação localizada no estado de SP. Quanto a este ponto, a autora ainda inclui no modelo uma restrição para não permitir a geração de débito na instalação localizada em SP, com o intuito de reproduzir uma situação que era fato na indústria objeto de seu estudo.

O modelo elaborado no presente estudo também restringe a formação de crédito de ICMS nos CDs em função da dificuldade que existe em se conseguir utilizar este montante. Entretanto, como se considera para este trabalho que a indústria repassa o ICMS para o elo seguinte da cadeia, conforme determina a sistemática de cálculo do ICMS e também de acordo com o que praticam todas as indústrias de bens de consumo não duráveis com as quais a autora do presente estudo teve contato, os débitos de ICMS não são considerados como custo para a empresa.

O capítulo seguinte apresenta o modelo matemático elaborado para o presente estudo. 


\section{MODELAGEM DO PROBLEMA}

Este capítulo define as características, as hipóteses e o contexto do problema de projeto de rede de distribuição física considerando benefícios fiscais baseados no crédito presumido, em que o cálculo do incentivo é proporcional ao crédito de venda, e apresenta o modelo matemático genérico de PLIM elaborado para explorar suas soluções.

\subsection{Definição do Problema}

O foco do presente estudo está nos projetos de rede de distribuição física, em que a partir de uma rede fixa de instalações industriais objetiva-se traçar o fluxo ótimo para o atendimento de mercados consumidores utilizando-se CDs como suporte para a operação. A existência e conseqüente utilização dos CDs é uma variável de decisão, bem como os fluxos de produto entre as instalações: da indústria para os CDs e destes até os centros de demanda.

Este é um problema típico de indústrias de bem de consumo não duráveis que possuem mais de uma unidade produtiva e que precisam contar com CDs para atender seus clientes, em geral localizados ao longo de todo o território nacional. O objetivo do modelo matemático proposto para solucionar este problema consiste em determinar a quantidade, a localização e a área de cobertura dos CDs de forma a minimizar a função de custo total, composta pelos custos de frete de transferência e distribuição, pelos custos fixos e variáveis de operação dos CDs e finalmente, para o caso específico deste trabalho, pelo ganho auferido com benefício fiscal relativo ao ICMS.

Para a representação teórica deste problema definiram-se algumas premissas, tomando-se o cuidado para que fossem suficientemente realistas para manter a complexidade inerente a esse tipo de problema, de modo que, com a simplificação realizada, as análises e conseqüentes conclusões realizadas não fosse prejudicadas. Essas premissas estão relacionadas a seguir:

- Consideram-se somente produtos acabados, de modo que não se inclui, portanto, o elo da cadeia referente aos fornecedores. 
- Considera-se um único período de tempo.

- Não se considera variação de estoques no sistema, nem em função do tempo (premissa anterior), nem em função do número de CDs (variação do estoque de segurança).

- Considera-se para o transporte o modal rodoviário, típico utilizado pela maioria das indústrias que realizam distribuição com cobertura em todo o território nacional.

- Considera-se que as entregas são realizadas pela indústria no modo $C I F$, modalidade de entrega tipicamente utilizada pelas indústrias de bens de consumo não duráveis, cujos principais clientes são atacadistas, distribuidores e grandes redes varejistas. Sendo o custo de transporte calculado de modo diferente, por exemplo, quando o custo fica a cargo do destinatário da mercadoria, o custo do transporte não incide no custo total do modelo proposto.

- Considera-se que o ICMS que incide sobre as transações da venda é repassado para o cliente.

- Consideram-se múltiplos produtos, de modo que cada produto possa ter uma margem de venda diferente.

- Consideram-se múltiplas origens ( $n$ fábricas), mas cada produto é produzido em apenas uma fábrica.

- Consideram-se múltiplos CDs.

- Consideram-se múltiplos pontos de demanda.

- Considera-se que as capacidades de fábricas são suficientes para atender toda a demanda.

- Considera-se que a distribuição é realizada somente pelos CDs.

- Considera-se que os CDs apresentam diferentes níveis de capacidade, de modo a capturar ganhos de escala em função de diferentes níveis de volume movimentado em cada CD. 
- Considera-se necessário que haja um fluxo mínimo de volume movimentado para abrir um CD com um determinado nível de capacidade; o fluxo mínimo é determinado em função do nível de capacidade a ser aberto. Isto deve-se à necessidade de garantia de movimentação mínima exigida pelos contratos com Operadores Logísticos.

- Considera-se que um mesmo cliente pode ser abastecido de CDs diferentes.

O tópico seguinte apresenta a formulação matemática com base em Programação Linear Inteira Mista elaborada para abordar o problema definido.

\subsection{O Modelo Matemático}

A seguir é apresentado o modelo matemático elaborado. Dado que o modelo está escrito de modo a abranger genericamente o grupo de problemas com características definidas no item anterior, o capítulo seguinte apresenta a descrição física do caso que será utilizado para a aplicação do modelo elaborado e análise dos resultados.

\section{Índices}

$i \quad \ldots$ Fábrica $[\mathrm{i}=1, \ldots, \mathrm{I}]$.

$j \quad \ldots$ Centros de Distribuição $[\mathrm{j}=1, \ldots, \mathrm{J}]$.

$k \quad \ldots$ Mercados $[\mathrm{k}=1, \ldots, \mathrm{K}]$.

$p$
$\quad \ldots$ Produtos $[\mathrm{p}=1, \ldots, \mathrm{P}]$.

$n \quad \ldots \quad$ Nível de capacidade dos CDs $[\mathrm{n}=1, \ldots, \mathrm{N}]$.

\section{Parâmetros}

$\operatorname{Dem}_{p k} \quad \ldots \quad$ Demanda do produto $p$ no mercado $k$ (t/ano).

$\mathrm{CapFab}_{i p} \quad \ldots$ Capacidade da fábrica $i$ para produzir o produto $p$ (t/ano).

${\operatorname{Cap} C D_{j n}} \quad \ldots \quad$ Capacidade do $\mathrm{CD} j$ no nível de capacidade $n$ (t/ano).

CTrns $_{i j} \quad \ldots \quad$ Custo do frete de transferência da fábrica $i$ para o $\mathrm{CD} j(\mathrm{R} \$ / \mathrm{t})$. 


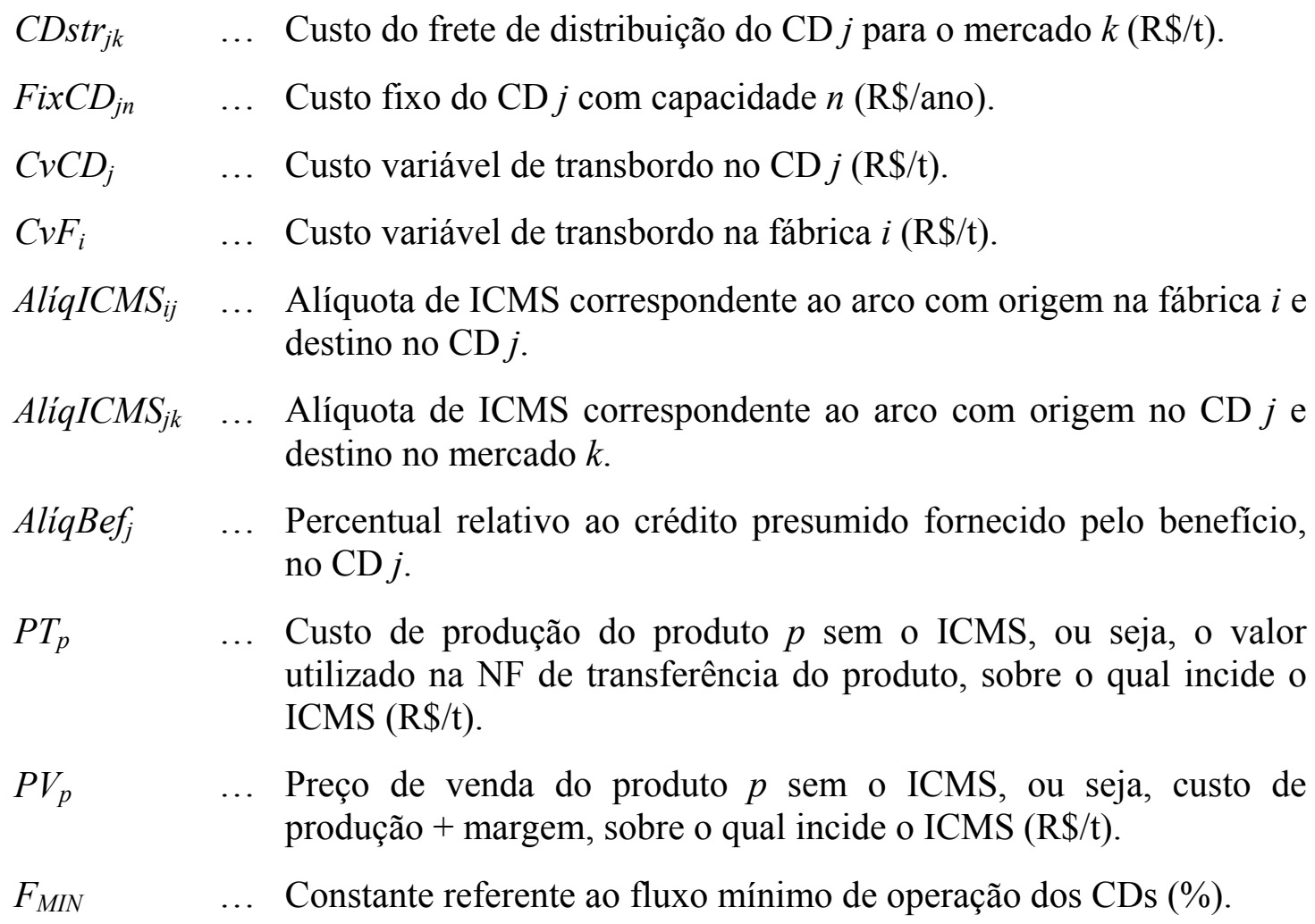

\section{Variáveis}

Trns $_{i j p} \quad \ldots$ Quantidade do produto $p$ transferida da fábrica $i$ para o $\mathrm{CD} j$ (t/ano).

$D_{s t r} D_{j k p} \quad \ldots$ Quantidade do produto $p$ distribuída do $\mathrm{CD} j$ para o mercado $k$ (t/ano).

$B F_{j} \quad \ldots$ Ganho auferido com o benefício fiscal com a distribuição a partir do $\mathrm{CD} j$ (R\$/ano).

$Z_{j n} \quad \ldots$ Variável binária: assume valor 1 caso o $\mathrm{CD} j$ com capacidade $n$ esteja aberto e 0 em caso contrário.

CT $\quad$.. Custo total da operação (R \$/ano). 


\section{Função Objetivo}

Minimizar Custo Total (CT)

$$
\begin{array}{ll}
C T=\sum_{i} \sum_{j} \sum_{p}\left(C \operatorname{Trns}_{i j} \times \operatorname{Trns}_{i j p}\right) & \text { / (A) Custo do frete de transferência } i-j \\
+\sum_{j} \sum_{k} \sum_{p}\left(C D s t r_{j k} \times D s t r D_{j k p}\right) & / \text { (B) Custo do frete de distribuição } j-k \\
+\sum_{j n}\left(F i x C D_{j n} \times Z_{j n}\right) & / \text { (C) Custo fixo anual do CD } j \\
+\sum_{j} \sum_{k} \sum_{p}\left(C v C D_{j} \times D s t r D_{j k p}\right) & \text { / (D) Custo de transbordo no CD } j \\
+\sum_{i} \sum_{k} \sum_{p}\left[\left(C v F_{i} \times T r n s_{i j p}\right)\right] & \text { / (E) Custo de transbordo na fábrica } i \\
-\sum_{j} B F_{j} & \text { / (F) Ganho fiscal a partir do CD } j
\end{array}
$$

\section{Restrições}

- Restrição de atendimento da demanda

$$
\sum_{j} D_{s t r} D_{j k p}=\operatorname{Dem}_{p k} \quad \forall k, \forall p
$$

- Restrição de capacidade de operação do $\mathrm{CD} j$

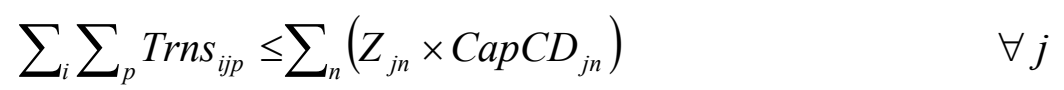

- Restrição para haver uma única capacidade de operação no $\mathrm{CD} j$

$$
\sum_{n} Z_{j n} \leq 1 \quad \forall j
$$


- Restrição de fluxo mínimo no $\operatorname{CD} j$ com capacidade $n$

$$
\sum_{i} \sum_{p} \text { Trns }_{i j p} \geq \sum_{n}\left(Z_{j n} \times F_{M I N} \times \operatorname{CapCD}_{j n}\right) \quad \forall j, \forall n
$$

- Balanço de massa no CD $j$

$$
\sum_{i} \operatorname{Trns}_{i j p}=\sum_{k} \operatorname{DstrD}_{j k p} \quad \forall j, \forall p
$$

- Saldo de ICMS nulo ou positivo no $\mathrm{CD} j$

$$
\operatorname{DstrD}_{j k p} \times \sum_{j}\left\{\left\{\left[\frac{P T_{p}}{\left(1-\text { AlíqICMS }_{i j}\right)}-P T_{p}\right]-\left[\frac{P V_{p}}{\left(1-\text { AlíqICMS }_{j k}\right)}-P V_{p}\right]\right\}-B F_{j}\right\} \geq 0
$$

Sendo que 'BF' é calculado como:

$$
B F_{j}=\sum_{p}\left\{\left[\frac{P V_{p}}{\left(1-\text { Alígef }_{j}\right)}\right]-P V_{p}\right\}
$$

- Binárias

$$
Z_{j n} \begin{cases}=1, \text { seo } C D_{j} \text { com capacidade n está operando } & \forall j, \forall n \\ =0, \text { em caso contrário } & \end{cases}
$$

- Não negatividade

$$
\begin{array}{ll}
\operatorname{Trns}_{i j p} \geq 0 & \forall i, \forall j, \forall p \\
\operatorname{DstrD}_{j k p} \geq 0 & \forall j, \forall k, \forall p \\
B F_{j} \geq 0 & \forall j
\end{array}
$$




\subsection{ASPeCtos Da Modelagem}

A função objetivo é composta por seis somatórias, as quais podem ser agrupadas em duas diferentes parcelas: (1) o custo logístico, composto pelos custos de frete e de transbordo e (2) o benefício fiscal relativo ao ICMS, que entra na função objetivo como uma parcela negativa. Pode, portanto, ser compreendida da seguinte maneira:

\section{Função Objetivo $=$ Minimizar Custo Total (CT) \\ $\mathrm{CT}=$ Custo Logístico - Benefício Fiscal (Parcela 1) \\ (Parcela 2)}

A primeira parcela, referente aos custos logísticos, é formada pelas 5 primeiras somatórias da função objetivo. Elas abrangem os custos de frete de transferência e de distribuição (somatórias A e B), o custo de abertura de CD (somatória C) e os custos de transbordo (somatórias D e E).

A segunda parcela é composta pela última somatória da função objetivo (somatória F), que representa o ganho auferido pelo benefício fiscal. Para computar este ganho o modelo considera o montante exato correspondente ao benefício fiscal auferido, visto que este valor consiste no que efetivamente deixará de ser recolhido pela empresa.

Quanto às restrições do modelo, tem-se que a primeira restrição apresentada determina que a demanda de todos os mercados deva ser plenamente atendida. A restrição (3) está relacionada à limitação do escoamento do produto ao nível de capacidade do $\mathrm{CD}$, enquanto que a restrição (4) garante que apenas um único nível de capacidade possa ser associado a cada $C D$. A variável binária associada a essa restrição é representada pela equação (9). É válido observar que, caso nenhum nível de capacidade tenha sido escolhido, a capacidade do $\mathrm{CD}$ será 'zero'(não haverá $\mathrm{CD}$ ), ou seja, acontecerá $\sum_{n} Z_{j n}=0$.

Para restringir que todos os CDs abertos tenham um fluxo mínimo de operação em relação à sua capacidade, uma condição de mercado importante considerando-se o ponto de vista de uma indústria que deseje ter neste $\mathrm{CD}$ uma operação própria, a restrição (5) garante que um $\mathrm{CD} j$ com nível de capacidade $n$ só será aberto caso o fluxo mínima a ser absorvido por este CD corresponda a pelo menos um determinado 
percentual de sua capacidade (determinado pela constante $F_{M I N}$ ). Apesar de esta restrição ser importante considerando-se o ponto de vista de uma empresa que deseje ter operação própria em seus CDs, caso ela opte por terceirizar a operação de seus CDs para operadores logísticos a restrição passa a ser desnecessária.

O balanço de massa nos CDs, que determina que o fluxo de entrada seja igual ao de saída, é representado pela restrição (6), enquanto que a restrição (7) corresponde à necessidade de haver saldo nulo ou positivo nos CDs. Essa restrição é importante do ponto de vista prático, pois no geral não é interessante para um estabelecimento acumular crédito de ICMS, haja vista que este não pode ser reavido em forma de valor monetário e nem sempre pode ser utilizado para a aquisição de determinados tipos de ativo.

O cálculo do ganho auferido com o benefício fiscal é estabelecido pela equação (8). Conforme apresenta esta equação, para calcular-se o montante do benefício obtido, aplica-se o percentual referente ao crédito presumido sobre o valor da base de cálculo do ICMS de todas as saídas de venda do estabelecimento em questão. Este valor, que será creditado ao saldo do imposto a pagar, é o valor do incentivo obtido.

Por fim, o grupo de restrições de (10) a (12) refere-se à usual exigência de nãonegatividade das variáveis de decisão. 


\section{DESCRIÇÃO DO CASO ESTUDADO}

Este capítulo apresenta a definição do caso que será utilizado para a aplicação do modelo matemático, trazendo uma descrição detalhada das premissas e dos parâmetros considerados.

\subsection{DESCRIÇão FísICA do CASO}

Para a aplicação do modelo matemático desenvolvido foi elaborado um problema com dimensões reais, baseado em informações reais de um ano de operação de uma indústria que fabrica e comercializa bens de consumo não duráveis, de modo que seja possível permitir generalizações dos resultados obtidos. A base de informações da indústria em questão refere-se ao ano de 2003.

Alguns dos parâmetros utilizados, tais como a localização das unidades de produção, os volumes produzidos, a distribuição da demanda entre os centros consumidores, os valores dos fretes e os custos de transbordo são dados reais. Entretanto, os valores de custo de produção e margem de venda dos produtos considerados foram alterados com o intuito de manter sigilo quanto às informações estratégicas da indústria em questão.

O problema definido envolve a produção e distribuição de três linhas de produtos, que não pertencem aos itens de cesta básica de nenhum dos Estados da Federação, de modo que estão sujeitos à tributação das alíquotas padrão de ICMS (Apêndice A).

Três fábricas, localizadas nos estados de São Paulo, Minas Gerais e Goiás, são responsáveis pela produção, de modo que em cada uma delas produz-se uma única linha de produto. Essas instalações são representadas na Figura 7 abaixo: 


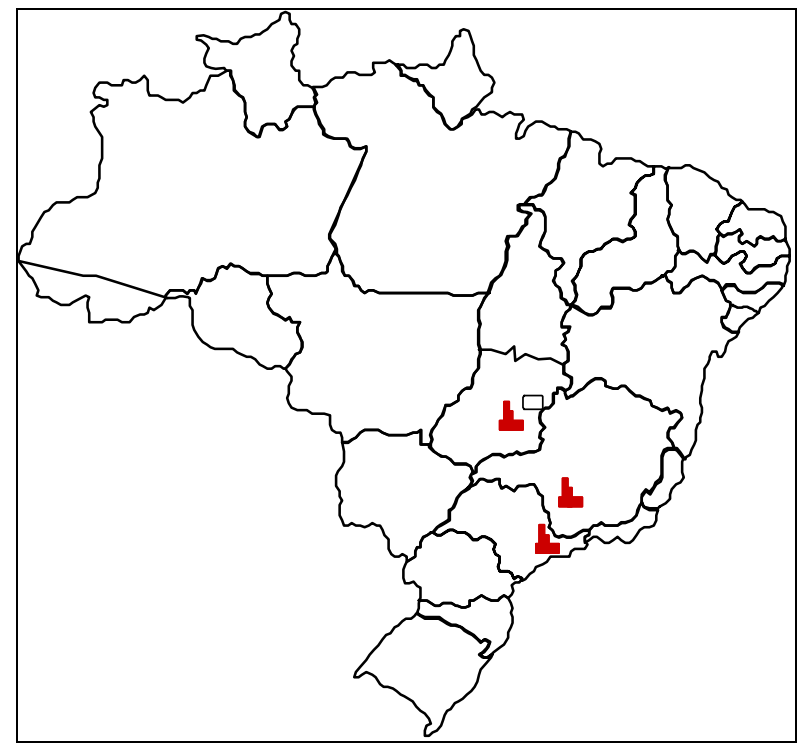

Figura 7. Representação da localização das instalações do problema

O fluxo dos produtos é orientado da fábrica para os CD's e então para os clientes, que consistem em estabelecimentos comerciais tais como distribuidores, atacadistas e grandes redes de varejistas. As fábricas não podem realizar entregas diretas para os clientes, tendo obrigatoriamente que enviar a mercadoria para um dos centros de distribuição.

Para as possíveis localizações dos CD's foram selecionados sete locais candidatos: três deles localizados nas capitais dos estados onde estão instaladas as fábricas (de modo que, dois na região Sudeste e um na região Centro-oeste) e os quatro restantes correspondem às duas capitais de maior concentração de demanda na região Sul e Nordeste. Os locais selecionados estão listados na Tabela 7 a seguir, ordenados conforme a seqüência Sul para Norte.

Tabela 7. Relação dos locais candidatos para abertura de centros de distribuição

\begin{tabular}{lll}
\hline \multicolumn{3}{c}{ LOCAIS CANDIDATOS (município e estado) } \\
\hline (1) Porto Alegre_RS & (5) Goiânia_GO \\
(2) Curitiba_PR & (6) Salvador_BA \\
(3) São Paulo_SP & (7) Recife_PE \\
(4) Belo Horizonte_MG & \\
\hline
\end{tabular}

Para reduzir o porte do modelo a ser resolvido, a base de clientes, formada essencialmente por distribuidores, atacadistas e varejistas, foi agrupada em mesoregiões do IBGE, contabilizando-se um total de 137 zonas de demanda. Tal como 
realizado por Yoshizaki (2002), para a agregação das regiões de demanda foram eliminadas as meso-regiões referentes à parte da Amazônia legal em função de ter acesso rodoviário restrito, o que incrementaria artificialmente os custos logísticos. Obteve-se assim, portanto, um total de 129 agrupamentos de demanda. Esses agrupamentos são apresentados na Tabela 8 a seguir.

Tabela 8. Regiões de demanda consideradas para as análises da dissertação.

\begin{tabular}{|ll}
\hline UF & NOME DA MESO-REGIÃO \\
\hline AC & VALE DO ACRE \\
& VALE DO JURUA \\
\hline AL & AGRESTE ALAGOANO \\
& LESTE ALAGOANO \\
& SERTAO ALAGOANO \\
\hline AM & CENTRO AMAZONENSE \\
\hline AP & SUL DO AMAPA \\
\hline BA & CENTRO NORTE BAIANO \\
& CENTRO SUL BAIANO \\
& EXTREMO OESTE BAIANO \\
& METROPOLITANA DE SALVADOR \\
& NORDESTE BAIANO \\
& SUL BAIANO \\
& VALE SAO-FRANCISCANO DA BAHIA \\
\hline CE & CENTRO-SUL CEARENSE \\
& JAGUARIBE \\
& METROPOLITANA DE FORTALEZA \\
& NOROESTE CEARENSE \\
& NORTE CEARENSE \\
& SERTOES CEARENSES \\
& SUL CEARENSE \\
\hline ES & CENTRAL ESPIRITO-SANTENSE \\
& LITORAL NORTE ESPIRITO-SANTENS \\
& NOROESTE ESPIRITO-SANTENSE \\
& SULESPIRITO-SANTENSE \\
\hline GO & CENTRO GOIANO \\
& LESTE GOIANO \\
& NOROESTE GOIANO \\
& NORTE GOIANO \\
& SUL GOIANO \\
\hline MA & CENTRO MARANHENSE \\
& LESTE MARANHENSE \\
& NORTE MARANHENSE \\
& OESTE MARANHENSE \\
& SUL MARANHENSE \\
\hline MG & CAMPO DAS VERTENTES \\
& CENTRAL MINEIRA \\
& METROPOLITANA DE BELO HORIZONTE \\
& NOROESTE DE MINAS \\
& NORTE DE MINAS \\
& OESTE DE MINAS \\
& SUL/SUDOESTE DE MINAS \\
& TRIANGULO MINEIRO/ALTO PARANAI \\
& VALE DO MUCURI \\
& VALE DO RIO DOCE \\
& ZONA DA MATA \\
\hline & \\
\hline
\end{tabular}

\begin{tabular}{|c|c|}
\hline \multirow{5}{*}{$\frac{U F}{M S}$} & NOME DA MESO-REGIÃO \\
\hline & CENTRO NORTE DE MATO GROSSO DO SUL \\
\hline & LESTE DE MATO GROSSO DO SUL \\
\hline & PANTANAL SUL MATO-GROSSENSE \\
\hline & SUDOESTE DE MATO GROSSO DO SUL \\
\hline \multirow[t]{5}{*}{$\overline{\text { MT }}$} & CENTRO-SUL MATO-GROSSENSE \\
\hline & NORDESTE MATO-GROSSENSE \\
\hline & NORTE MATO-GROSSENSE \\
\hline & SUDESTE MATO-GROSSENSE \\
\hline & SUDOESTE MATO-GROSSENSE \\
\hline \multirow[t]{5}{*}{ PA } & BAIXO AMAZONAS \\
\hline & METROPOLITANA DE BELEM \\
\hline & NORDESTE PARAENSE \\
\hline & SUDESTE PARAENSE \\
\hline & SUDOESTE PARAENSE \\
\hline \multirow[t]{4}{*}{ PB } & AGRESTE PARAIBANO \\
\hline & BORBOREMA \\
\hline & MATA PARAIBANA \\
\hline & SERTAO PARAIBANO \\
\hline \multirow[t]{5}{*}{$\overline{P E}$} & AGRESTE PERNAMBUCANO \\
\hline & MATA PERNAMBUCANA \\
\hline & METROPOLITANA DE RECIFE \\
\hline & SAO FRANCISCO PERNAMBUCANO \\
\hline & SERTAO PERNAMBUCANO \\
\hline \multirow[t]{4}{*}{$\overline{\mathbf{P I}}$} & CENTRO-NORTE PIAUIENSE \\
\hline & NORTE PIAUIENSE \\
\hline & SUDESTE PIAUIENSE \\
\hline & SUDOESTE PIAUIENSE \\
\hline \multirow[t]{10}{*}{$\overline{P R}$} & CENTRO OCIDENTAL PARANAENSE \\
\hline & CENTRO ORIENTAL PARANAENSE \\
\hline & CENTRO-SUL PARANAENSE \\
\hline & METROPOLITANA DE CURITIBA \\
\hline & NOROESTE PARANAENSE \\
\hline & NORTE CENTRAL PARANAENSE \\
\hline & NORTE PIONEIRO PARANAENSE \\
\hline & OESTE PARANAENSE \\
\hline & SUDESTE PARANAENSE \\
\hline & SUDOESTE PARANAENSE \\
\hline \multirow[t]{6}{*}{ RJ } & BAIXADAS \\
\hline & CENTRO FLUMINENSE \\
\hline & METROPOLITANA DO RIO DE JANEIRO \\
\hline & NOROESTE FLUMINENSE \\
\hline & NORTE FLUMINENSE \\
\hline & SUL FLUMINENSE \\
\hline
\end{tabular}

UF NOME DA MESO-REGIÃO

RN AGRESTE POTIGUAR

LESTE POTIGUAR

OESTE POTIGUAR

RO LESTE RONDONIENSE

MADEIRA-GUAPORE

RR NORTE DE RORAIMA

RS CENTRO OCIDENTAL RIO-GRANDENSE

CENTRO ORIENTAL RIO-GRANDENSE

METROPOLITANA DE PORTO ALEGRE

NORDESTE RIO-GRANDENSE

NOROESTE RIO-GRANDENSE

SUDESTE RIO-GRANDENSE

SUDOESTE RIO-GRANDENSE

GRANDE FLORIANOPOLIS

NORTE CATARINENSE

OESTE CATARINENSE

SERRANA

SUL CATARINENSE

VALE DO ITAJAI

SE AGRESTE SERGIPANO

LESTE SERGIPANO

SERTAO SERGIPANO

SP ARACATUBA

ARARAQUARA

ASSIS

BAURU

CAMPINAS

ITAPETININGA

LITORAL SUL PAULISTA

MACRO METROPOLITANA PAULISTA

MACRO

METROPOLITANA DE SAO PAULO

PIRACICABA

PRESIDENTE PRUDENTE

RIBEIRAO PRETO

SAO JOSE DO RIO PRETO

VALE DO PARAIBA PAULISTA

TO OCIDENTAL DO TOCANTINS

ORIENTAL DO TOCANTINS

Para a transferência e a distribuição dos produtos é utilizado exclusivamente o modal rodoviário, típico da operação. Ambos os fretes, de transferência e de distribuição, são pagos pelo próprio embarcador (a indústria), ou seja, a modalidade adotada para o frete de distribuição é a $C I F$, o que implica ainda que a entrega da mercadoria seja realizada no local especificado no pedido do cliente. 
Definido o sistema físico e as hipóteses do problema, o tópico a seguir apresenta os parâmetros do modelo, bem como sua forma de cálculo.

\subsection{Cálculo dos Parâmetros}

A seguir são apresentados os parâmetros adotados para o modelo e especificada sua forma de cálculo.

\section{- Produtos:}

Como na indústria em questão cada uma das fábricas é especializada em uma única linha de produtos, agregaram-se todos os itens produzidos em cada uma das fábricas em uma única categoria de produto, de modo que foram obtidos três produtos: Produto GO, Produto MG e Produto SP.

\section{- Custo, preço e margem de venda dos produtos:}

Para determinar o preço de venda calculou-se o preço médio de venda ponderado de toda a linha de produtos de cada uma das fábricas, de modo a obter um preço médio ponderado para cada agregação de produto adotada (Produto GO, Produto MG e Produto SP).

Entretanto, as informações correspondentes à margem de venda e ao custo de produção (preço de transferência) foram alteradas com o intuito de preservar sigilo em relação às informações estratégicas da empresa. Sendo assim, adotou-se para a margem de venda de todos os produtos o percentual de $200 \%$ e o preço de transferência foi calculado reduzindo-se esse percentual do preço de venda.

A Tabela 9 a seguir apresenta as informações referente a preço de transferência, preço de venda e margem adotadas para cada produto:

Tabela 9. Parâmetros de custo, preço e margem de venda dos produtos.

\begin{tabular}{rccc}
\hline Produto & $\begin{array}{c}\text { Preço de transferência } \\
(\mathbf{R} \$ \mathbf{t})\end{array}$ & $\begin{array}{c}\text { Preço de venda } \\
(\mathbf{R} \$ \mathbf{t})\end{array}$ & Margem \\
\hline Produto GO & 1.000 & 3.000 & $200 \%$ \\
Produto MG & 1.500 & 4.500 & $200 \%$ \\
Produto SP & 667 & 2.000 & $200 \%$ \\
\hline
\end{tabular}




\section{- Volumes de demanda:}

O volume de demanda total de cada produto, bem como sua distribuição geográfica, são apresentados na Figura 8, a seguir. O Apêndice B apresenta os volumes de demanda de cada produto por região de demanda.

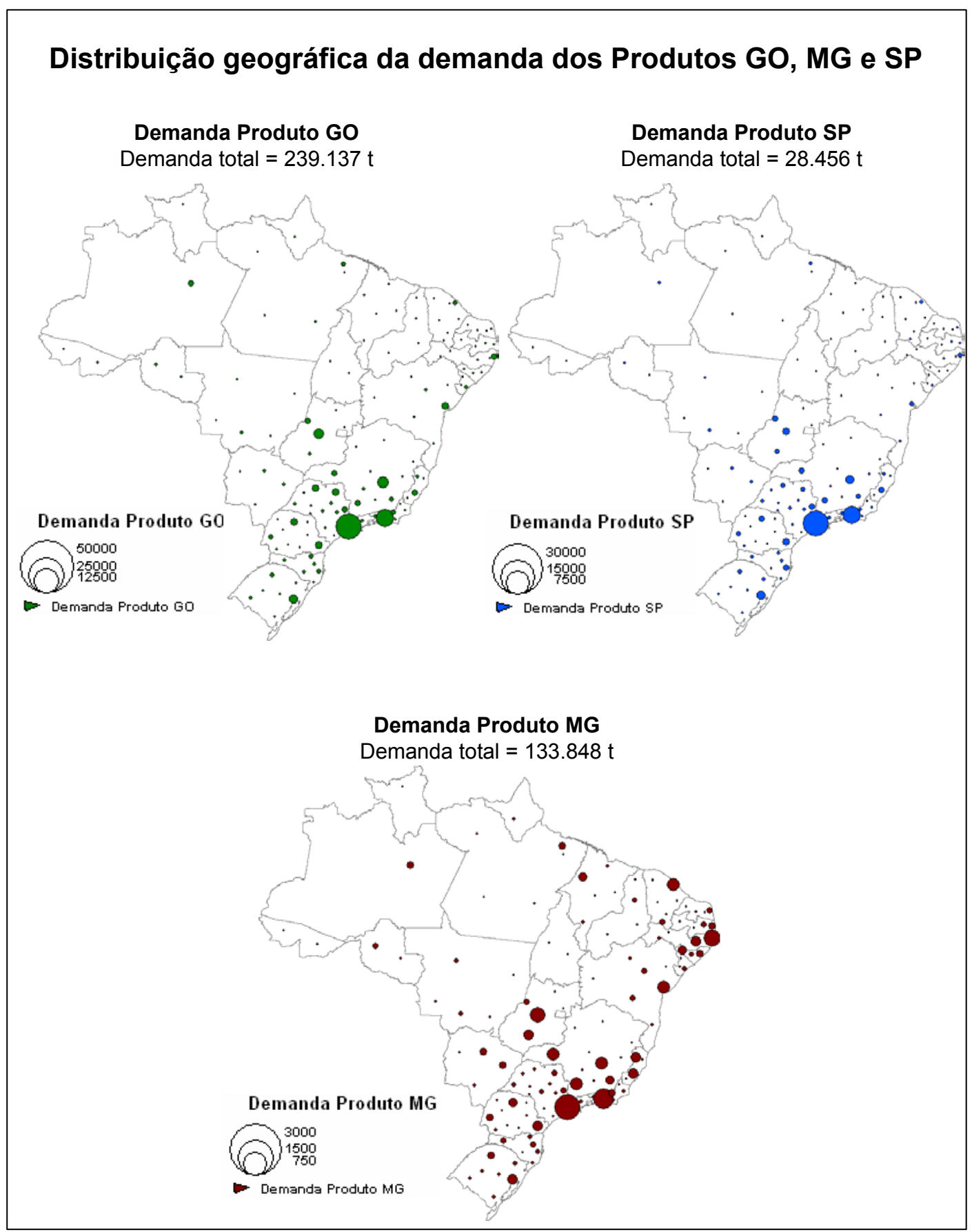

Figura 8.Distribuição geográfica da demanda dos produtos GO, MG e SP. 


\section{- Capacidade dos armazéns:}

Em relação à capacidade dos armazéns, consideraram-se cinco níveis. Os valores dos fluxos máximos e mínimos correspondente a cada nível de capacidade dos CDs são apresentados na Tabela 10 a seguir:

Tabela 10. Níveis de capacidade e valores de fluxo mínimo nos CDs.

\begin{tabular}{|c|c|c|}
\hline $\begin{array}{c}\text { Nível de } \\
\text { capacidade }\end{array}$ & $\begin{array}{c}\text { Capacidade máxima } \\
\text { anual (t/ano) }\end{array}$ & $\begin{array}{c}\text { Fluxo mínimo para possibilitar } \\
\text { a abertura (t/ano) }\end{array}$ \\
\hline N.1 & 30.000 & 24.000 \\
\hline N.2 & 90.000 & 72.000 \\
\hline N.3 & 150.000 & 120.000 \\
\hline N.4 & 225.000 & 180.000 \\
\hline N.5 & 300.000 & 240.000 \\
\hline
\end{tabular}

Em função do colocado por Yoshizaki (2002), que o limite de 300.000 t/ano para a capacidade de um armazém foi definido após consulta a especialistas de mercado, neste trabalho adotou-se esta referência para determinar o volume da capacidade máxima para um $C D$. É válido comentar que o maior $C D$ não absorve a demanda máxima se necessário.

\section{- Restrição de fluxo mínimo nos CDs:}

De acordo com a prática dos operadores logísticos, deve-se movimentar nos CDs um fluxo mínimo de $80 \%$ do nível de capacidade de cada CD.

\section{- Custos de armazenagem:}

A determinação dos custos fixos dos armazéns foi realizada conforme o apresentado por Yoshizaki (2002):

CustoFixo_CD $=984.550,00 \times\left[\frac{T}{(35.000)^{0,845351}}\right]$,

onde ' $T$ ' é a movimentação anual do CD em toneladas.

Conforme Yoshizaki (2002), esta curva de ajuste para o custo fixo é válida para centros de distribuição de mercadorias secas acondicionadas em caixas de papelão ondulado, características inerentes aos produtos e forma de acondicionamento dos mesmos do 
estudo de caso utilizado para o presente estudo. Ainda segundo Yoshizaki (2002) sobre a determinação da equação utilizada para a determinação dos custos fixos:

"Foram usados custos conhecidos (reais) de seis centros de distribuição diferentes mas com procedimento de operação iguais, com movimentações (capacidades) anuais entre 18.000 t e 54.000 t. O depósito padrão tinha capacidade de 35.000 t/ano, considerandose que o custo fixo aumenta aproximadamente $80 \%$ caso a capacidade dobre (ganho de escala)."

Quanto aos custos variáveis de transbordo nas fábricas, estes foram calculados com base na média dos custos variáveis de movimentação de todas as instalações produtivas; de maneira semelhante, para determinar o custo médio das unidades de distribuição considerou-se o valor médio cobrado pelos operadores logísticos em todos os CDs. Desse modo, adotou-se um valor de R\$ 1,75 / tonelada para as movimentações nas fábricas e R \$ 45,6 / tonelada para as movimentações nos CDs. Deste modo, assumiu-se que o custo variável dos CDs é constante independente do seu tamanho: os ganhos de escala estão associados aos custos fixos de instalação e operação (Fundação Vanzolini, 2000 apud Yoshizaki,2002).

\section{- Custos de frete:}

Os custos de frete foram calculados com base em um banco de dados com os valores de frete pagos pela empresa em um ano de operação com cobertura em todo Brasil. Como a análise da base de frete da indústria não apontou variações sazonais nítidas, os fretes foram considerados homogêneos. As equações de frete de transferência e de venda obtidas através de uma regressão linear dos dados de frete são apresentadas a seguir:

$$
\begin{aligned}
& C_{\text {frete_transferência }}=16,32+0,08 * \text { Distância } \\
& C_{\text {frete_venda }}=85,06+0,10 * \text { Distância }
\end{aligned}
$$

A amostra utilizada para gerar as regressões continha 1.200 pontos no caso das vendas e 60 pontos no caso das transferências, ambas já sem os outliers, e envolviam uma distância que compreendia, no caso das vendas, entre 5 e 1.300 km e 50 e 2.000 
$\mathrm{km}$ no caso das transferências. $O \mathrm{R}^{2}$ obtido foi de 0,92 no caso da equação de fretes de transferência e de 0,84 na equação de fretes de venda.

\section{- Distâncias:}

Os valores das distâncias entre os centróides de cada meso-região foram calculados considerando-se um fator de correção de 1,24 em relação à respectiva distância esférica (distância em linha reta, medida no arco de circunferência em coordenadas esféricas nas latitudes e longitudes da origem e destino, tal como apresenta Ballou, 1999). O fator 1,24 foi obtido calculando-se a média da correlação entre as distâncias médias reais obtidas na base de dados da indústria objeto deste estudo e da distância esférica.

\section{- Nível de serviço:}

Para a indústria objeto deste estudo o nível de serviço para o cliente consiste no cumprimento dos prazos de entrega acordados entre as duas partes (indústria/cliente), independente de quais sejam eles. Deste modo, o caso base construído para aplicação do modelo não considera restrições de nível de serviço para o atendimento da demanda.

Entretanto, para avaliar o impacto da inserção de restrições de nível de serviço no resultado do modelo, definiu-se que para os mercados de maior demanda, que na curva $\mathrm{ABC}$ representam $30 \%$ do volume total demandado, as entregas devem ser realizadas em até um dia (distância de até $500 \mathrm{~km}$ ), enquanto que para os mercados com volume intermediário de demanda, suficiente para completar $40 \%$ de todo o volume demandado, definiu-se como prazo de entrega dois dias (distância até $750 \mathrm{~km}$ ).

No modelo matemático essas restrições foram tratadas por meio da exclusão dos arcos com distância superior aos valores determinados, pois se considera distância como uma proxi do tempo de entrega: Tempo = Distância / Velocidade Média. Tomando-se como premissa uma velocidade média de $62 \mathrm{~km} / \mathrm{hora}$, obtida com base nos dados da indústria objeto deste estudo, excluiu-se do modelo inicial 233 arcos. 


\section{- Incentivos fiscais:}

Os incentivos avaliados neste estudo são os apresentados a seguir:

- Goiás: oferta de crédito presumido de $3 \%$ da base de cálculo para estabelecimento de comércio atacadista que destine mercadoria para comercialização, produção ou industrialização.

- Minas Gerais: oferta de crédito de 9\% da base de cálculo para mercadorias remetidas por estabelecimento atacadista ou central de distribuição para comercialização, produção ou industrialização.

Optou-se por considerar estes incentivos por duas razões principais:

(i) Não são específicos para determinado tipo de mercadoria;

(ii) Um incentivo é oferecido pelo estado de GO, considerado como "pobre" (emite mercadorias para outros estados sempre com alíquota de $12 \%$, gerando portanto um maior saldo de crédito de ICMS para a apuração do imposto devido) e o outro incentivo é oferecido por MG, um estado "rico" (emite mercadorias para estados "ricos" com alíquota de $12 \%$ e para estados "pobres" com alíquota de 7\%, gerando portanto um menor saldo de crédito de ICMS para a apuração do imposto devido).

Definidos os parâmetros, o próximo capítulo trata sobre a aplicação do modelo. 


\section{APLICACAÇÃO DO MODELO E ANÁLISE DOS RESULTADOS}

Este capítulo discorre sobre a aplicação do modelo matemático ao caso descrito no capítulo anterior. São analisados três cenários diferentes, ou seja, três diferentes "situações" em que o modelo será aplicado, que apresentam características de parâmetros/restrições específicas e diferentes entre si: Cenário Base, Cenário Fiscal GO e Cenário Fiscal MG.

O Cenário Base consiste na aplicação do modelo matemático ao problema apresentado no capítulo anterior. Neste cenário não são considerados benefícios ficais nem restrição de saldo de ICMS nos CDs, de modo que a solução apresentada considera apenas aspectos logísticos. A inclusão desses dois fatores ocorre no modelo correspondente aos Cenários Fiscais, a partir do qual são avaliados isoladamente tanto o incentivo fiscal oferecido pelo Estado de Goiás (Cenário Fiscal GO) quanto o oferecido pelo Estado de Minas Gerais (Cenário Fiscal MG). Tanto no Cenário Base quanto nos Cenários Fiscais não são consideradas restrições de nível de serviço, mas há restrições de fluxo mínimo nos CDs, caso eles sejam abertos.

O objetivo em rodar um cenário livre da influência de incentivos fiscais consiste em analisar a relação entre a solução logística ótima apresentada pelo Cenário Base e as soluções obtidas considerando-se a oferta de incentivos fiscais em GO e em MG (Cenários Fiscal GO e Fiscal MG). Para tanto, são feitas comparações em termos dos fluxos e custos obtidos em cada Cenário. Os cenários rodados para as análises fiscais apresentam tanto benefício fiscal quanto restrição de saldo de ICMS nos CDs.

\subsection{Processamento do Modelo}

O modelo base logístico possui 2.730 variáveis, 35 variáveis binárias e 3.162 restrições (nos modelos fiscais são acrescidas mais 7 restrições). O software escolhido para sua implementação foi o What'sBest! 8.0, da Lindo Systems Inc, visto que a pesquisadora já o havia utilizado em ambiente profissional, tendo portanto plena capacitação para a utilização do mesmo. 
Uma das vantagens apresentadas pelo What'sBest! consiste na facilidade da estruturação do modelo, uma vez que a interface do software faz-se por meio do Microsoft ${ }^{\circledR}$ Office Excel. Por outro lado, uma dificuldade inerente ao formato necessário para a estruturação do modelo (por meio de tabelas em planilhas) consiste no redimensionamento dos parâmetros do modelo: a cada alteração realizada faz-se necessário editar cada uma das tabelas geradas para o modelo que traz informação referente a este parâmetro.

A título de curiosidade, a Figura 9 a seguir apresenta o relatório gerado pelo What'sBest! referente à solução do Cenário Base.

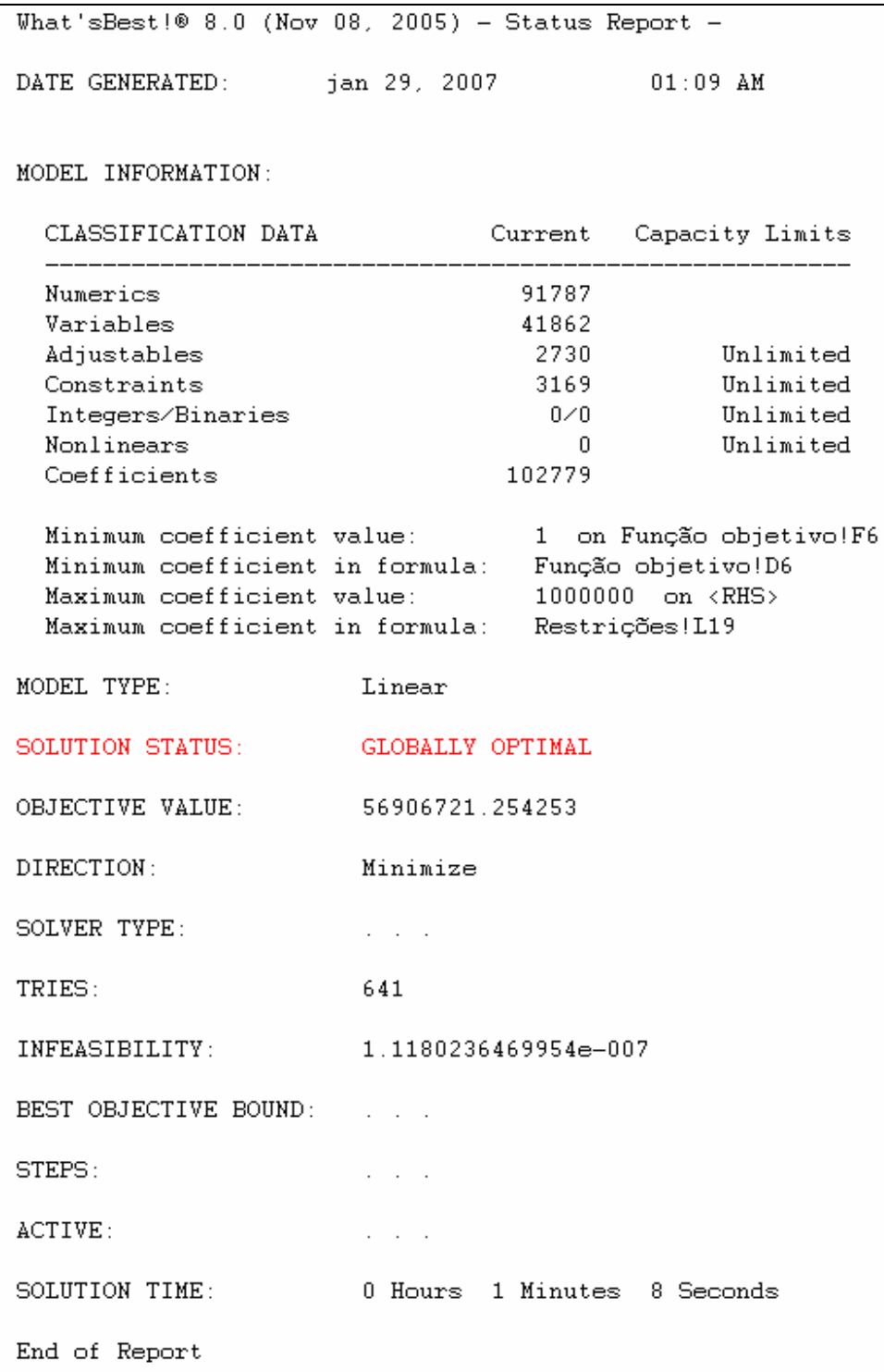

Figura 9. Relatório de solução do What'sBest! referente à solução do Cenário Base. 
Para a elaboração dos mapas, muito utilizados para a representação dos resultados obtidos, utilizou-se o sistema de informações geográficas MAPTITUDE 4.0.

Para o processamento do modelo utilizou-se um computador Dell Latitude 120L com

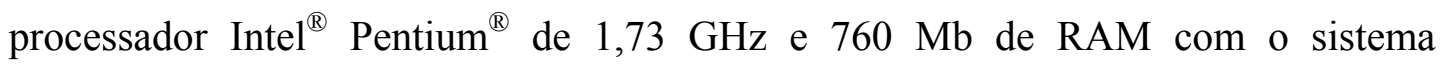
operacional Windows XP da Microsoft ${ }^{\circledR}$. O tempo médio consumido para o processamento de cada cenário foi de aproximadamente 2,5 minutos.

A seguir são apresentadas as soluções obtidas com a aplicação do modelo.

\subsection{CenÁRio BASE: AbORdagem Logística}

O Cenário Base, estruturado para gerar a solução logística ótima sem a influência de aspectos fiscais, além de não considerar os benefícios fiscais de $\mathrm{GO}$ e $\mathrm{MG}$, teve a restrição de saldo positivo nos CDs excluída de seu grupo de restrições. Pretende-se, desta maneira, verificar se a solução logística gerada apresenta a tendência de acumular crédito negativo de ICMS nos CDs.

A Tabela 11 a seguir traz informações referentes ao resultado obtido pelo Cenário Base: da relação dos CDs disponíveis, quais foram abertos, com quais capacidades, qual volume de produtos passou por eles e qual o saldo final de ICMS:

Tabela 11. Resultados obtidos pelo Cenário Base: CDs abertos, capacidades, fluxos e saldo de ICMS.

\begin{tabular}{cccc}
\hline CDs & Capacidade $(\mathbf{t})$ & Fluxo $(\mathbf{t})$ & Saldo $(\mathbf{M R} \mathbf{)}$ \\
\hline CD SP & 30.000 & 30.000 & 6.173 \\
CD MG & 150.000 & 146.441 & 37.324 \\
CD PR & - & - & - \\
CD RS & - & - & - \\
CD GO & 225.000 & 225.000 & 49.024 \\
CD BA & - & - & - \\
CD PE & - & - & - \\
Total & 405.000 & 401.441 & $\mathbf{9 2 . 5 2 1}$ \\
\hline
\end{tabular}

É possível observar que a solução logística ótima não indica tendência de acúmulo de saldo negativo de ICMS nos CDs utilizados pelo modelo, de modo que, caso estivesse sido acrescida ao Cenário Base, a restrição para não haver saldo de ICMS negativo não teria sido uma restrição ativa. É válido lembrar que no caso do estudo 
realizado por Pantalena (2004), a restrição que impedia o acúmulo de saldo positivo de ICMS nos CDs era uma restrição ativa.

A Tabela 11 também permite verificar que só foram abertos os CDs que se situam próximo às fábricas e que a capacidade máxima desses CDs, na sua faixa de capacidade, foi quase que integralmente utilizada, salvo no caso do CD de Minas Gerais, em que houve uma capacidade ociosa de 3.500 toneladas $(2,4 \%$ da capacidade do $\mathrm{CD}$ ). Logo, economias decorrentes de maior consolidação não se justificam pelo custo fixo adicional de maior capacidade nos CDs (verificar que nenhum deles teve a capacidade teórica máxima de 300 mil toneladas/ano instalada).

A Tabela 12 a seguir mostra os fluxos de transferência entre Fábricas e CDs ocorridos para cada um dos produtos no Cenário Base. A Figura 10 apresentada em seguida ilustra os fluxos de distribuição gerados para o mesmo cenário. 
Tabela 12. Fluxos de transferência do Cenário Base.

\begin{tabular}{lccc}
\hline $\begin{array}{l}\text { Orientação do fluxo } \\
\text { (Origem --> Destino) }\end{array}$ & PD_GO & $\begin{array}{l}\text { Volume (t) } \\
\text { PD_MG }\end{array}$ & PD_SP \\
\hline FA_GO -->CD_GO & 225.000 & - & - \\
FA_GO --> CD_MG & 7.292 & - & - \\
FA_GO -->CD_SP & 6.845 & - & - \\
FA_MG -->CD_MG & - & 133.848 & - \\
FA_SP --> CD_MG & - & - & 5.301 \\
FA_SP -->CD_SP & - & - & 23.155 \\
TOTAL & $\mathbf{2 3 9 . 1 3 7}$ & $\mathbf{1 3 3 . 8 4 8}$ & $\mathbf{2 8 . 4 5 6}$ \\
\hline
\end{tabular}

\section{Fluxos de distribuição do Cenário Base}

Produto GO

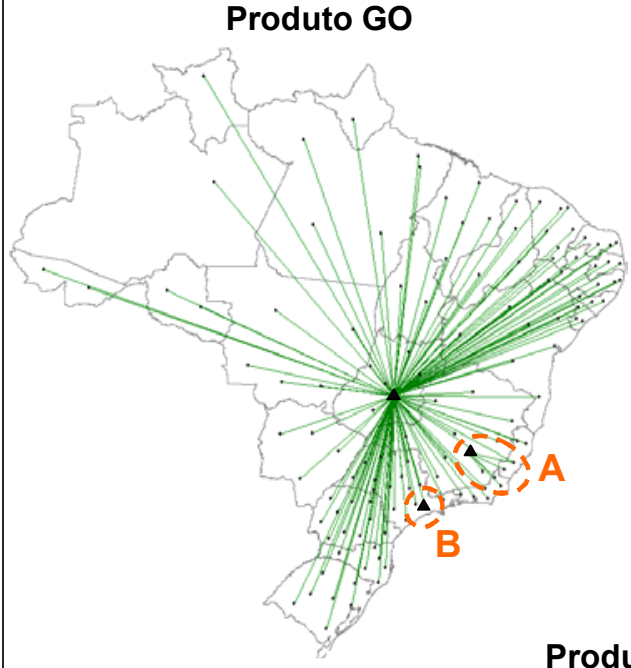

Produto SP

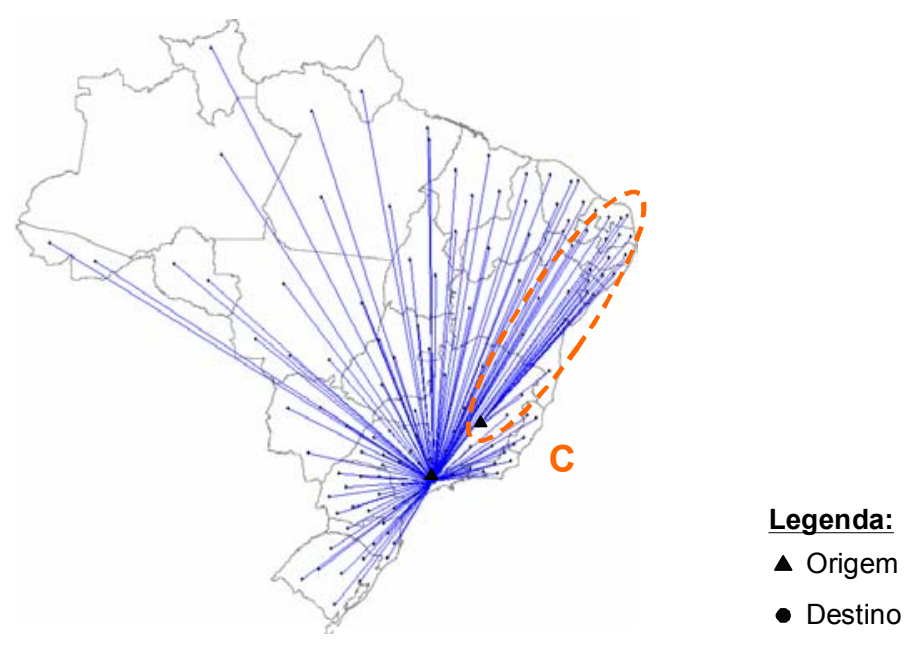

Figura 10. Fluxos de distribuição do Cenário Base. 
Verifica-se que, em função de o tamanho escolhido para o CD GO não absorver toda a produção da fábrica situada neste mesmo estado, o produto da fábrica de GO foi distribuído também pelos CDs de MG e de SP, este último tendo absorvido o volume de apenas uma única região de demanda (ver na Figura 10 indicações 'A' e 'B').

Quanto ao produto da fábrica de SP, este foi distribuído também pelo CD MG para alguns dos estados da região nordeste, dado que o volume adicional absorvido do Produto GO tomou a capacidade máxima alocada para o CD SP (ver na Figura 10 indicação ' $C$ '). Por fim, o produto de MG foi totalmente distribuído pelo CD MG.

A Figura 11 a seguir apresenta os custos resultantes da otimização do Cenário Base:

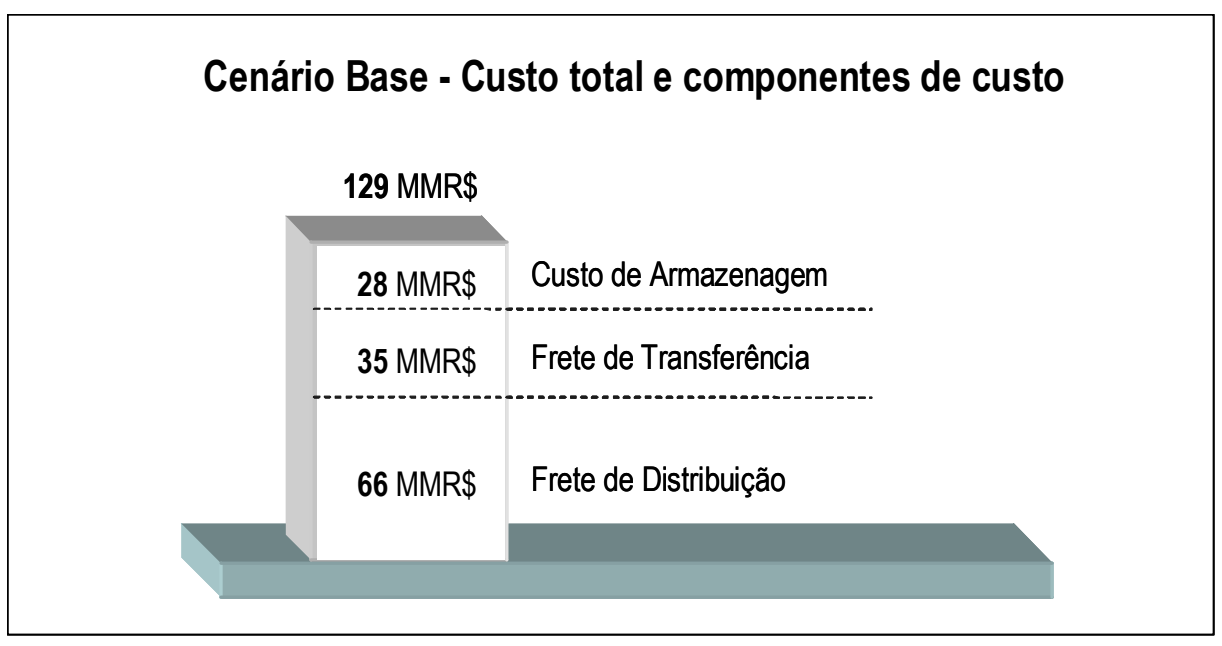

Figura 11. Custos do Cenário Base.

O próximo tópico apresenta o resultado obtido com os cenários fiscais e traz uma comparação entre os mesmos e o cenário base (logístico).

\subsection{CENÁRios Fiscal GO E Fiscal MG}

Para gerar os resultados dos cenários fiscais, a restrição referente à necessidade de haver saldo nulo ou positivo de ICMS nos CDs foi adicionada. Observa-se que, para os dois cenários gerados, Fiscal GO e Fiscal MG, foram abertos os mesmos CDs do Cenário Base. Entretanto, os fluxos de transferência e de distribuição sofreram algumas alterações, conforme se pode observar nas Tabelas 13 e 14 e nas Figuras 12 e 13 apresentadas a seguir: 
Tabela 13. Fluxos de transferência do Cenário Fiscal GO.

\begin{tabular}{lccc}
\hline $\begin{array}{l}\text { Orientação do fluxo } \\
\text { (Origem --> Destino) }\end{array}$ & PD_GO & PD_MG & PD_SP \\
\hline FA_GO --> CD_GO & 239.137 & - & - \\
FA_MG --> CD_GO & - & 56.989 & - \\
FA_MG --> CD_MG & - & 76.859 & - \\
FA_SP --> CD_GO & - & - & 3.874 \\
FA_SP --> CD_SP & - & - & 24.582 \\
TOTAL & $\mathbf{2 3 9 . 1 3 7}$ & $\mathbf{1 3 3 . 8 4 8}$ & $\mathbf{2 8 . 4 5 6}$ \\
\hline
\end{tabular}

\section{Fluxos de distribuição do Cenário Fiscal GO}

Produto GO

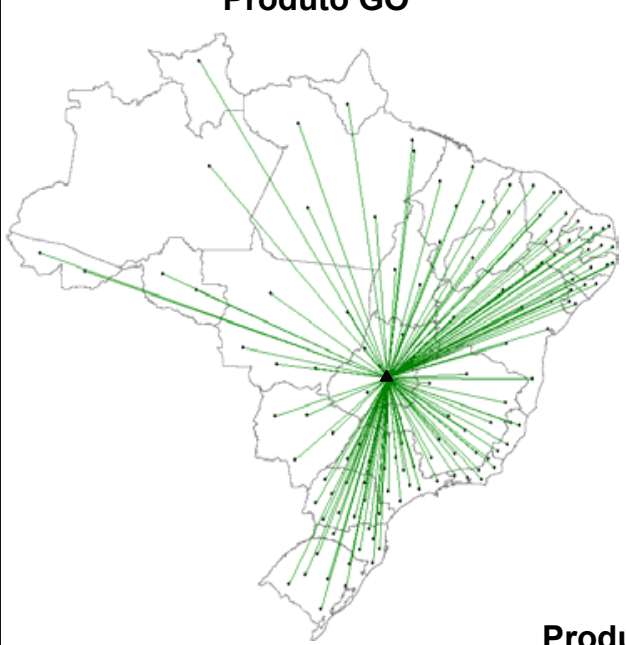

Produto SP

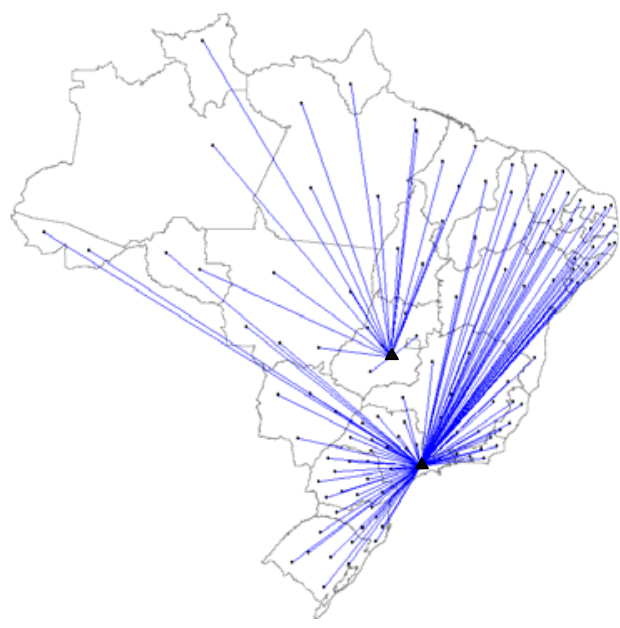

$2 \rightarrow$
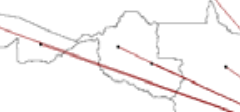

Produto MG
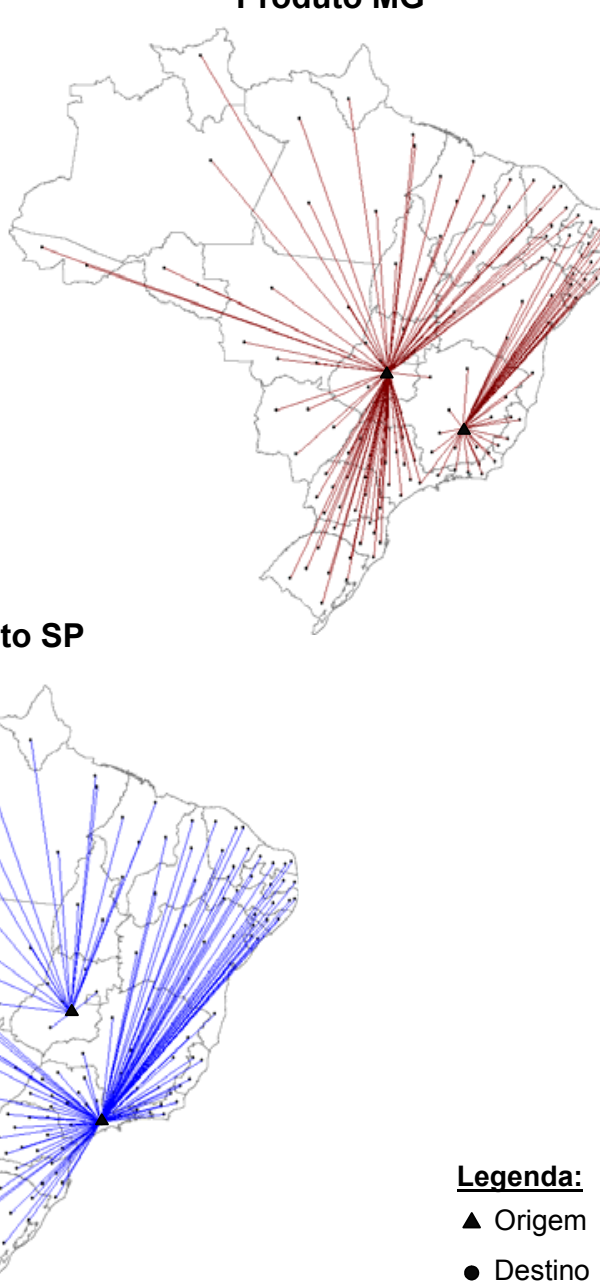

Figura 12. Fluxos de distribuição do Cenário Fiscal GO. 
Tabela 14. Fluxos de transferência do Cenário Fiscal MG.

\begin{tabular}{lccc}
\hline $\begin{array}{c}\text { Orientação do fluxo } \\
\text { (Origem --> Destino) }\end{array}$ & \multicolumn{3}{c}{ Volume (t) } \\
\hline FA_GO --> CD_GO & 65.979 & - & - \\
FA_GO --> CD_MG & 173.158 & - & - \\
FA_MG --> CD_GO & - & 18.113 & - \\
FA_MG --> CD_MG & - & 45.894 & - \\
FA_MG --> CD_SP & - & 69.841 & - \\
FA_SP --> CD_GO & - & - & 2.349 \\
FA_SP --> CD_MG & - & - & 5.948 \\
FA_SP --> CD_SP & - & - & 20.159 \\
TOTAL & $\mathbf{2 3 9 . 1 3 7}$ & $\mathbf{1 3 3 . 8 4 8}$ & $\mathbf{2 8 . 4 5 6}$ \\
\hline
\end{tabular}

\section{Fluxos de distribuição do Cenário Fiscal MG}

Produto GO

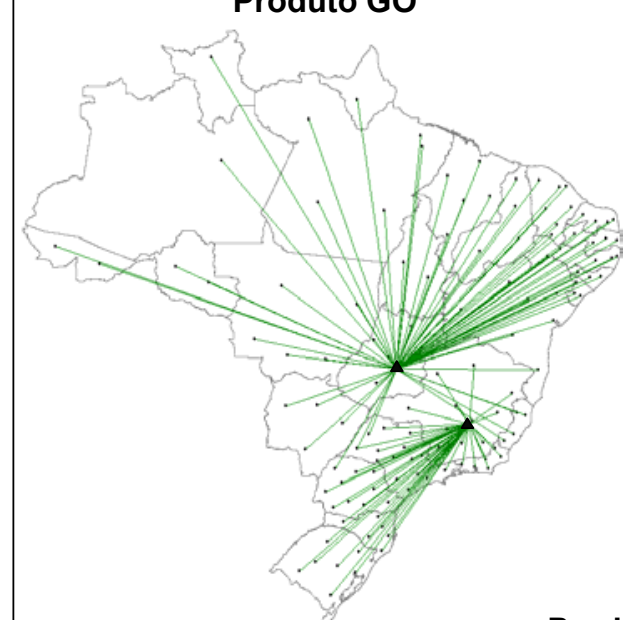

Produto SP

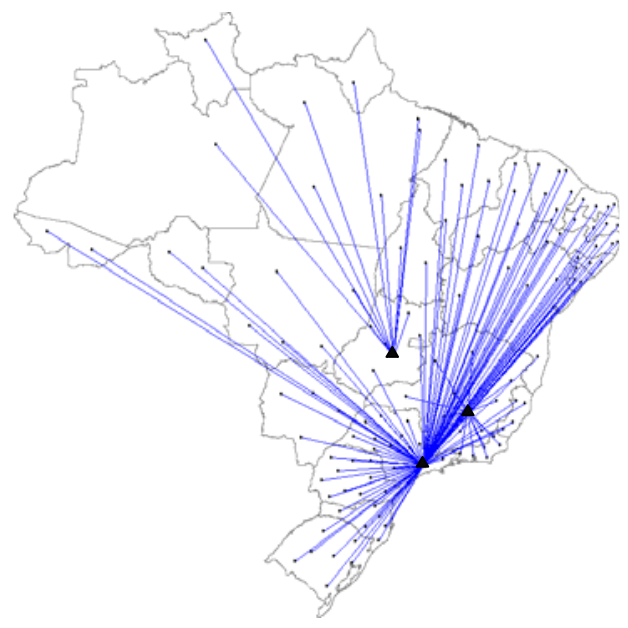

Produto MG

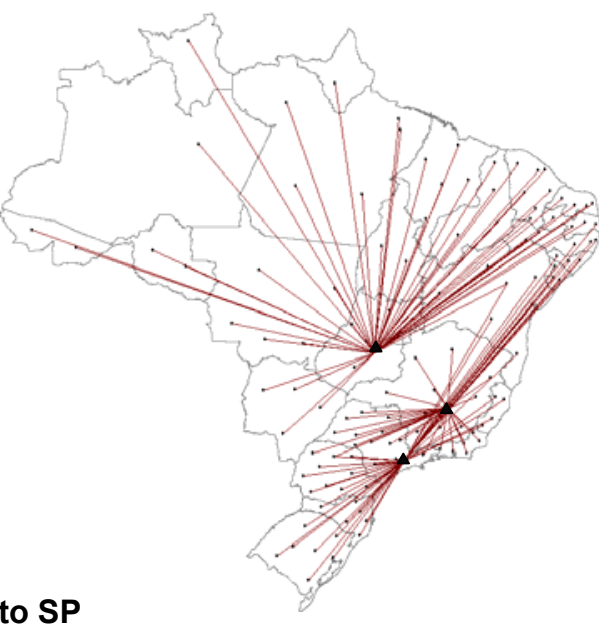

Figura 13. Fluxos de distribuição do Cenário Fiscal MG. 
Observa-se que, em relação ao Cenário Base, o Cenário Fiscal GO apresenta as seguintes diferenças em termos de fluxo de distribuição:

- O Produto GO passa a ser integralmente distribuído pelo CD GO.

- A distribuição do Produto de MG para as regiões S, CO, N, parte do NE e para o estado de SP (quase que integralmente) passa a ser realizada pelo CD GO.

- O CD GO absorve parte da distribuição do Produto SP, focando no atendimento à região $\mathrm{N}$, enquanto que o atendimento fica centralizado no $\mathrm{CD}$ SP.

Fica claro, portanto, que no Cenário Fiscal GO o CD GO absorve um fluxo maior do que no Cenário Base. Efeito semelhante pode ser observado no Cenário Fiscal MG, cujas principais alterações comparadas ao Cenário Base em termos de fluxo de distribuição estão relacionadas a seguir:

- O CD de MG absorve a distribuição do Produto GO para as regiões S e SE quase que integralmente, excluindo-se o estado do ES e o oeste de SP e noroeste do PR; enquanto que o CD SP deixa de distribuir o Produto GO.

- O Produto de MG permanece utilizando o CD MG apenas para o abastecimento do próprio estado de MG, para o RJ, parte de SP e noroeste do PR; para as demais regiões, a distribuição é descentralizada para os CDs SP e GO.

- Parte da distribuição do Produto SP continua a ser realizada pelo CD MG, mas com uma nova área de abrangência, que inclui os estados de MG e RJ apenas. O abastecimento da região $\mathrm{N}$, salvo os estados do $\mathrm{AC}$ e $\mathrm{RO}$, passa a ser realizado pelo $\mathrm{CD}$ GO, enquanto que o CD SP abastece o restante do país.

É interessante observar que no Cenário Fiscal MG o CD MG fica incumbido do atendimento aos estados "exportadores", independente do local de fabricação do Produto. Como a alíquota de ICMS com origem em MG e destino em um estado exportador corresponde a $12 \%$ e a $7 \%$ quando o destino é um estado importador, enviando para estados exportadores o CD MG consegue um débito de ICMS maior, o que o permite capturar maiores ganhos com o benefício fiscal. A Figura 14 a seguir permite visualizar melhor estes fluxos: 


\section{Fluxos de distribuição do Cenário Fiscal MG: fluxos com origem no CD MG}

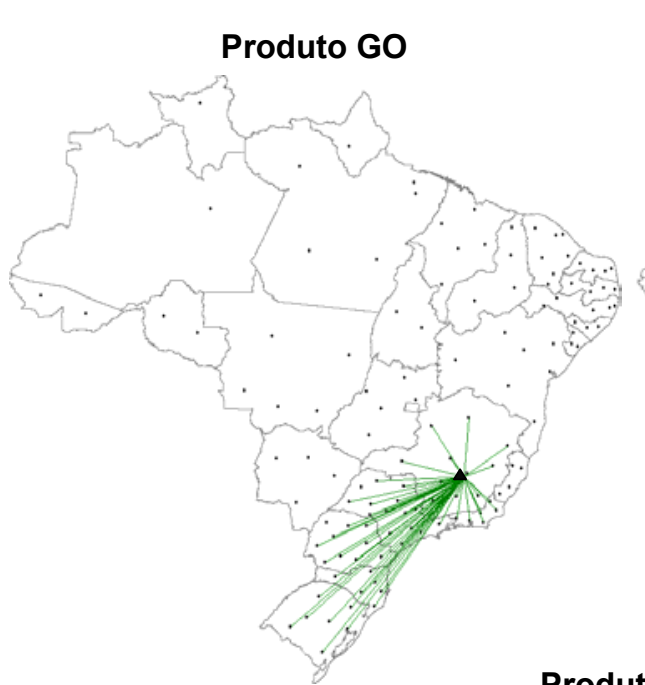

Produto SP

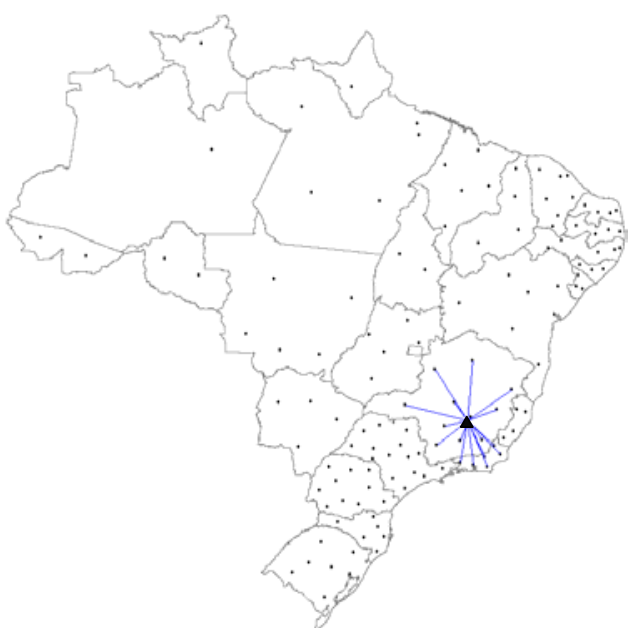

Produto MG
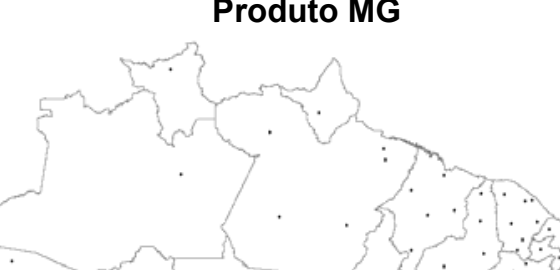

Legenda:

A Origem

- Destino

Figura 14. Fluxos de distribuição com origem no CD MG do Cenário Fiscal MG.

Apesar da configuração logística em termos de localização dos CDs não ter se alterado nos três cenários avaliados até o momento, para possibilitar as alterações de fluxo geradas com o intuito de capturar os ganhos relativos ao incentivo fiscal oferecido em cada um dos casos, o resultado dos cenários apontou uma necessidade diferenciada em termos do tamanho de cada um dos CDs. A Figura 15 a seguir ilustra tal fato, apresentando simultaneamente para os três cenários a capacidade e o fluxo de cada um dos CDs utilizados: 


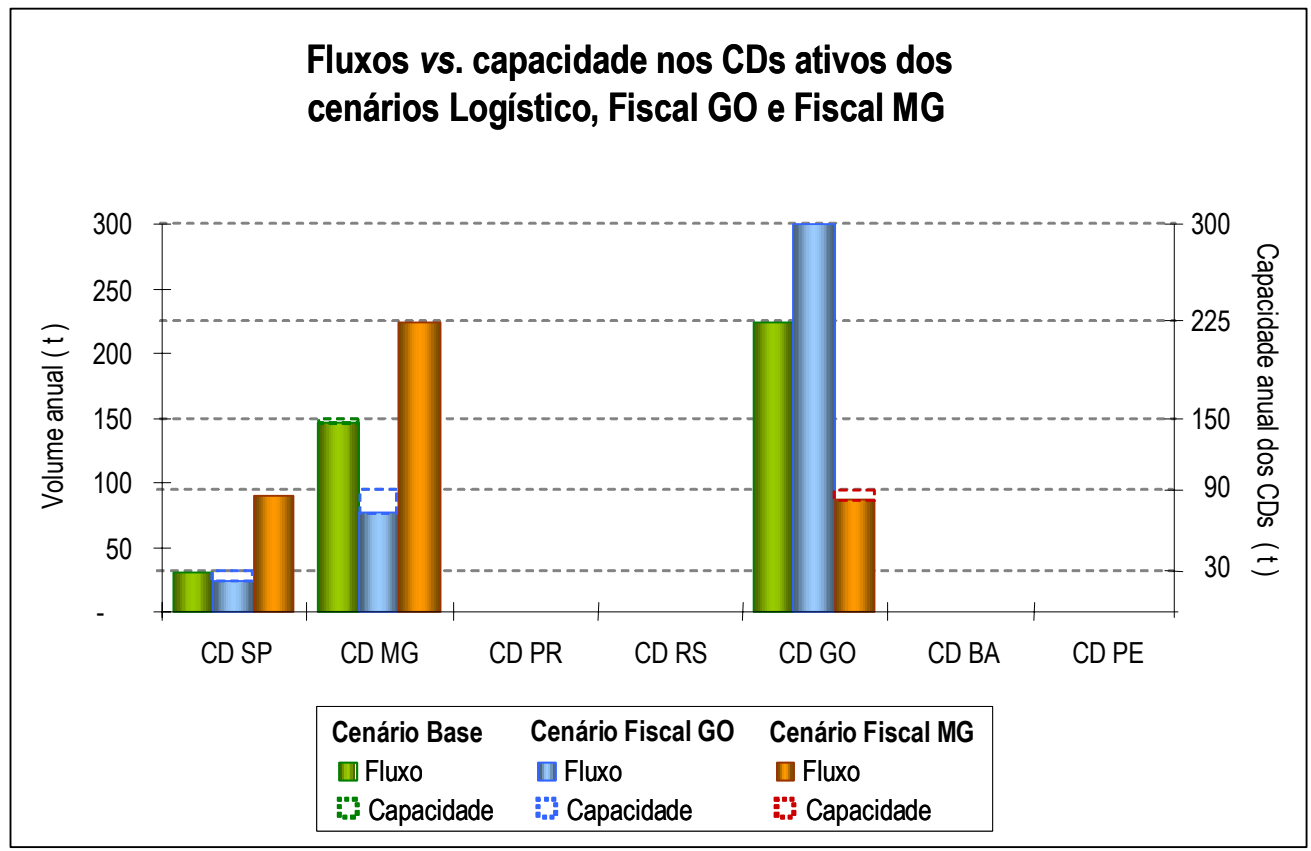

Figura 15. Fluxos vs. capacidade nos CDs ativos dos cenários Base, Fiscal GO e Fiscal MG.

A Tabela 15 a seguir apresenta o total de cada produto distribuído por cada CD nos cenários Base, Fiscal GO e Fiscal MG.

Tabela 15. Total de cada produto distribuído por cada CD nos cenários Base, Fiscal GO e Fiscal MG.

\begin{tabular}{|c|c|c|c|c|c|c|c|c|c|}
\hline \multirow{3}{*}{ PRODUTO } & \multicolumn{9}{|c|}{ VOLUME POR CD DE ORIGEM (t) } \\
\hline & \multicolumn{3}{|c|}{ CENÁRIO BASE } & \multicolumn{3}{|c|}{ CENÁRIO FISCAL GO } & \multicolumn{3}{|c|}{ CENÁRIO FISCAL MG } \\
\hline & CD_SP & CD_MG & CD_GO & CD_SP & CD_MG & CD_GO & CD_SP & CD_MG & CD_GO \\
\hline $\mathrm{PL}$ & 6.845 & 7.292 & 225.000 & 0 & 0 & 239.137 & 0 & 173.158 & 65.979 \\
\hline$P$ & 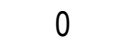 & 133.848 & 0 & U & 76.859 & 56.989 & 69.841 & 45.894 & 18.113 \\
\hline $\mathrm{PD}$ & 23.155 & 5.301 & 0 & 24.582 & 0 & 3.874 & 20.159 & 5.948 & 2.349 \\
\hline Total por CD & 30.000 & 146.441 & 225.000 & 24.582 & 76.859 & 300.000 & 90.000 & 225.000 & 86.44 \\
\hline
\end{tabular}

Observa-se que, para viabilizar todas as alterações nos fluxos, o tamanho de cada CD nos cenários Fiscal GO e Fiscal MG foi alterado em relação ao Cenário Base.

Em relação ao Cenário Fiscal GO, observa-se que o benefício fiscal oferecido por GO atraiu para este estado um CD com capacidade máxima de 300.000 t/ano (75.000 toneladas a mais do que no Cenário Base). Verifica-se também que o CD SP não sofreu alteração em sua capacidade máxima, mas teve seu fluxo reduzido em relação 
ao fluxo ocorrido no Cenário Base. Por fim, o CD MG sofreu significativa redução em sua capacidade: passou de 150.000 t/ano no Cenário Base para 90.000 t/ano.

Ainda sobre o Cenário Fiscal GO, como o $\mathrm{CD}$ GO foi aberto com a máxima capacidade permitida pelos parâmetros do modelo, rodou-se um novo cenário com o intuito de verificar-se o quanto de fluxo adicional o CD GO poderia absorver para gerar uma solução de custo inferior. Para tanto, alterou-se o parâmetro referente à capacidade máxima permitida para os CDs de 300.000 toneladas para 410.000 toneladas por ano, com capacidade portanto para absorver o fluxo de toda demanda. Apesar da alteração da capacidade máxima permitida para os CDs, o custo fixo foi mantido o mesmo do CD com capacidade máxima de 300.000 toneladas.

A solução ótima recomendada para este caso foi a abertura de um único $\mathrm{CD}$, localizado em GO, com a nova capacidade máxima permitida: 410.000 toneladas por ano, com uma redução de $2,1 \%$ nos custos totais. A Tabela 16 a seguir apresenta um comparativo de custos entre os cenários Fiscal GO original e Fiscal GO com o parâmetro referente à capacidade máxima dos CDs alterado (na figura, denominado de Fiscal GO - CD Max de 410.000).

Tabela 16. Comparativo de custos entre o Cenário Fiscal GO original e com alteração do parâmetro referente à capacidade máxima dos CDs alterado.

\begin{tabular}{|c|c|c|c|c|c|}
\hline \multirow{2}{*}{ CENÁRIO } & \multicolumn{5}{|c|}{ CUSTOS (MMR\$) } \\
\hline & Transferência & Distribuição & Armazenagem & Incentivo & Custo TOTAL \\
\hline Fiscal GO & 38,67 & 65,11 & 28,20 & $(30,36)$ & 101,63 \\
\hline Fiscal GO - CD Max de 410.000 & 46,10 & 68,97 & 26,98 & $(42,58)$ I I & 99,48 \\
\hline
\end{tabular}

Conforme é possível observar na Tabela 16, o aumento nos custos de frete de transferência e de distribuição, que equivalem respectivamente a MMR\$ 7,4 e MMR\$ 3,6 (indicação ' $\mathbf{A}$ ') foi compensado pela economia obtida por meio da maior captura do benefício fiscal, que teve um incremento de MMR\$12,2, bem como pela redução de MMR\$ 1,2 com economia nos custos de armazenagem (indicação 'B').

De volta à Figura 15, verifica-se que no Cenário Fiscal MG o $\mathrm{CD}$ de maior capacidade foi alocado ao estado de MG, com uma capacidade anual de 225.000 toneladas, ou seja, 75.000 a mais do que no Cenário Base. Em relação aos demais 
CDs, observa-se que o CD SP teve sua capacidade incrementada em 60.000 t/ano, enquanto que o CD GO teve sua capacidade mantida igual à do Cenário Base.

A Tabela 17 e a Figura 16, a seguir, que apresentam os componentes de custo de cada um dos cenários, possibilitam melhor compreender as propostas geradas para cada um dos casos.

Tabela 17. Custos dos cenários Base, Fiscal GO e Fiscal MG.

\begin{tabular}{cccccc}
\hline Cenário & $\begin{array}{c}\text { Frete de } \\
\text { Transferência } \\
\text { (MMR\$) }\end{array}$ & $\begin{array}{c}\text { Frete de } \\
\text { Distribuição } \\
\text { (MMR\$) }\end{array}$ & $\begin{array}{c}\text { Custo de } \\
\text { Armazenagem } \\
\text { (MMR\$) }\end{array}$ & $\begin{array}{c}\text { Ganho de } \\
\text { Incentivo } \\
\text { (MMR\$) }\end{array}$ & $\begin{array}{c}\text { Custo Total } \\
\text { (MMR\$) }\end{array}$ \\
\hline Base & 35,4 & 65,8 & 28,1 & & 129,2 \\
Fiscal GO & 38,7 & 65,1 & 28,2 & $-30,4$ & 101,6 \\
Fiscal MG & 52,3 & 60,1 & 28,2 & $-73,0$ & 67,6 \\
\hline
\end{tabular}

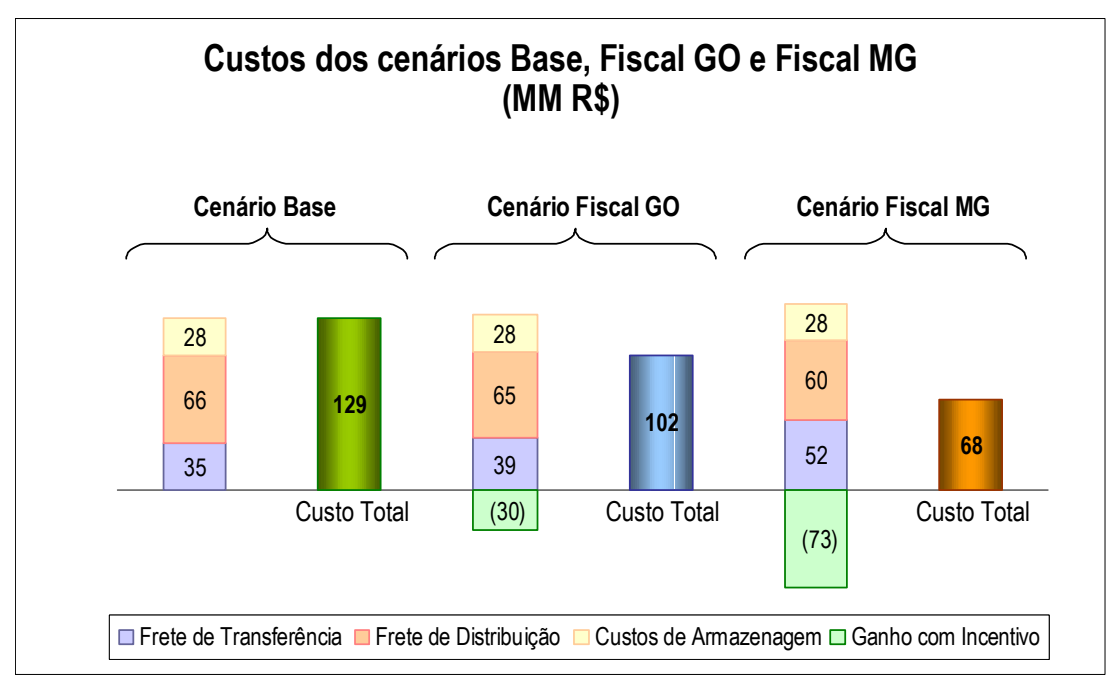

Figura 16. Custos dos cenários Base, Fiscal GO e Fiscal MG.

Observa-se que nos Cenários Fiscal GO e Fiscal MG ocorre uma redução dos custos de distribuição, enquanto que os custos de transferêncica acentuam-se (esta tendência é mais fortemente verificada no Cenário Fiscal MG). Comparando-se com o Cenário Base, verifica-se um aumento dos custos logístico nos Cenários Fiscal GO e Fiscal MG de $2,1 \%$ e $8,8 \%$ respectivamente. Conforme era esperado, aumentam-se os custos logísticos para possibilitar a captura do benefício fiscal. Apesar de este efeito ter ocorrido para os valores de parâmetro considerados nestes cenários, espera-se que para valores de venda inferiores os custos logísticos passem a preponderar sobre o benefício fiscal na decisão 
da malha ótima. Para verificar se isto realmente ocorre, realizam-se no capítulo seguinte algumas análises de sensibilidade considerando a variação do preço do produto.

Um ponto que chama a atenção é o fato de que os custos de armazenagem apresentam valores muito próximos nos três cenários apesar de se ter aberto CDs com capacidades diferentes em cada um deles. A Tabela 18, a seguir, ajuda a compreender o ocorrido, mostrando que a somatória dos custos fixos dos CDs apresenta valores muito semelhantes para os três cenários considerados, apenas com baixo incremento nos Cenários Fiscais, e indicando o mesmo valor de custo variável para todos os cenários, uma vez que o volume movimentado em cada fábrica e nos CDs não muda.

Tabela 18. Detalhamento dos custos de armazenagem dos Cenários Base, Fiscal GO e Fiscal MG.

\begin{tabular}{|c|c|c|c|c|}
\hline & Cenário $B$ ase & Cenário Fiscal GO & Cenário Fiscal MG \\
\hline \multirow{4}{*}{$\begin{array}{l}\text { ㅇ } \\
\text { ํ }\end{array}$} & Capacidade ( $\mathrm{t} /$ ano) & 225.000 & 300.000 & 90.000 \\
\hline & Fluxo $(\mathrm{t})$ & 225.000 & 300.000 & 86.441 \\
\hline & Custo Fixo do CD (R\$/ano) & 4.746 .551 & 6.053 .342 & 2.187 .657 \\
\hline & Custo Variável de Movimentação Fábrica GO + CD (R\$) & 10.571 .801 & 13.990 .514 & 4.255 .887 \\
\hline \multirow{4}{*}{ 인 } & Capacidade ( $\mathrm{t} /$ ano) & 150.000 & 90.000 & 225.000 \\
\hline & Fluxo (t) & 146.441 & 76.859 & 225.000 \\
\hline & Custo Fixo do CD (R\$/ano) & 3.369 .141 & 2.187 .657 & 4.746 .551 \\
\hline & Custo Variável de Movimentação Fábrica MG + CD (R\$) & 7.082 .355 & 3.910 .610 & 10.663 .298 \\
\hline \multirow{4}{*}{$\begin{array}{l}\text { के } \\
\text { ㅇ }\end{array}$} & Capacidade ( t/ ano) & 30.000 & 30.000 & 90.000 \\
\hline & Fluxo $(t)$ & 30.000 & 24.582 & 90.000 \\
\hline & Custo Fixo do CD (R\$/ano) & 864.260 & 864.260 & 2.187 .657 \\
\hline & Custo Variável de Movimentação Fábrica SP + CD (R\$) & 1.442 .226 & 1.195 .258 & 4.177.197 \\
\hline \multirow{3}{*}{\multicolumn{2}{|c|}{$\begin{array}{l}\text { Custo fixo de CD total do cenário }(\mathrm{R} \$) \\
\text { Custo varável de movimentação total do cenário (R\$) } \\
\text { Custo de armazenagem total do cenário }(\mathrm{R} \$)\end{array}$}} & 8.979 .952 & 9.105 .259 & 9.121 .864 \\
\hline & & 19.096.382 & 19.096.382 & 19.096.382 \\
\hline & & 28.076.334 & 28.201 .641 & 28.218.247 \\
\hline
\end{tabular}

Em relação à questão do Saldo de ICMS, no caso específico do Cenário Fiscal MG observa-se que o saldo de ICMS no CD de MG foi igual a zero, ou seja, este cenário indicou uma tendência de se acumular crédito de ICMS, de modo que a restrição de haver saldo positivo de ICMS nos CDs foi uma restrição ativa. A Figura 17 ilustra os fluxos de produtos e o saldo de ICMS de cada CD nos cenários Base, Fiscal GO e Fiscal MG. A circunferência tracejada chama a atenção para a marcação correspondente ao saldo nulo de ICMS no CD de MG. 


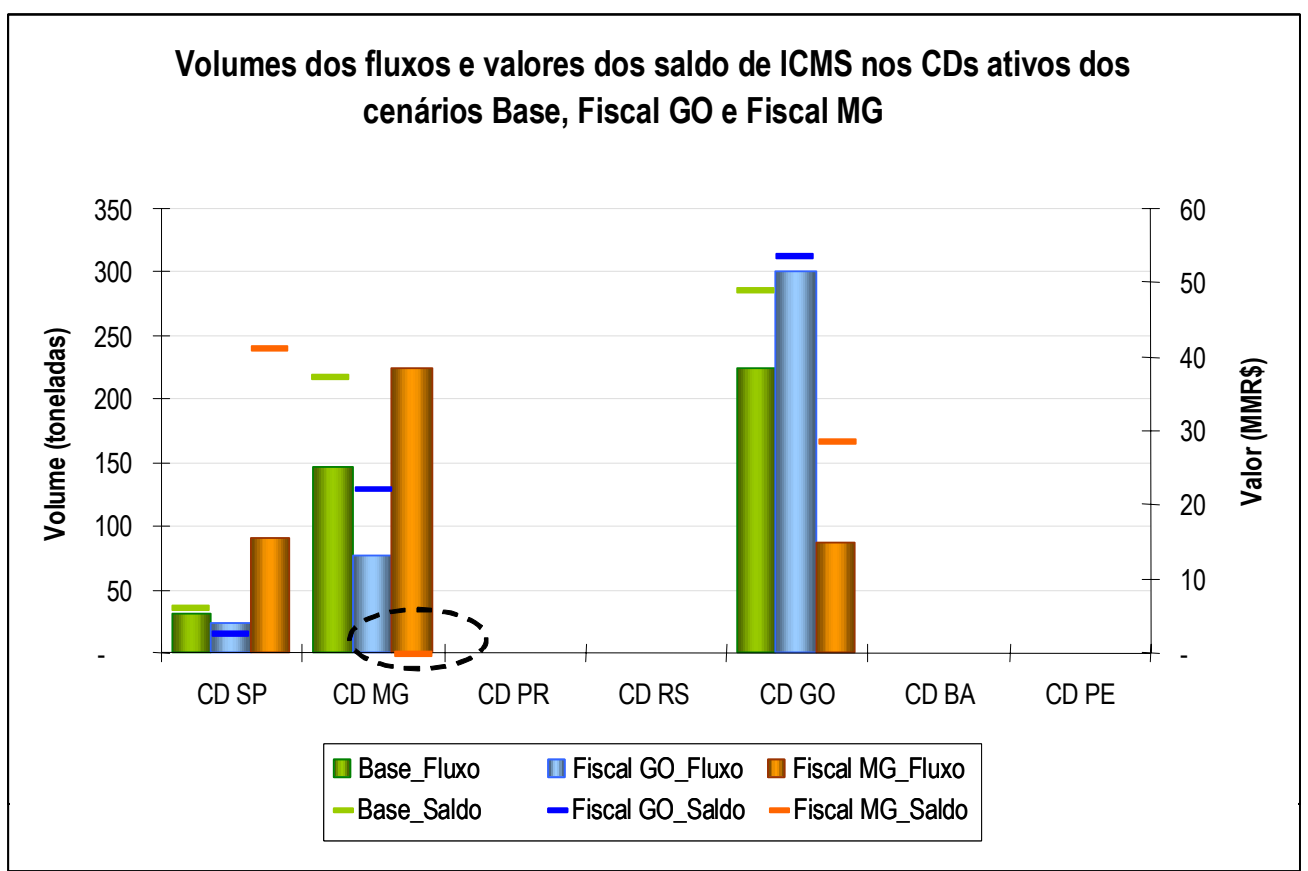

Figura 17. Fluxos e valores dos saldos de IMCS nos CDs ativos dos cenários Base, Fiscal GO e Fiscal MG.

\subsection{CONClusões do CAPÍtulo}

Por meio da aplicação do modelo matemático no problema elaborado foi possível estimar os tradeoffs entre custos logísticos (transporte e armazenagem) e incentivos fiscais baseados no crédito presumido de ICMS.

A aplicação do modelo a um cenário livre de aspectos fiscais possibilitou comparar o impacto gerado pelos benefícios fiscais oferecidos por $\mathrm{GO}$ ou por $\mathrm{MG}$ na recomendação puramente logística: o CD do estado fornecedor do incentivo fiscal sempre atraiu para si um fluxo de produtos superior ao verificado no Cenário Base, de modo que a solução ótima recomendou capacidades maiores para estes CDs, conforme era esperado.

Constatou-se, portanto, que os benefícios fiscais considerados nas análises exerceram impacto suficiente para mudar a decisão proposta pelo modelo logístico. Como se sabe, os incentivos fiscais baseados no crédito presumido do ICMS são calculados em função do preço de venda das mercadorias, o que nos leva a questionar até que ponto 
alterações no preço ou na margem dos produtos sustentam a decisão obtida considerando-se os valores adotados para os parâmetros do estudo de caso.

O capítulo seguinte realiza análises de sensibilidade para buscar responder a estas questões bem como para avaliar o impacto da influência de restrições de nível de serviço e de exigência de fluxo mínimo nos CDs no modelo. 


\section{ANÁLISES DE SENSIBILIDADE}

Neste capítulo são reportados os resultados obtidos com a variação dos seguintes parâmetros: preços dos produtos, margem de venda dos produtos, fluxo mínimo de movimentação nos CDS e inserção de restrição de nível de serviço. A análise dos resultados mediante a essas variações são importantes para a compreensão dos tradeoffs avaliados no estudo.

\subsection{Estrutura dos CenÁrios}

A Figura 18 a seguir apresenta a estrutura de cenários adotada para conduzir as análises de sensibilidade:

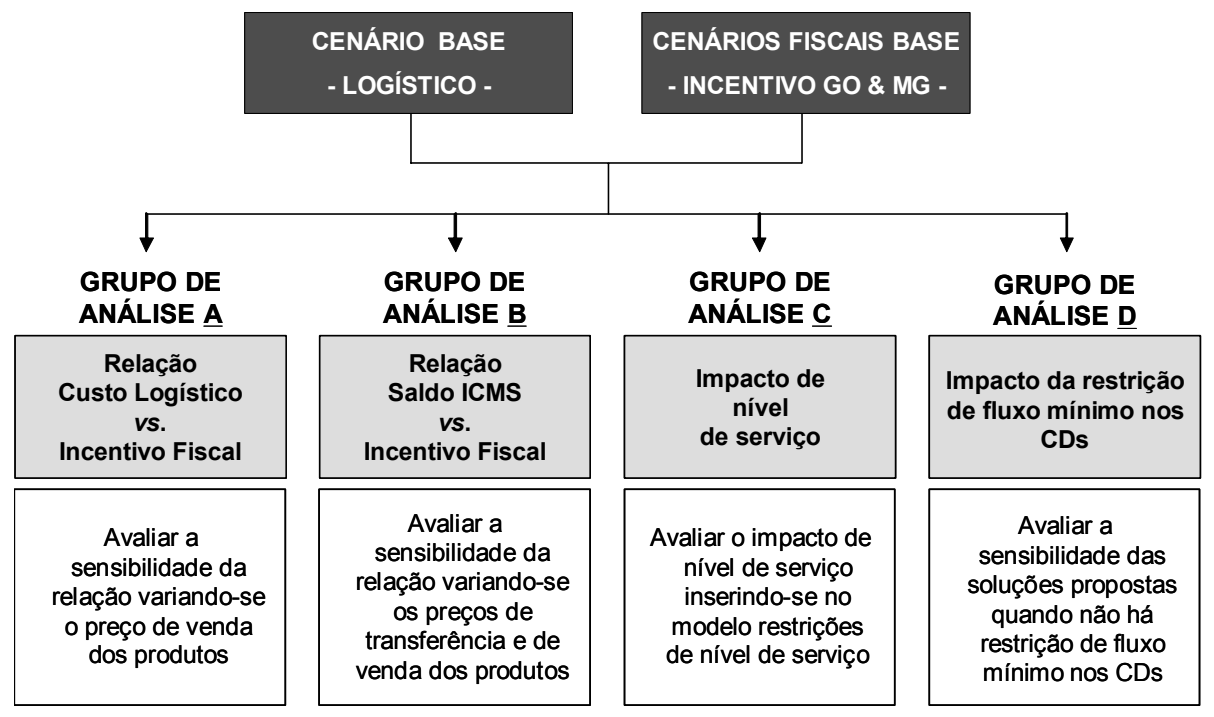

Figura 18. Estrutura dos cenários a serem analisados.

Para melhor compreender a figura bem como as explicações apresentadas em seguida, cabe explicitar o conceito que aqui será atribuído a 'Grupo de Análise' e a 'Cenário': o primeiro (Grupo de Análise) refere-se ao tópico a que se dedica a análise, ou seja, seu objetivo, de modo que todos seus cenários têm a mesma estrutura; o segundo termo (Cenário) é empregado para designar diferentes "situações" em que o modelo será aplicado, que apresentam características de parâmetros/restrições específicas e diferentes entre si. Exemplificando, temos que, 
para realizar as análises propostas pelo Grupo A, o modelo matemático precisará ser aplicado a diversos cenários, como em uma análise de sensibilidade.

As análises propostas para Grupo A buscam identificar o ponto de quebra da relação custo logístico e incentivo fiscal dos cenários Fiscal GO e Fiscal MG, ou seja, pontos em que ocorram mudanças da decisão proposta (em termos de localização e capacidade dos CDs abertos) em função do aumento de incentivo fiscal capturado. Para tanto, o modelo será aplicado a diversos cenários com diferentes preços dos produtos. Todos os cenários são rodados sem restrição de nível de serviço.

Com uma proposta de análise semelhante à do Grupo A, as análises propostas pelo Grupo B buscam identificar o ponto de quebra da relação saldo de ICMS e incentivo fiscal, ou seja, pontos em que ocorram mudanças da decisão proposta (em termos de localização e capacidade dos CDs abertos) em função da impossibilidade de acúmulo de saldo de ICMS nos CDs. Para avaliar o ponto de quebra desta relação o modelo será aplicado a diversos cenários com diferentes margens dos produtos. Assim como no caso anterior, todos os cenários rodados para a análise do Grupo $\mathrm{B}$ não apresentam restrição de nível de serviço.

O Grupo C propõe análises que buscam avaliar o impacto da inserção de restrição de nível de serviço no Cenário Base e nos Cenários Fiscais. Neste caso, as restrições de nível de serviço são adicionadas aos cenários Base, Fiscal GO e Fiscal MG e são geradas as novas soluções.

Por fim, as análises do Grupo D têm como objetivo avaliar o impacto da restrição de fluxo mínimo para os CDs. Para tanto, a restrição de fluxo mínimo é retirada dos cenários Base, Fiscal GO e Fiscal MG e são geradas as novas soluções.

Para orientar as análises dos resultados são utilizados alguns recursos que permitem uma visualização agregada dos dados, tais como tabelas, gráficos e mapas, entre outros. Entretanto, conforme coloca Yoshizaki (2002), a mente humana tem limitações para tratar questões multidimensionais, de modo que, mesmo com um número reduzido de dimensões, é difícil descrever e analisar os resultados gerados pelo uso da PLIM, que avalia todos os tradeoffs simultaneamente. Deste modo, em alguns casos foi necessário ir à minúcia dos resultados obtidos. 


\subsection{GRUPO DE ANÁLISE A: TRADEOFF ENTRE CUSTOS LOGÍSTICOS E INCENTIVO FISCAL}

Para avaliar se alterações nos preços dos produtos impactam na decisão apresentada considerando-se os parâmetros de custo do caso estudado (Cenários Fiscal GO e Fiscal MG), realizou-se uma análise de sensibilidade para variações deste parâmetro. Para tanto, foram gerados cenários em que a os preços de venda e de transferência de todos os produtos foram incrementados e decrescidos em intervalos de $15 \% \mathrm{em}$ relação ao valor original dos preços de transferência e de venda dos produtos. A Figura 19 seguir apresenta os resultados, em termos de capacidades e fluxos dos CDs abertos, obtidos para o caso do Cenário Fiscal GO:



Figura 19. Representação das capacidades e fluxos dos CDs ativos nos cenários de variação dos preços dos produtos considerando-se incentivo fiscal fornecido pelo estado de GO.

Conforme se pode observar, a decisão de quais CDs devem operar não foi alterada em nenhuma das variações de preço consideradas. É interessante observar que apenas uma redução de $90 \%$ nos preços originais de venda e transferência gerou uma nova decisão quanto aos tamanhos dos CDs abertos: redução de $25 \%$ da capacidade do CD GO e ampliação de $67 \%$ da capacidade do CD MG em relação ao Cenário Fiscal GO (que no gráfico corresponde ao ' $00 \%$ '). Essa nova proposta coincide com 
a configuração ótima apresentada pelo Cenário Base em termos de quais CDs devem estar em operação e quais suas respectivas capacidade, mas seus custos totais são $1,63 \%$ inferiores em função do benefício auferido.

Um outro ponto interessante que pode ser observado na Figura 19 consiste no fato de que, apesar de os cenários em que há redução de 75\% e 60\% nos preços não terem apresentado como solução ótima uma nova configuração em termos de capacidades dos CDs, houve uma capacidade ociosa no CD GO equivalente a $6,2 \%$ de sua capacidade (ver na Figura 19 indicação 'A'), situação que já não se repete do Cenário $(-30 \%)$ em diante.

A situação descrita no parágrafo acima indica que, para uma variação de preços entre $-45 \%$ e $-75 \%$, os preços dos produtos não são suficientemente altos para justificar a passagem de um volume maior pelo CD GO de modo a tomar toda a sua capacidade, mas por outro lado, são suficientes para que a decisão de manter um CD de máxima capacidade em GO seja mantida.

Considerando-se que a decisão da nova configuração de CDs proposta por estes cenários não é utilizada somente para captura de benefícios fiscais, estes mesmos cenários de variação de preço foram rodados com a recomendação de tamanho de CDs gerada pelo Cenário Base Logístico. O intuito de realizar estas análises consiste em avaliar o potencial que a malha logística proposta pelo Cenário Base Logístico (CD SP com 30.000 toneladas/ano de fluxo, CD MG com 150.000 toneladas/ano de fluxo e CD GO com 225.000 toneladas/ano de fluxo) tem para capturar o benefício fiscal em questão. A Tabela 19 a seguir apresenta os resultados obtidos; nela, a indicação "Travado" ao lado do nome do cenário identifica os cenários que foram rodados com a recomendação de capacidade dos CDs proposta pelo Cenário Base Logístico.

Tabela 19. Potencial de incentivo da malha logística proposta pelo Cenário Base nos cenários de variação de preço de $(-75 \%)$ e $(-60 \%)$.

\begin{tabular}{|c|c|c|c|c|c|}
\hline \multirow{2}{*}{ CENÁRIO } & \multicolumn{5}{|c|}{ CUSTOS (MMR\$) } \\
\hline & Transferência & Distribuição & Armazenagem & Incentivo & Custo TOTAL \\
\hline Fiscal GO (- 75\%) & 37,65 & 64,64 & 28,20 & $\overline{(6,90)} \overline{\bar{i}}$ & 123,60 \\
\hline Fiscal GO (- 75\%)_Travado & 37,18 & 64,03 & 28,08 & $(5,35)$ & 123,94 \\
\hline Fiscal GO (- 60\%) & 37,57 & 64,76 & 28,20 & $(\overline{1} \overline{1}, \overline{0} \overline{)})$ & 119,45 \\
\hline Fiscal GO (- 60\%)_Travado & 37,45 & 63,80 & 28,08 & $(8,60)$ & 120,72 \\
\hline
\end{tabular}


Conforme apresenta a Tabela 19 (indicações 'A' e 'B') os resultados indicam que o potencial que a malha logística do Cenário Base tem para capturar incentivo nos casos de variações de preço de (-75\%) e (-60\%) equivale a 78\% do montante de incentivo capturado pela malha logística ótima proposta para cada um desses cenários (manutenção do tamanho do $\mathrm{CD}$ SP, incremento do $\mathrm{CD}$ GO e redução do CD MG). Ao olhar-se para os custos totais dos cenários verifica-se um baixo impacto: incremento de $0,3 \%$ para variação de preço de $(-75 \%)$ e de $1,1 \%$ para variação de preço de $(-60 \%)$.

De volta à Figura 19, é interessante observar que para o Cenário (-45\%) a recomendação da malha indica que há uma capacidade ociosa em todos os CDs em operação (ver na Figura 19 indicação 'B'). As variações a partir deste cenário indicam que ocorre uma ocupação total do $\mathrm{CD} \mathrm{GO}$, enquanto que o $\mathrm{CD} \mathrm{MG}$ gradativamente vai perdendo fluxo para o $\mathrm{CD}$ SP, até que a recomendação se estabilize no cenário $(+30 \%)$.

Um outro fato que chama atenção em relação à Figura 19 consiste na indicação ' $\mathbf{C}$ ': no Cenário (-45\%) o CD SP não é usado em sua máxima capacidade, mas no Cenário $(+15 \%)$ essa tendência se inverte.

Apesar de os cenários com variação de preço terem apresentado alterações pouco significativas em termos de fluxos, a Tabela 20 permite observar que em relação aos custos totais houve grande variação, gerada quase que em sua totalidade em função dos ganhos capturados com o incentivo fiscal oferecido por GO: 
Tabela 20. Custos correspondentes aos cenários de variação dos preços dos produtos considerando-se incentivo fiscal oferecido pelo estado de GO.

\begin{tabular}{cccccc}
\hline \multirow{2}{*}{ CENÁRIO } & \multicolumn{5}{c}{ CUSTOS (MMR\$) } \\
\cline { 2 - 6 } & Transferência & Distribuição & Armazenagem & Incentivo & Custo TOTAL \\
\hline Fiscal GO (- 90\%) & 36,66 & 64,53 & 28,08 & $(2,13)$ & 127,14 \\
Fiscal GO (- 75\%) & 37,65 & 64,64 & 28,20 & $(6,90)$ & 123,60 \\
Fiscal GO (- 60\%) & 37,57 & 64,76 & 28,20 & $(11,09)$ & 119,45 \\
Fiscal GO (- 45\%) & 38,12 & 64,97 & 28,20 & $(16,10)$ & 115,20 \\
Fiscal GO (- 30\%) & 38,69 & 65,01 & 28,20 & $(21,19)$ & 110,72 \\
Fiscal GO (- 15\%) & 38,67 & 65,07 & 28,20 & $(25,77)$ & 106,18 \\
Fisacl GO ( 00\%) & 38,67 & 65,11 & 28,20 & $(30,36)$ & 101,63 \\
Fiscal GO (+ 15\%) & 38,68 & 65,26 & 28,20 & $(35,08)$ & 97,06 \\
Fiscal GO (+ 30\%) & 38,69 & 65,44 & 28,20 & $(39,86)$ & 92,48 \\
Fiscal GO (+ 45\%) & 38,69 & 65,44 & 28,20 & $(44,45)$ & 87,88 \\
\hline
\end{tabular}

A Figura 20 a seguir ilustra a variação dos custos apresentados na Tabela 20. Por meio dela é possível verificar que houve pouca variação dos custos logísticos quando comparada à variação do benefício fiscal auferido em cada um dos cenários avaliados. Isto ocorre uma vez que o benefício fiscal varia em função do preço, que é uma ordem de grandeza maior do que os custos logísticos - por exemplo, para o Cenário Fiscal GO o custo logístico médio equivale a 329 R \$/t, enquanto que o preço dos produtos varia entre 2.000 e $4.500 \mathrm{R} \$ / \mathrm{t}$.

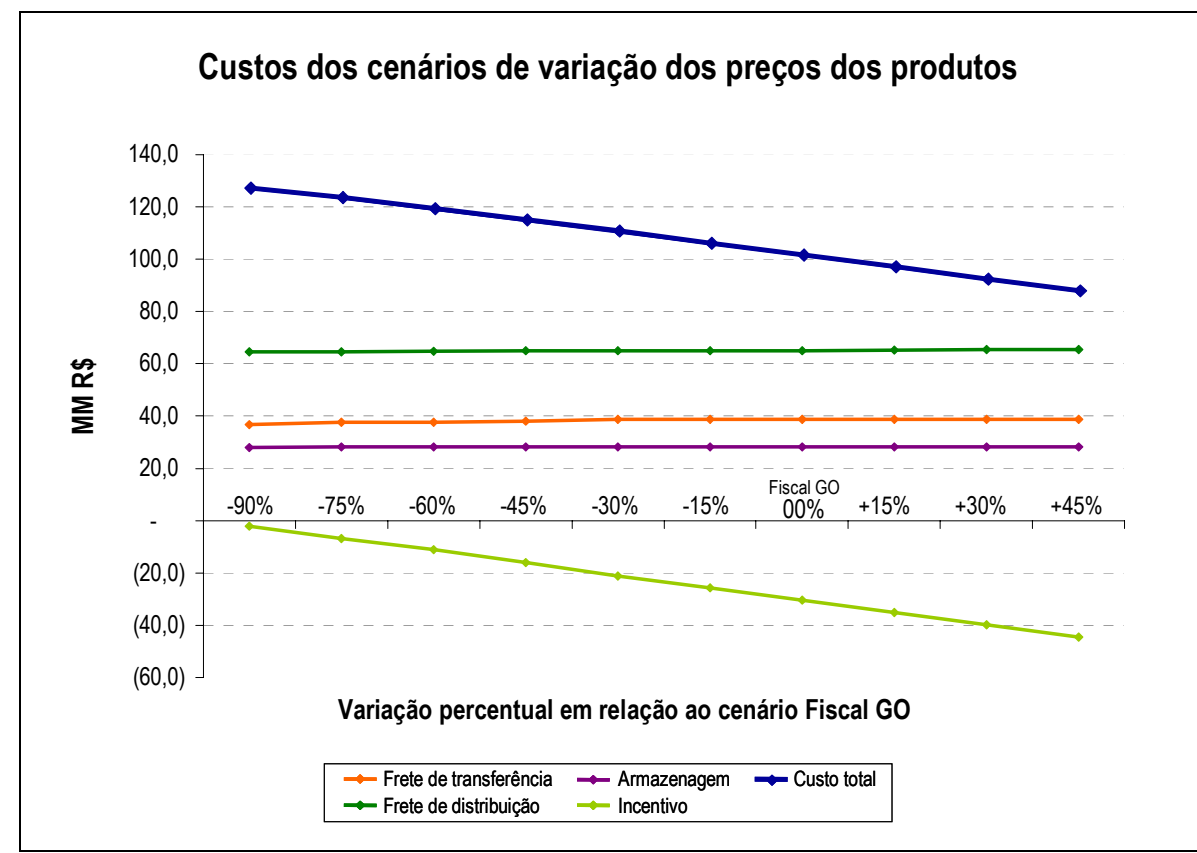

Figura 20. Representação gráfica dos custos dos cenários de variação dos preços dos produtos em relação ao Cenário Fiscal GO. 
No caso de Minas Gerais, como o valor percentual do incentivo é maior do que o de Goiás, os resultados apresentados em termos de fluxos e configuração dos CDs mostraram-se um pouco mais sensíveis às variações de preço. A Figura 21 a seguir apresenta os resultados obtidos em termos de capacidades e fluxos dos CDs abertos:

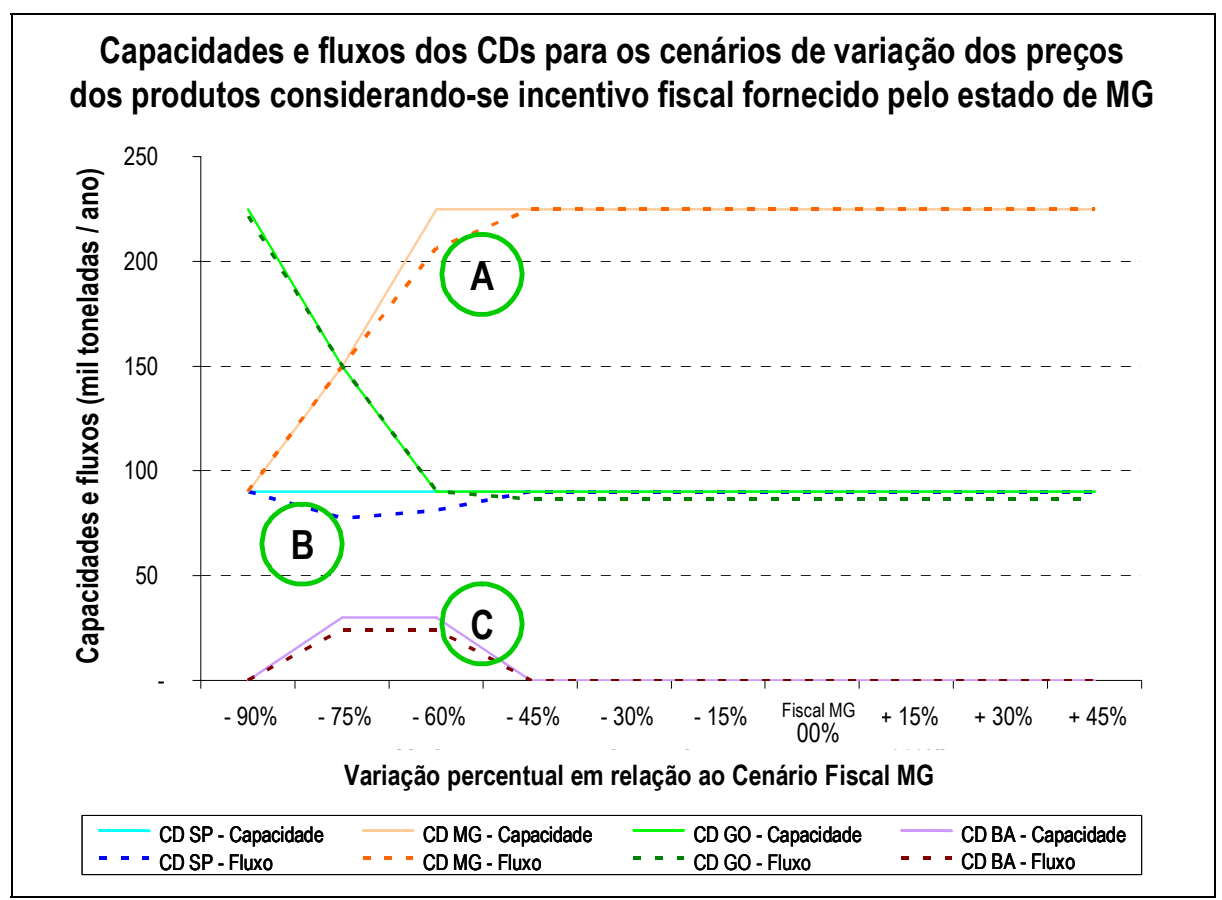

Figura 21. Representação das capacidades e fluxos dos CDs ativos nos cenários de variação dos preços dos produtos considerando-se incentivo fiscal fornecido pelo estado de MG.

Observa-se que a decisão quanto ao tamanho dos CDs só estabilizou no Cenário $(-45 \%)$, o que indica que a decisão da infra-estrutura logística ótima é mais sensível às variações de preços diante do incentivo fiscal oferecido por $\mathrm{MG}$ do que o oferecido por GO. Por outro lado, é possível verificar que no Cenário Fiscal MG os fluxos ótimos recomendados estabilizaram-se mais rápido do que no Cenário Fiscal GO: Cenário (+30\%) para este e Cenário (-45\%) para aquele.

É interessante observar que os Cenários (-75\%) e (-60\%) trouxeram a decisão, até o momento inédita, da abertura do $\mathrm{CD} B A$ (ver na Figura 21 indicação ' $C$ '), que passou a absorver os fluxos de distribuição relacionados na Tabela 21 a seguir. 
Tabela 21. Fluxos de abastecimento a partir do CD BA nos Cenários Fiscais MG com variação de preço de $-75 \%$ e $-60 \%$.

\begin{tabular}{|c|c|c|c|c|c|c|c|c|c|}
\hline \multirow[b]{2}{*}{ UF Destino } & \multicolumn{3}{|c|}{ Fluxos para o Cenário $(-75 \%)(t)$} & \multicolumn{3}{|c|}{ Fluxos para o Cenário $(-60 \%)(t)$} & \multicolumn{3}{|c|}{ Demanda $(t)$} \\
\hline & PD_GO & PD_MG & PD_SP & PD_GO & PD_MG & PD_SP & PD_GO & PD_MG & PD_SP \\
\hline $\mathrm{AL}$ & 1.210 & 411 & 923 & 1.210 & 411 & 497 & 1.666 & 411 & 923 \\
\hline$B A$ & 5.466 & 2.775 & 835 & 5.466 & 2.775 & - & 8.789 & 2.805 & 1.584 \\
\hline CE & - & 1.535 & - & - & 1.535 & - & 3.358 & 1.535 & 1.193 \\
\hline MA & - & 183 & - & - & 183 & - & 1.427 & 534 & 653 \\
\hline PB & - & 1.098 & 605 & - & 1.098 & 366 & 1.229 & 1.098 & 663 \\
\hline PE & 1.089 & 2.639 & 1.984 & 2.882 & 2.639 & 1.984 & 4.773 & 2.639 & 2.105 \\
\hline PI & - & 257 & - & - & 257 & - & 897 & 257 & 256 \\
\hline RN & - & 610 & 293 & - & 610 & - & 1.135 & 610 & 307 \\
\hline SE & 1.561 & 358 & 168 & 1.561 & 358 & 168 & 1.569 & 358 & 168 \\
\hline Total & 9.326 & 9.866 & 4.808 & 11.119 & 9.866 & 3.015 & 24.843 & 10.247 & 7.852 \\
\hline$\%$ vs. Demanda & $38 \%$ & $96 \%$ & $61 \%$ & $45 \%$ & $96 \%$ & $38 \%$ & $100 \%$ & $100 \%$ & $100 \%$ \\
\hline
\end{tabular}

Verifica-se que os maiores volumes absorvidos pelo CD BA são do Produto MG para os estados da região NE: tanto no caso do Cenário (-75\%) quanto no do Cenário (-60\%) o CD BA assume a distribuição de $96 \%$ da demanda do Produto MG nos estados relacionados na Tabela 21. Como conseqüência deste fato verifica-se que houve no CD de São Paulo uma ociosidade equivalente a 86\% e 90\% (ver na Figura 21 indicação 'B'), visto que a distribuição de cargas assumida pelo CD BA era, nos demais cenários, incumbida ao CD SP.

Para fundamentar a decisão da abertura do CD BA, rodou-se novamente os Cenários $(-75 \%)$ e $(-60 \%)$ forçando-os a ter a mesma configuração de CDs do Cenário (-45\%): CD SP e CD GO com capacidade de 90.000 t/ano e CD MG com capacidade de 225.000 t/ano. Os custos resultantes foram 1,52\% superior no caso do Cenário (-75\%) e 0,15\% superior no caso do Cenário (-60\%) comparado aos dos respectivos cenários originais. Percebe-se que as diferenças nos custos são muito pequenas, principalmente no caso do Cenário $(-60 \%)$.

Um outro ponto interessante que chama a atenção em relação aos Cenários (-75\%) e (-60\%) consiste nos tamanhos e fluxos propostos para os CDs SP e GO: apesar do tamanho proposto para o CD MG apresentar um incremento de capacidade de 50\% em toneladas, ele não é completamente ocupado em princípio (ocupação inicial de $100 \%$ passa a ser de $92 \%$ com a perda de fluxo para o CD SP), diferentemente do CD GO, que em ambos os cenários apresenta ocupação de $100 \%$. 
Em termos de custos, assim como no caso do Cenário Fiscal GO, o incentivo fiscal oferecido por MG gerou grande impacto nos custos totais, conforme pode ser observado na Tabela 22 a seguir:

Tabela 22. Custos correspondentes aos cenários de variação dos preços dos produtos considerando-se incentivo fiscal oferecido pelo estado de MG.

\begin{tabular}{cccccc}
\hline \multirow{2}{*}{ CENÁRIO } & \multicolumn{5}{c}{ CUSTOS (MMR\$) } \\
\cline { 2 - 6 } Fiscal MG (- $90 \%)$ & Transferência & Distribuição & Armazenagem & Incentivo & Custo TOTAL \\
Fiscal MG (- 75\%) & 41,83 & 60,82 & 28,22 & $(3,37)$ & 127,50 \\
Fiscal MG (- 60\%) & 47,96 & 56,53 & 28,89 & $(13,17)$ & 120,20 \\
Fiscal MG (- 45\%) & 52,71 & 56,49 & 29,08 & $(27,17)$ & 111,11 \\
Fiscal MG (- 30\%) & 52,19 & 60,13 & 28,22 & $(40,09)$ & 100,46 \\
Fiscal MG (- 15\%) & 52,25 & 60,11 & 28,22 & $(51,06)$ & 89,52 \\
Fisacl MG ( 00\%) & 52,27 & 60,12 & 28,22 & $(62,03)$ & 78,58 \\
Fiscal MG (+ 15\%) & 52,27 & 60,12 & 28,22 & $(72,98)$ & 67,63 \\
Fiscal MG (+ 30\%) & 52,28 & 60,12 & 28,22 & $(83,94)$ & 56,68 \\
Fiscal MG (+ 45\%) & 52,44 & 60,20 & 28,22 & $(95,14)$ & 45,72 \\
\hline
\end{tabular}

\subsection{GRUPo de ANÁlise B: tRADEOFF ENTRE SALdo DE ICMS E INCENTIVO FISCAL}

Para avaliar se alterações nas margens dos produtos impactam na decisão apresentada, considerando-se os parâmetros de custo do caso estudado (Cenários Fiscal GO e Fiscal MG), realizou-se uma análise de sensibilidade para variações deste parâmetro. Para tanto, foram gerados cenários em que a margem de todos os produtos foi incrementada e decrescida em intervalos de $15 \%$ em relação ao valor original dos preços de transferência dos produtos, ou seja, manteve-se o preço de transferência do produto e incrementou-se ou decresceu-se o preço de venda em intervalos de 15\% em relação ao original. A Figura 22, a seguir, apresenta os resultados, em termos de capacidades e fluxos dos CDs abertos, obtidos para o caso do Cenário Fiscal GO. 


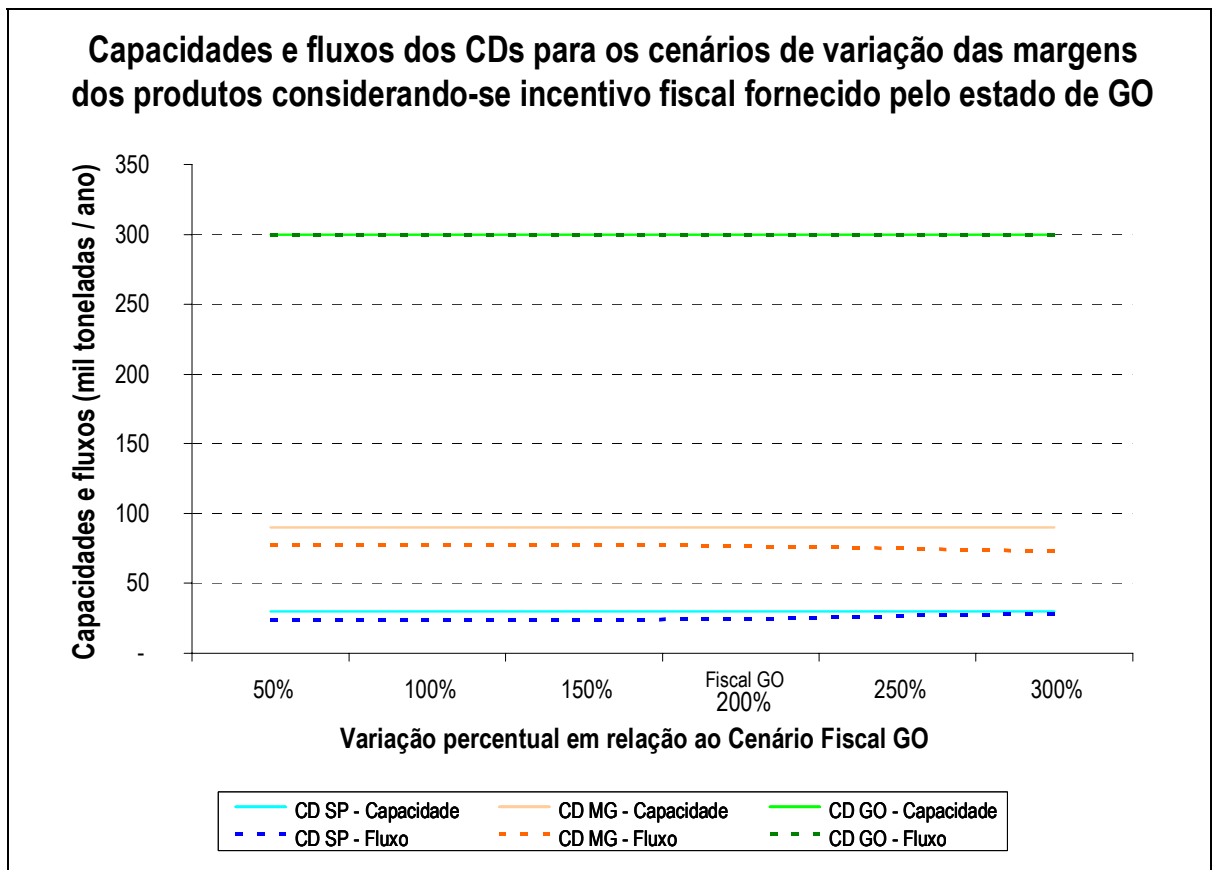

Figura 22. Representação das capacidades e fluxos dos CDs ativos nos cenários de variação das margens dos produtos considerando-se incentivo fiscal fornecido pelo estado de GO.

A Figura 22 permite verificar que as alterações na margem dos produtos não gerou alterações no resultado ótimo no que diz respeito ao tamanho proposto para os CDs. Mesmos em relação aos fluxos ótimos de cada cenário houve pouca variação, envolvendo os fluxos dos CDs MG e SP: com o aumento da variação da margem, observa-se uma transferência gradativa dos fluxos do CD MG para o CD SP, até que a capacidade deste último fosse totalmente utilizada.

Por outro lado, a Figura 23, apresentada a seguir, permite observar que diante do incentivo fiscal de MG as variações de margem dos produtos provocam grandes alterações no que diz respeito à recomendação dos CDs. 


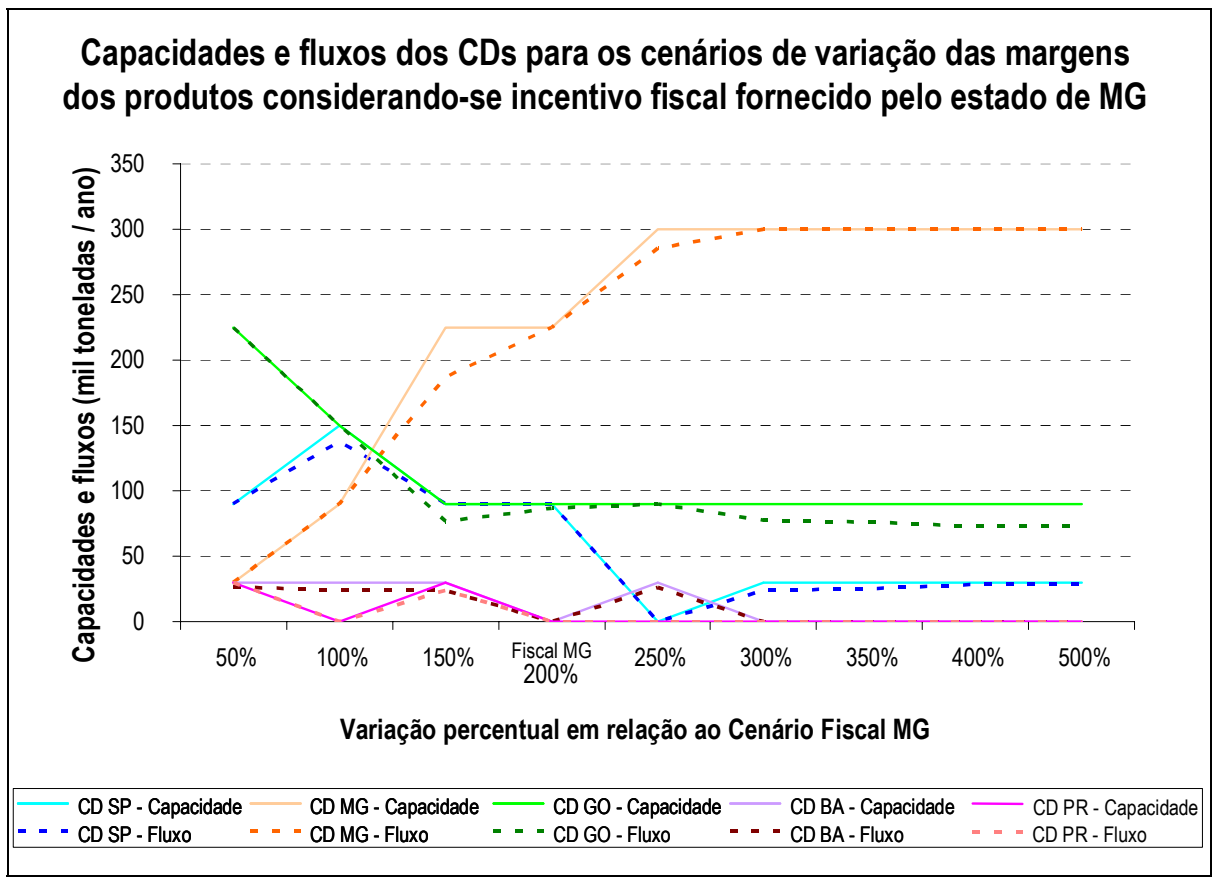

Figura 23. Representação das capacidades e fluxos dos CDs ativos nos cenários de variação das margens dos produtos considerando-se incentivo fiscal fornecido pelo estado de MG.

Verifica-se que, apesar da tendência crescente de aumento de fluxo no CD MG e de redução de fluxo no $\mathrm{CD} \mathrm{GO}$, o resultado das decisões só estabilizou-se a partir dos cenários com variação da margem superior a 300\%, quando o $\mathrm{CD}$ atingiu a capacidade máxima permitida de 300.000 t/ano.

Investigando-se os resultados dos cenários verificou-se que a instabilidade que ocorre entre os Cenários (50\%) e (200\%) vem em decorrência do mix de produtos alocado para o CD MG com o intuito de maximizar a obtenção do beneficio. As Figuras 24 a 26 a seguir ilustram a distribuição dos produtos em cada um dos CDs abertos nos cenários gerados para as análises de variação de margem diante do incentivo fiscal de MG. Uma análise futura poderia contemplar o relaxamento da restrição de capacidade do CD MG para volumes maiores do que 300.000 t/ano. 


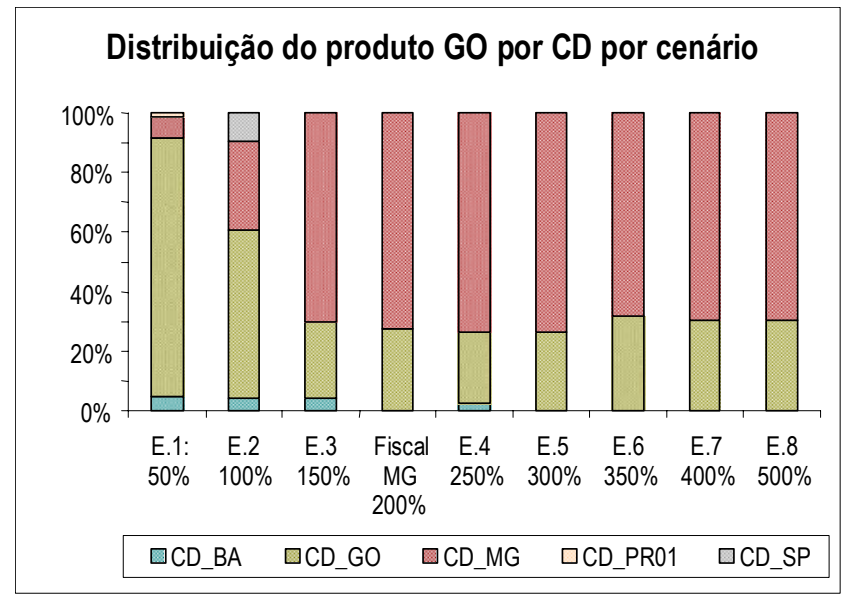

Figura 24. Distribuição do produto GO em cada um dos CDs abertos nos cenários de variação de margem diante do incentivo fiscal de MG.

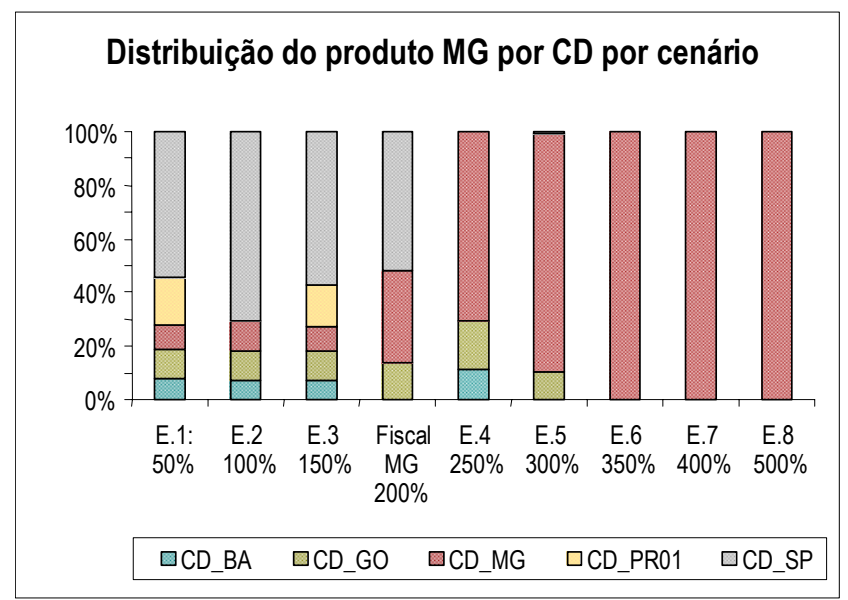

Figura 25. Distribuição do produto MG em cada um dos CDs abertos nos cenários de variação de margem diante do incentivo fiscal de MG.

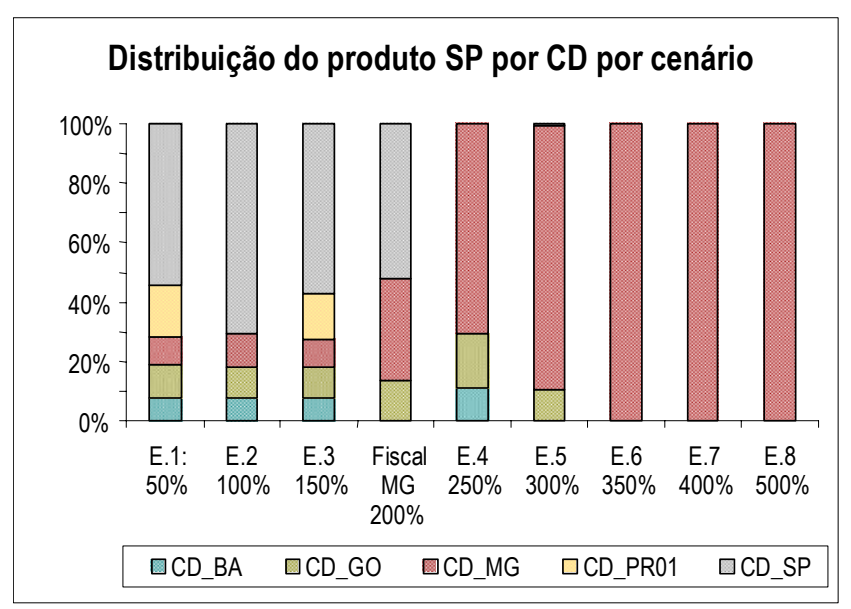

Figura 26. Distribuição do produto SP em cada um dos CDs abertos nos cenários de variação de margem diante do incentivo fiscal de MG. 
O que impulsiona a formação de diferentes mix de produto nos CDs em cada um dos cenários é a restrição que não permite a existência de saldo positivo de ICMS nos CDs. Quando esta restrição tem um papel ativo no modelo, as soluções propostas sofrem efeito dos diferentes preços dos produtos para buscar o máximo valor de benefício fiscal. Como conseqüência, a instabilidade das decisões geradas pelo modelo só é eliminada quando houver "folga" nesta restrição.

As Tabelas 23 e 24, a seguir, apresentam os custos dos cenários gerados para as análises de sensibilidade do tradeoff entre saldo de ICMS e incentivo fiscal.

Tabela 23. Custos correspondentes aos cenários de variação da margem dos produtos considerando-se incentivo fiscal oferecido pelo estado de GO.

\begin{tabular}{lccccc}
\hline \multirow{2}{*}{ CENÁRIO } & \multicolumn{5}{c}{ CUSTOS (MMR\$) } \\
\cline { 2 - 6 } & Transferência & Distribuição & Armazenagem & Incentivo & Custo TOTAL \\
\hline Fiscal GO (50\%) & 39,73 & 64,64 & 28,20 & $(15,30)$ & 117,27 \\
Fiscal GO (100\%) & 38,70 & 65,00 & 28,20 & $(20,17)$ & 111,73 \\
Fiscal GO (150\%) & 38,67 & 65,06 & 28,20 & $(25,25)$ & 106,68 \\
Fiscal GO Inicial = (200\%) & 38,67 & 65,11 & 28,20 & $(30,36)$ & 101,63 \\
Fiscal GO (250\%) & 38,68 & 65,26 & 28,20 & $(35,59)$ & 96,56 \\
Fiscal GO (300\%) & 38,69 & 65,44 & 28,20 & $(40,88)$ & 91,46 \\
\hline
\end{tabular}

Tabela 24. Custos correspondentes aos cenários de variação da margem dos produtos considerando-se incentivo fiscal oferecido pelo estado de MG.

\begin{tabular}{lccccc}
\hline \multirow{2}{*}{ CENÁRIO } & \multicolumn{5}{c}{ CUSTOS (MMR\$) } \\
\cline { 2 - 6 } & Transferência & Distribuição & Armazenagem & Incentivo & Custo TOTAL \\
\hline Fiscal MG ( 50\%) & 45,92 & 57,93 & 28,62 & $(5,38)$ & 127,09 \\
Fiscal MG ( 100\%) & 49,90 & 55,32 & 28,89 & $(19,04)$ & 115,07 \\
Fiscal MG (150\%) & 56,72 & 56,05 & 29,95 & $(47,16)$ & 95,55 \\
Fiscal MG Inicial = (200\%) & 52,27 & 60,12 & 28,22 & $(72,98)$ & 67,63 \\
Fiscal MG (250\%) & 53,40 & 59,99 & 28,20 & $(113,48)$ & 28,10 \\
Fiscal MG (300\%) & 48,59 & 62,54 & 28,20 & $(141,58)$ & $(2,24)$ \\
Fiscal MG (350\%) & 46,48 & 62,87 & 28,20 & $(162,83)$ & $(25,27)$ \\
Fiscal MG (400\%) & 46,56 & 61,42 & 28,20 & $(181,45)$ & $(45,26)$ \\
Fiscal MG (500\%) & 46,56 & 61,15 & 28,20 & $(217,74)$ & $(81,82)$ \\
\hline
\end{tabular}

Um ponto que chama atenção na Tabela 24 é o fato de o custo total dos cenários em que a variação da margem supera os 300\% apresentar valor negativo, resultado de uma 
situação em que os ganhos de incentivo fiscal superam os custos logísticos. Isto é possível uma vez que o ganho em incentivo fiscal é calculado em função do valor de venda do produto, de modo que o aumento deste gera como conseqüência o aumento do valor do incentivo, enquanto que os custos logísticos não sofrem impacto algum.

Como o aumento de margem potencializa o ganho de incentivo fiscal, um fato interessante que se observa nos cenários de variação de margem considerando-se incentivo fiscal oferecido pelo estado de $\mathrm{MG}$ é o aumento do valor de débito de ICMS no CD MG, conforme se pode observar na Tabela 25 a seguir. Este aumento no débito é utilizado para poder conseguir-se um maior montante de incentivo fiscal respeitando-se a restrição de não acumular crédito de ICMS no CD.

Tabela 25. Montante de incentivo fiscal, saldo, crédito e débito de ICMS correspondente ao CD MG em cada um dos cenários de variação da margem dos produtos considerando-se incentivo fiscal oferecido pelo estado de MG.

\begin{tabular}{|c|c|c|c|c|}
\hline \multirow{2}{*}{ CENÁRIO } & \multicolumn{4}{|c|}{ MONTANTE DE ICMS ASSOCIADO AO CD MG (MMR\$) } \\
\hline & Saldo & Crédito & Débito & Incentivo \\
\hline Fiscal MG ( $50 \%)$ & 0,00 & 6,52 & $(11,90)$ & 5,38 \\
\hline Fiscal MG ( $100 \%)$ & 0,00 & 14,96 & $(34,00)$ & 19,04 \\
\hline Fiscal MG $(150 \%)$ & 0,00 & 27,55 & $(74,71)$ & 47,16 \\
\hline Fiscal MG Inicial $=(200 \%)$ & 0,00 & 39,26 & $(112,24)$ & 72,98 \\
\hline Fiscal MG $(250 \%)$ & 0,00 & 56,54 & $(170,03)$ & 113,48 \\
\hline Fiscal MG $(300 \%)$ & 0,00 & 63,67 & $(205,25)$ & 141,58 \\
\hline Fiscal MG $(350 \%)$ & 0,00 & 66,58 & $(229,42)$ & 162,83 \\
\hline Fiscal MG $(400 \%)$ & 0,00 & 66,73 & $(248,17)$ & 181,45 \\
\hline Fiscal MG $(500 \%)$ & $(8,83)$ & 66,73 & $(293,30)$ & 217,74 \\
\hline
\end{tabular}

\subsection{GRUPO de ANÁlise C: NÍVEL DE SERVIÇO}

Para avaliar o impacto que restrições de nível de serviço geram nos Cenários Base, Fiscal GO e Fiscal MG, inseriram-se no modelo matemático as restrições de nível de serviço conforme especificado no capítulo referente à definição dos parâmetros do modelo. Definiu-se que, para os mercados de maior demanda, que na curva $A B C$ representam $30 \%$ do volume total demandado, as entregas devem ser realizadas em até um dia (distância de até $500 \mathrm{~km}$ ), enquanto que para os mercados com volume 
intermediário de demanda, suficiente para completar $40 \%$ de todo o volume demandado, definiu-se como prazo de entrega dois dias (distância até $750 \mathrm{~km}$ ).

A Tabela 26, a seguir, apresenta a relação dos mercados aos quais foi associada restrição de nível de serviço:

Tabela 26. Relação dos mercados aos quais associou-se restrição de nível de serviço.

\begin{tabular}{lcccc}
\hline \multicolumn{1}{c}{$\begin{array}{c}\text { Mercado } \\
\text { (Nome da Meso-região) }\end{array}$} & $\begin{array}{c}\text { Demanda } \\
\text { anual (t) }\end{array}$ & $\begin{array}{c}\% \text { da demanda } \\
\text { no total } \\
\text { demandado }\end{array}$ & $\begin{array}{c}\% \\
\text { Acumulado }\end{array}$ & $\begin{array}{c}\text { Distância máxima } \\
\text { para atendimento }\end{array}$ \\
\hline Metropolitana de São Paulo & 86.332 & $13 \%$ & $13 \%$ & $500 \mathrm{~km}$ \\
\hline Metropolitana do Rio de Janeiro & 47.085 & $7 \%$ & $20 \%$ & $500 \mathrm{~km}$ \\
\hline Metropolitana de Belo Horizonte & 18.264 & $3 \%$ & $23 \%$ & $500 \mathrm{~km}$ \\
\hline Centro Goiano & 14.907 & $2 \%$ & $25 \%$ & $500 \mathrm{~km}$ \\
\hline Metropolitana de Porto Alegre & 11.980 & $2 \%$ & $27 \%$ & $500 \mathrm{~km}$ \\
\hline Metropolitana de Curitiba & 10.821 & $2 \%$ & $28 \%$ & $500 \mathrm{~km}$ \\
\hline Norte Central Paranaense & 8.307 & $1 \%$ & $30 \%$ & $500 \mathrm{~km}$ \\
\hline Metropolitana de Salvador & 8.023 & $1 \%$ & $31 \%$ & $750 \mathrm{~km}$ \\
\hline Central Espírito-Santense & 7.834 & $1 \%$ & $32 \%$ & $750 \mathrm{~km}$ \\
\hline Sul/Sudoeste de Minas & 7.193 & $1 \%$ & $33 \%$ & $750 \mathrm{~km}$ \\
\hline Metropolitana de Recife & 7.184 & $1 \%$ & $34 \%$ & $750 \mathrm{~km}$ \\
\hline Triângulo Mineiro/Alto Paranaí & 7.129 & $1 \%$ & $35 \%$ & $750 \mathrm{~km}$ \\
\hline São José do Rio Preto & 6.967 & $1 \%$ & $36 \%$ & $750 \mathrm{~km}$ \\
\hline Campinas & 6.869 & $1 \%$ & $37 \%$ & $750 \mathrm{~km}$ \\
\hline Macro Metropolitana Paulista & 6.796 & $1 \%$ & $38 \%$ & $750 \mathrm{~km}$ \\
\hline Ribeirão Preto & 6.537 & $1 \%$ & $39 \%$ & $750 \mathrm{~km}$ \\
\hline Noroeste Goiano & 6.059 & $1 \%$ & $40 \%$ & $750 \mathrm{~km}$ \\
\hline & $\mathbf{2 6 8 . 2 8 7}$ & $\mathbf{4 0 \%}$ & $\mathbf{4 0 \%}$ & \\
\hline & & & &
\end{tabular}

As Figuras 27 a 29 bem como as Tabelas 27 a 29 apresentam os fluxos de distribuição ótimos gerados para os Cenários Base, Fiscal GO e Fiscal MG com restrições de nível de serviço. 


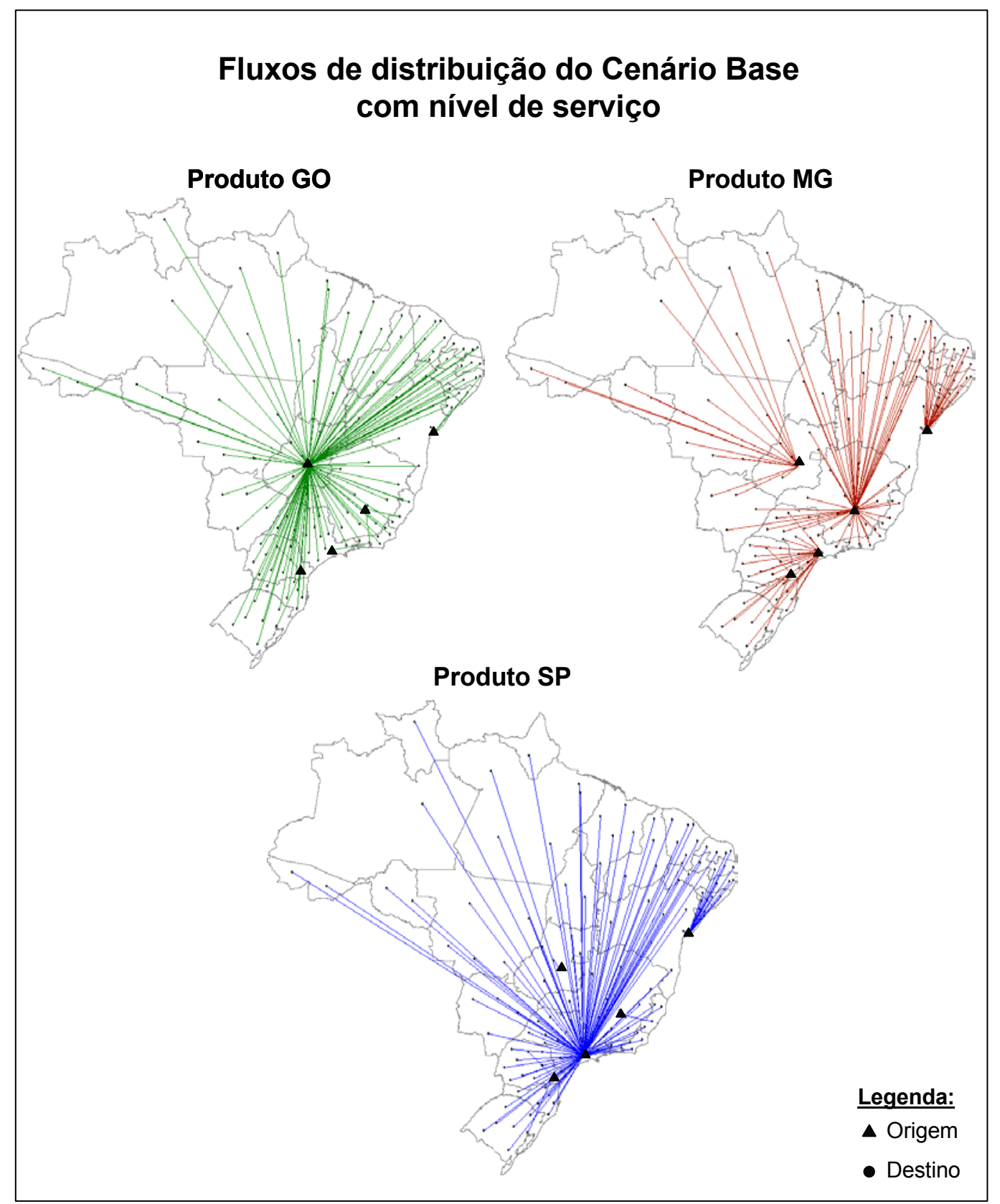

Figura 27. Fluxos de distribuição do Cenário Base com restrição de nível de serviço. 


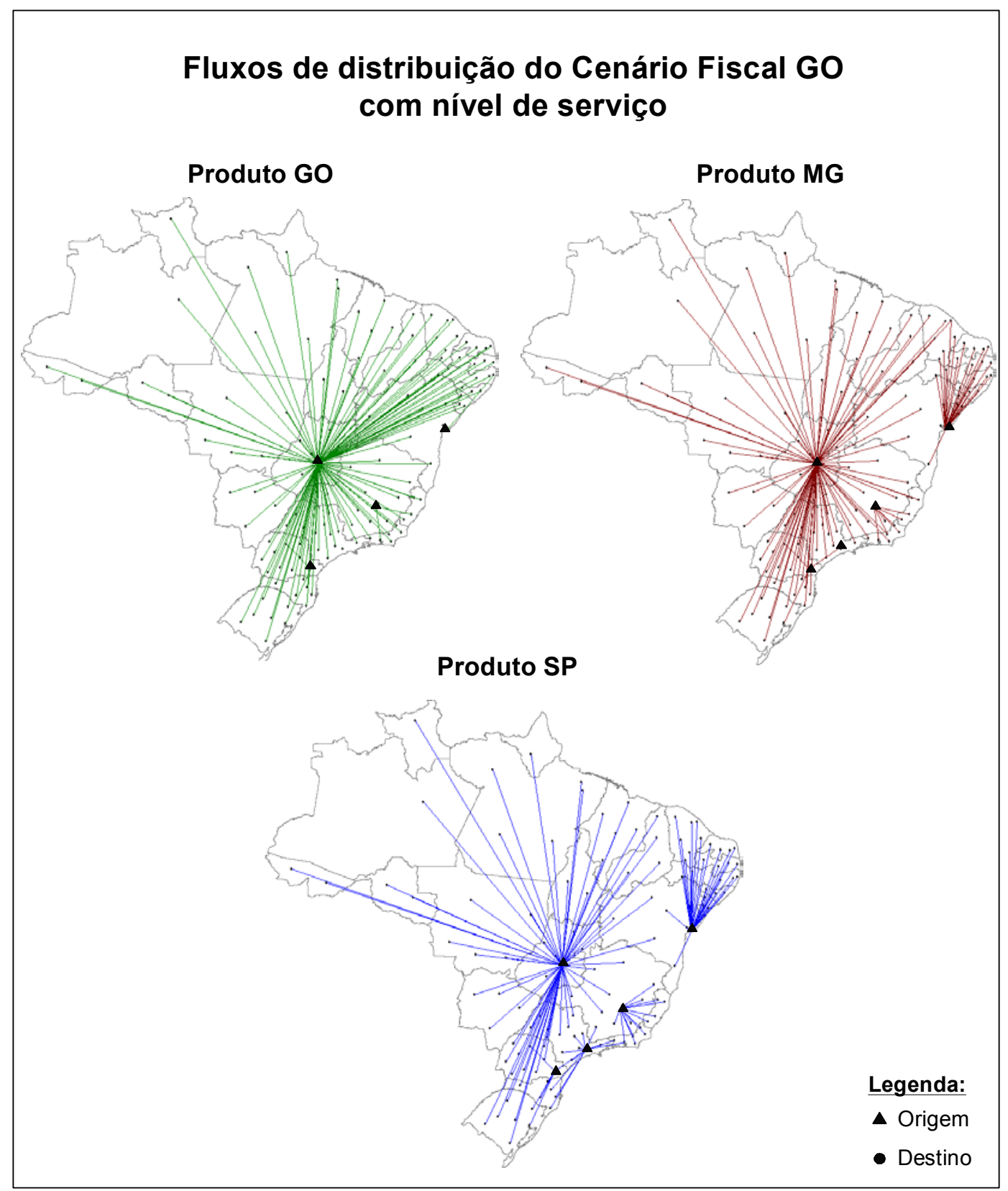

Figura 28. Fluxos de distribuição do Cenário Fiscal GO com restrição de nível de serviço. 


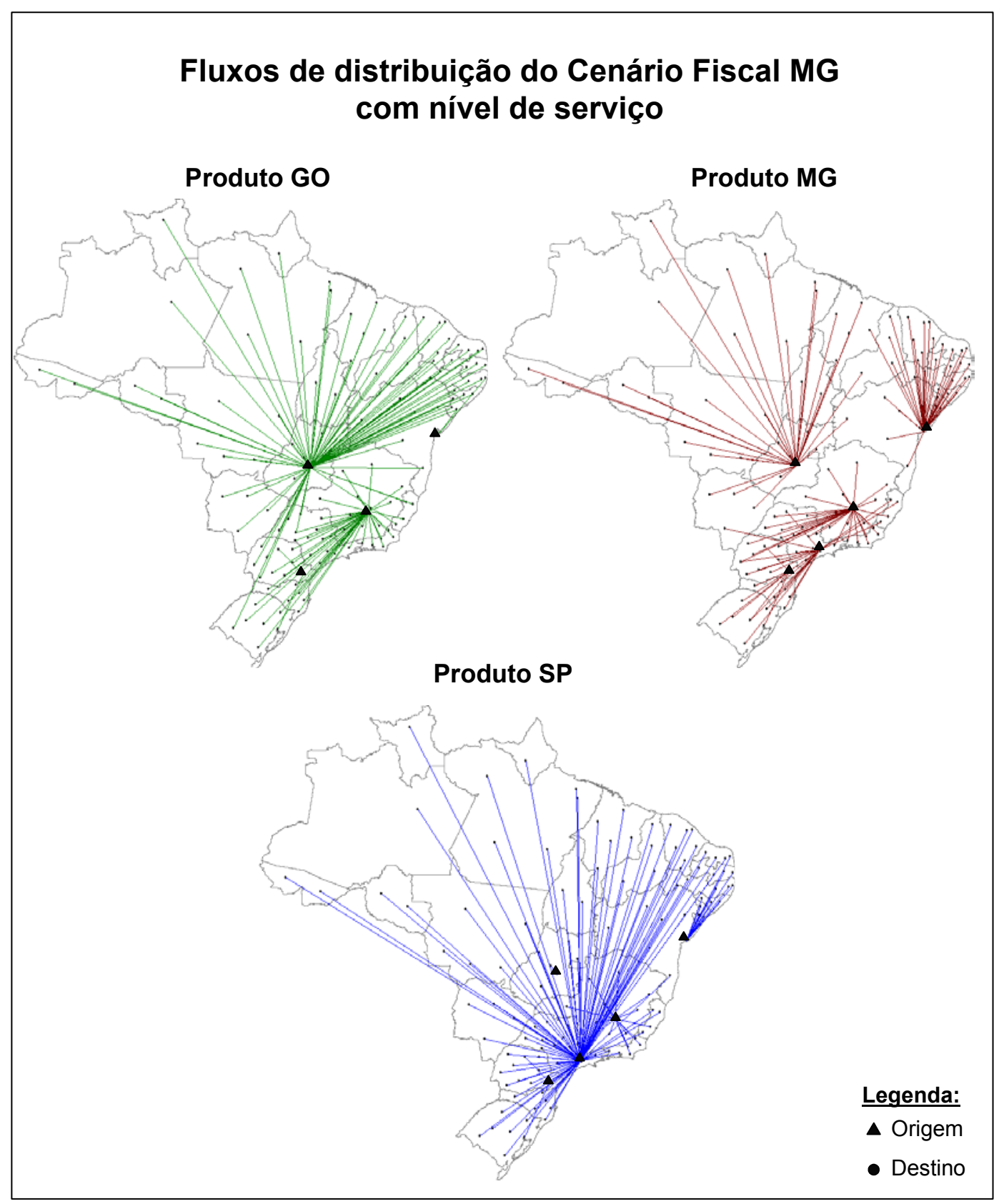

Figura 29. Fluxos de distribuição do Cenário Fiscal MG com restrição de nível de serviço. 
Tabela 27. Fluxos de transferência do Cenário Base com Nível de Serviço.

\begin{tabular}{lccc}
\hline $\begin{array}{l}\text { Orientação do fluxo } \\
\text { (Origem --> Destino) }\end{array}$ & PD_GO & $\begin{array}{c}\text { Volume (t) } \\
\text { PD_MG }\end{array}$ & PD_SP \\
\hline FA_GO --> CD_BA & 11.533 & - & - \\
FA_GO --> CD_GO & 115.825 & - & - \\
FA_GO --> CD_MG & 38.046 & - & - \\
FA_GO --> CD_PR & 18.497 & - & - \\
FA_GO --> CD_SP & 55.236 & - & - \\
FA_MG --> CD_BA & - & 7.720 & - \\
FA_MG --> CD_GO & - & 11.670 & - \\
FA_MG --> CD_MG & - & 50.494 & - \\
FA_MG --> CD_PR & - & 10.410 & - \\
FA_MG --> CD_SP & - & 53.554 & - \\
FA_SP --> CD_BA & - & - & 4.747 \\
FA_SP --> CD_GO & - & - & 1.244 \\
FA_SP --> CD_MG & - & - & 1.460 \\
FA_SP --> CD_PR & - & - & 1.093 \\
FA_SP --> CD_SP & - & - & 19.912 \\
TOTAL & $\mathbf{2 3 9 . 1 3 7}$ & $\mathbf{1 3 3 . 8 4 8}$ & $\mathbf{2 8 . 4 5 6}$ \\
\hline
\end{tabular}

Tabela 28. Fluxos de transferência do Cenário Fiscal GO com Nível de Serviço.

\begin{tabular}{|c|c|c|c|}
\hline \multirow{2}{*}{$\begin{array}{l}\text { Orientação do fluxo } \\
\text { (Origem --> Destino) }\end{array}$} & \multicolumn{3}{|c|}{ Volume (t) } \\
\hline & PD_GO & PD_MG & PD_SP \\
\hline FA_GO --> CD_BA & 9.328 & - & - \\
\hline FA_GO $\rightarrow>$ CD_GO & 118.030 & - & - \\
\hline FA_GO --> CD_MG & 43.182 & - & - \\
\hline FA_GO --> CD_PR & 18.497 & - & - \\
\hline FA_GO --> CD_SP & 50.100 & - & - \\
\hline FA_MG --> CD_BA & - & 8.116 & - \\
\hline FA_MG $-->$ CD_GO & - & 52.687 & - \\
\hline FA_MG --> CD_MG & - & 29.044 & - \\
\hline FA_MG $-->$ CD_PR & - & 10.067 & - \\
\hline FA_MG --> CD_SP & - & 33.934 & - \\
\hline FA_SP $\rightarrow$-.> CD_BA & - & - & 6.556 \\
\hline FA_SP --> CD_GO & - & - & 9.283 \\
\hline FA_SP $-->$ CD_MG & - & - & 5.215 \\
\hline FA_SP $\rightarrow$ CD_PR & - & - & 1.436 \\
\hline FA_SP --> CD_SP & - & - & 5.966 \\
\hline TOTAL & 239.137 & 133.848 & 28.456 \\
\hline
\end{tabular}

Tabela 29. Fluxos de transferência do Cenário Fiscal MG com Nível de Serviço.

\begin{tabular}{|c|c|c|c|}
\hline \multirow{2}{*}{$\begin{array}{l}\text { Orientação do fluxo } \\
\text { (Origem --> Destino) }\end{array}$} & \multicolumn{3}{|c|}{ Volume (t) } \\
\hline & PD_GO & PD_MG & PD_SP \\
\hline FA_GO $-->$ CD_BA & 9.599 & - & - \\
\hline FA_GO --> CD_GO & 61.764 & - & - \\
\hline FA_GO $-->$ CD_MG & 99.177 & - & - \\
\hline FA_GO --> CD_PR & 18.497 & - & - \\
\hline FA_GO $\rightarrow$ CD_SP & 50.100 & - & - \\
\hline FA_MG $-->$ CD_BA & - & 9.657 & - \\
\hline FA_MG --> CD_GO & - & 14.767 & - \\
\hline FA_MG $-->$ CD_MG & - & 46.577 & - \\
\hline FA_MG --> CD_PR & - & 10.076 & - \\
\hline FA_MG $\rightarrow$ CD_SP & - & 52.771 & - \\
\hline FA_SP $\rightarrow$-> CD_BA & - & - & 4.744 \\
\hline FA_SP $\rightarrow$ CD_GO & - & - & 1.244 \\
\hline FA_SP $-->$ CD_MG & - & - & 4.246 \\
\hline FA_SP --> CD_PR & - & - & 1.093 \\
\hline FA_SP $-->$ CD_SP & - & - & 17.129 \\
\hline TOTAL & 239.137 & 133.848 & 28.456 \\
\hline
\end{tabular}


Verifica-se que, para atender às restrições de nível de serviço, foram abertos, além dos CDs localizados nos estados em que há instalações industriais, novos CDs nos estados de PR e BA: enquanto que o primeiro fica responsável pelo abastecimento dos três estados da região Sul, o segundo absorve os fluxos para abastecimento da região Nordeste. A Figura 30, a seguir, permite observar a melhora do nível de serviço entre os cenários em que há restrição de nível e os que não há.



Figura 30. Percentual do volume total da demanda entregue por faixa de nível de serviço.

Por meio da Figura 30 é possível observar o significativo aumento do nível de serviço em todos os Cenários com restrição de nível de serviço: verifica-se que em todos os casos que houve um incremento do volume entregue a partir de distâncias inferiores a $500 \mathrm{~km}$ e redução do volume entregue a partir de distâncias superiores a $750 \mathrm{~km}$. No caso do Cenário Base, por exemplo, a concentração do volume total entregue a partir de distâncias inferiores a $500 \mathrm{~km}$ passou de $24 \%$ no Cenário Base sem restrição de nível de serviço para $67 \%$ no Cenário Base NS, enquanto que as entregas realizadas a partir de distâncias superiores a $750 \mathrm{~km}$ concentravam no Cenário Base $47 \%$ do volume e passaram a absorver apenas $22 \%$ do volume no Cenário Base NS.

Se por um lado observa-se uma melhora significativa do nível de serviço nos Cenários que contemplam restrições de nível de serviço, por outro lado, naturalmente 
observa-se um incremento nos custos logísticos e uma redução do benefício físcal capturado nesses Cenários, conforme se pode observar na Figura 31 a seguir:

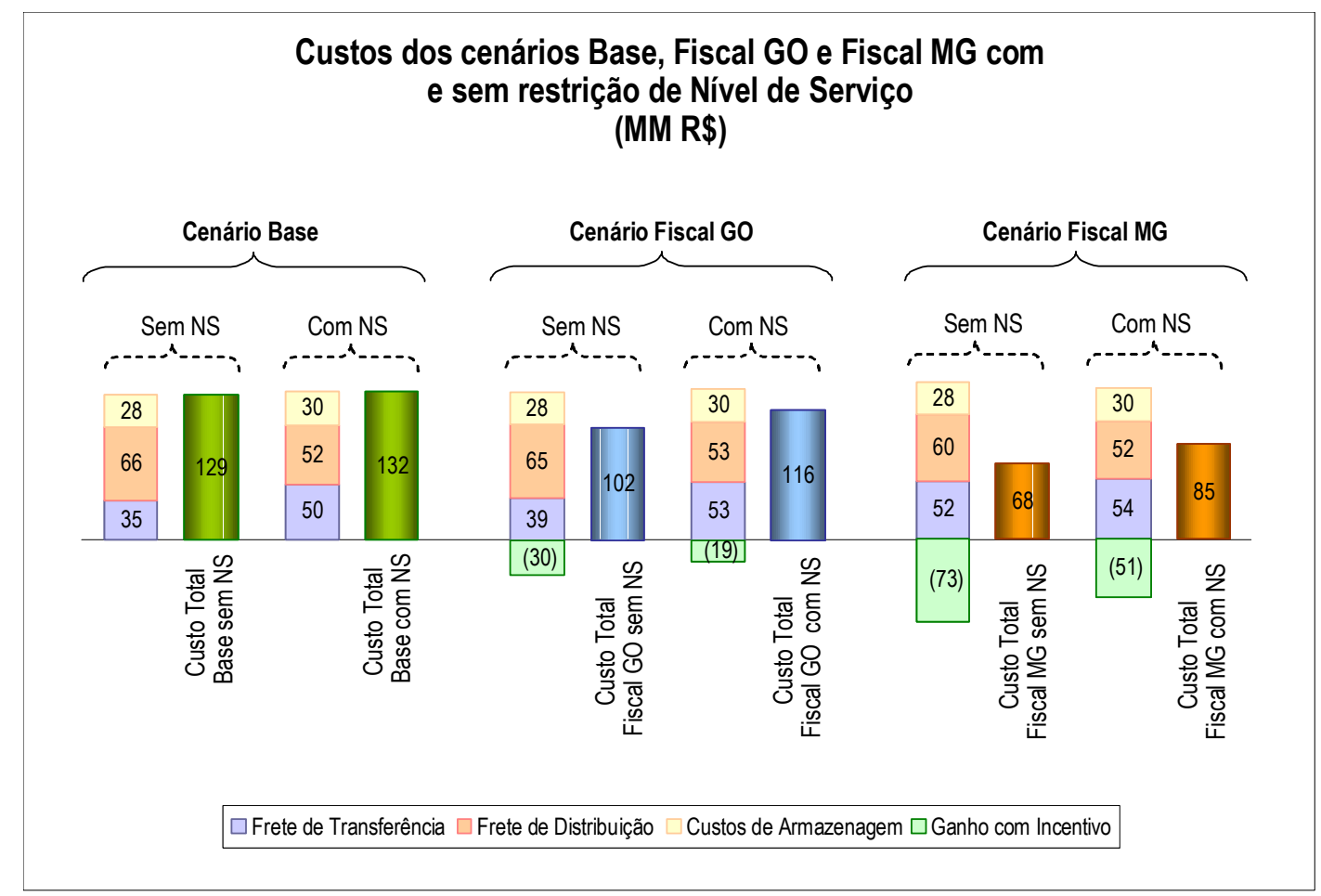

Figura 31. Comparativo de custos dos cenários Base, Fiscal GO e Fiscal MG com e sem restrições de nível de serviço.

A mesma informação apresentada na Figura 31 é também apresentada na Tabela 30 a seguir.

Tabela 30. Comparativo de custos dos cenários Base, Fiscal GO e Fiscal MG com e sem restrições de nível de serviço.

\begin{tabular}{|c|c|c|c|c|c|c|}
\hline & & $\begin{array}{c}\text { Frete de } \\
\text { transferência } \\
\text { (MMR\$) }\end{array}$ & $\begin{array}{c}\text { Frete de } \\
\text { distribuição } \\
\text { (MMR\$) } \\
\end{array}$ & $\begin{array}{c}\text { Custo de } \\
\text { armazenagem } \\
\text { (MMR\$) }\end{array}$ & $\begin{array}{c}\text { Ganho com } \\
\text { incentivo } \\
\text { (MMR\$) } \\
\end{array}$ & $\begin{array}{l}\text { Custo Total } \\
\text { (MMR\$) }\end{array}$ \\
\hline \multirow{2}{*}{. 을 } & Sem restrição de NS & 35,42 & 65,75 & 28,08 & - & 129,24 \\
\hline & Com restrição de NS & 49,81 & 52,35 & 29,75 & - & 131,91 \\
\hline \multirow{2}{*}{ 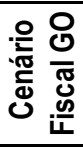 } & Sem restrição de NS & 38,67 & 65,11 & 28,20 & $-30,36$ & 101,63 \\
\hline & Com restrição de NS & 52,66 & 52,68 & 29,95 & $-18,86$ & 116,43 \\
\hline \multirow{2}{*}{.은 } & Sem restrição de NS & 52,27 & 60,12 & 28,22 & $-72,98$ & 67,63 \\
\hline & Com restrição de NS & 54,24 & 51,99 & 29,75 & $-51,00$ & 84,99 \\
\hline
\end{tabular}


Comparando-se os custos dos cenários com e sem restrições de nível de serviço, verifica-se que a inclusão de restrições de nível de serviço implicou em um custo total adicional de 2,1\% no caso do Cenário Base, de 14,6\% no caso de Cenário Fiscal GO e de 25,7\% no caso do Cenário Fiscal MG. É interessante observar que este incremento dos custos está relacionado parte ao aumento dos custos logísticos, mas principalmente ao incentivo que se deixa de capturar, conforme mostra a Tabela 31 a seguir.

Tabela 31. Comparativo da variação dos custos logísticos e do incentivo fiscal capturado nos cenários Base, Fiscal GO e Fiscal MG com e sem restrições de nível de serviço.

\begin{tabular}{|c|c|c|c|}
\hline & & $\begin{array}{l}\text { Custo logístico } \\
\text { (MM R\$) }\end{array}$ & $\begin{array}{l}\text { Incentivo fiscal } \\
\text { capturado } \\
\text { (MMR\$) }\end{array}$ \\
\hline \multirow{3}{*}{ 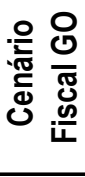 } & Sem restrição de NS & 131,99 & $-30,36$ \\
\hline & Com restrição de NS & 135,29 & $-18,86$ \\
\hline & Variação \% Fiscal GO NS vs. Fiscal GO & $2,50 \%$ & $-37,88 \%$ \\
\hline \multirow{3}{*}{ 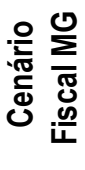 } & Sem restrição de NS & 140,61 & $-72,98$ \\
\hline & Com restrição de NS & 135,98 & $-51,00$ \\
\hline & Variação \% Fiscal MG NS vs. Fiscal MG & $-3,29 \%$ & $-30,12 \%$ \\
\hline
\end{tabular}

\subsection{GRUPO DE ANÁliSE D: RESTRIÇÃo DE FLUXO MÍNIMO NOS CDS}

Para verificar o impacto que a imposição de fluxos mínimo de movimentação nos CDs gera nos resultados dos Cenários Base, Fiscal GO e Fiscal MG, alterou-se o valor do parâmetro $F_{M I N}$ do modelo matemático de 0,80 para 0 . Desse modo, a restrição de número (5) ficou da seguinte maneira:

- Restrição de fluxo mínimo no $\mathrm{CD} j$ com capacidade $n$

$\sum_{i} \sum_{p} \operatorname{Trns}_{i j p} \geq \sum_{n} Z_{j n} \times F_{M I N} \times \operatorname{CapCD}_{j n} \quad \forall j, \forall n$

Se $F_{\text {MIN }}=0$, então $\sum_{i} \sum_{p} \operatorname{Trns}_{i j p} \geq 0$

Ao se rodar os cenários Base, Fiscal GO e Fiscal MG com o valor da constante $F_{M I N}$ equivalente a zero, os resultados obtidos foram idênticos aos cenários originais (em 
que o valor do parâmetro equivale a 0,8 ), o que indica que para estes cenários a restrição (5) do modelo matemático não é ativa.

A Tabela 32 a seguir mostra que para estes cenários a ocupação mínima verificada em um CD foi equivalente a $82 \%$, no caso do CD SP no Cenário Fiscal GO.

Tabela 32. Percentual de ocupação dos CDs nos Cenários Base, Fiscal GO e Fiscal MG sem restrição de ocupação mínima nos CDs.

\begin{tabular}{|c|c|c|c|c|c|c|c|}
\hline CD SP & CD MG & CD PR & CD RS & CD GO & CD BA & CD PE & TOTAL \\
\hline
\end{tabular}

\begin{tabular}{|c|c|c|c|c|c|c|c|c|c|}
\hline \multirow{3}{*}{ 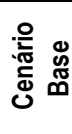 } & Capacidade ( $\mathrm{t}$ / ano) & 30.000 & 150.000 & - & - & 225.000 & - & - & 405.000 \\
\hline & Fluxo (t) & 30.000 & 146.441 & - & - & 225.000 & - & - & 401.441 \\
\hline & $\%$ de ocupação do CD & $100 \%$ & $98 \%$ & - & - & $100 \%$ & - & - & $99 \%$ \\
\hline \multirow{3}{*}{ 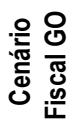 } & Capacidade ( $\mathrm{t}$ / ano) & 30.000 & 90.000 & - & - & 300.000 & - & - & 420.000 \\
\hline & Fluxo (t) & 24.582 & 76.859 & - & - & 300.000 & - & - & 401.441 \\
\hline & $\%$ de ocupação do $C D$ & $82 \%$ & $85 \%$ & - & - & $100 \%$ & - & - & $96 \%$ \\
\hline \multirow{3}{*}{ 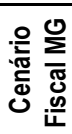 } & Capacidade ( $\mathrm{t} / \mathrm{ano}$ ) & 90.000 & 225.000 & - & - & 90.000 & - & - & 405.000 \\
\hline & Fluxo (t) & 90.000 & 225.000 & - & - & 86.441 & - & - & 401.441 \\
\hline & $\%$ de ocupação do $C D$ & $100 \%$ & $100 \%$ & - & - & $96 \%$ & - & - & $99 \%$ \\
\hline
\end{tabular}

\subsection{CONCLUSÕES do CAPítulo}

As principais conclusões obtidas a partir das análises realizadas ao longo deste capítulo são as seguintes:

- Grupo de Análise A: relação do custo logístico vs. incentivo fiscal. A análise de sensibilidade realizada com a variação do preço dos produtos mostrou que, para valores menores de preço o fator logístico passa a preponderar sobre o fator fiscal na decisão da malha logística ótima, conforme já se esperava. Um indicativo deste efeito consiste na redução da capacidade proposta para os CDs localizados nos estados que ofereciam benefícios fiscais quando houve a queda dos preços dos produtos.

- Grupo de Análise B: relação do Saldo de ICMS vs. Incentivo Fiscal. Alterando-se a margem de venda do produto foi possível verificar que o saldo de ICMS é um limitante na captura de incentivos fiscais em algumas das instalações quando as margens de venda são elevadas. 
- Grupo de Análise C: impacto do nível de serviço. Verificou-se por meio das análises que restrições de nível de serviço penalizam de maneira mais intensa a captura de incentivos fiscais do que a questão logística, traduzida pelo incremento dos custos de frete de transferência e de distribuição e também pelos custos de armazenagem.

- Grupo de Análise D: impacto da restrição de fluxo mínimo nos CDs. Para os parâmetros do problema formulado a restrição de fluxo mínimo nos CDs não esteve ativa nos Cenários Base, Fiscal GO e Fiscal MG, de modo que a atribuição do valor zero ao parâmetro que determina fluxo mínimo nos CDs não apresentou qualquer efeito sobre a solução gerada por meio da aplicação do modelo a estes cenários. 


\section{CONSIDERAÇÕES FINAIS}

Para a elaboração desta dissertação propôs-se como objetivo desenvolver um modelo matemático que determine uma logística de menor custo considerando incentivos fiscais baseados no crédito presumido do ICMS, que seja capaz de avaliar, portanto, os tradeoffs entre custos logísticos (transporte + armazenagem) e a redução no saldo de ICMS a pagar proporcionada por este tipo de benefício. A aplicação deste modelo a situações realísticas e a análise dos resultados obtidos também foram propostos como objetivos a serem alcançados.

Conclui-se, portanto, que os objetivos apresentados foram alcançados. Por meio da aplicação do modelo matemático desenvolvido nesta dissertação a um caso estruturado com parâmetros reais pôde-se observar que os incentivos fiscais baseados no crédito presumido do ICMS exercem grande impacto na decisão de fluxos de rede otimizados. Desse modo, demonstrou-se, mais uma vez, que associar planejamento tributário ao planejamento logístico é de suma importância para obter-se a otimização de uma rede de distribuição física.

Quanto às conclusões obtidas por meio das análises, que demonstraram o potencial dos incentivos fiscais na redução do montante de imposto devido pelas empresas, é válido colocar que as alterações geradas na malha logística para possibilitar uma maior captura destes incentivos geram incrementos de custos logísticos diretamente relacionados ao incremento do custo Brasil. Isto porque estes custos adicionais, gerados principalmente em função do incremento do transporte, referem-se ao maior consumo de combustível e ao maior desgaste de pneus e mesmo das rodovias nacionais.

Em comparação com o Cenário Base, por exemplo, para cada R \$1,00 que se ganha de incentivo fiscal no Cenário GO se gasta $\mathrm{R} \$ 0,09$ de custos logísticos. No caso do Cenário MG, cada R\$1,00 ganho de incentivo implica em um gasto de R\$0,16. Enfim, trata-se de incremento de custos reais para se obter ganhos monetários puramente fiscais. 


\subsection{SUGESTÕes PARA ESTUdOS FUTUROS}

Como sugestão para a continuidade dos estudos iniciados neste trabalho propõem-se as seguintes alternativas:

- Análise de incentivos fornecidos por estados diferentes daqueles em que estão situadas as fábricas. No problema formulado para esta dissertação as duas fábricas à que cabiam a produção dos maiores volumes estavam localizadas cada uma em um dos estados que fornecia benefício fiscal. A análise de cenários que não consideram esta premissa pode gerar resultados interessantes, visto que o aumento da distância a ser percorrida entre o local de produção e o CD de distribuição gerará incrementos de custos logísticos superiores aos gerados nos cenários avaliados neste estudo.

- Análise de casos em que as fábricas produzam qualquer um dos produtos considerados. Para o caso analisado, cada fábrica produzia apenas um produto. Analisar um caso em que cada fábrica produza qualquer um dos produtos considerados, de modo que caiba ao modelo decidir qual volume de produção será alocado a cada fábrica, pode gerar resultados interessantes.

- Análise da oferta simultânea de incentivos por mais de um estado. Todos os cenários considerados para o presente estudo consideravam ou o fornecimento de incentivo em um estado ou em outro, de modo que a oferta simultânea dos incentivos não foi considerada.

- Formulação de um modelo matemático que contemple outros tipos de incentivos fiscais. $\mathrm{O}$ foco deste estudo esteve nos incentivos baseados no crédito presumido de ICMS. Entretanto, outros incentivos fiscais também poderão ser considerados para futuros estudos. 


\section{GLOSSÁRIO}

SIGLAS

COFINS.......... Contribuição para FINSOCIAL.

CONFAZ....... Conselho Nacional de Política Fazendária.

CTN............... Código Tributário Nacional.

FGTS............ Fundo de Garantia por Tempo de Serviço.

ICMS............. Imposto sobre a Circulação de Mercadorias e Serviços de Transporte Interestaduais, Intermunicipais ou de Telecomunicações.

INSS............. Instituto Nacional de Seguridade Social.

II..................... Imposto sobre Importação.

IOF..................Imposto sobre Operações Financeiras.

IPI.................. Imposto sobre Produtos Industrializados.

IPVA.............. Imposto sobre a Propriedade de Veículos Automotivos.

NF................. Nota Fiscal.

PIB ................Produto Interno Bruto.

PIS............... Contribuição para o Programa de Integração Social.

PLIM..............Programação Linear Inteira Mista.

\section{EXPRESSÕES E TERMOS TÉCNICOS}

Base de cálculo.......... É o valor sobre o qual se aplica a taxa do imposto. No caso estudado, a base de cálculo para determinar tanto o valor do imposto devido quanto o benefício auferido é o valor dos produtos informado na NF: valor de produção no caso das transferências e valor de venda, já se incluindo a margem de venda, no caso das vendas.

CIF.......................... Cost Insurance Freight. Originalmente é um termo utilizado para designar modalidades de contrato em comércio exterior. Para este estudo a definição de CIF utilizada considera que a 
providência e o custo do transporte até o ponto de destino da mercadoria ficam por conta do emitente da mercadoria.

Fato gerador................É a situação definida em lei que enseja a cobrança de tributo. No caso estudado, o fato gerador do ICMS são as operações de venda e de transferência de produtos.

FOB...........................Free on Board. Originalmente é um termo utilizado para designar modalidades de contrato em comércio exterior. Neste estudo a definição de FOB utilizada considera que o custo do transporte do emitente até o ponto de destino da mercadoria fica por conta do destinatário da mercadoria.

Tradeoff .................... Compensação. 


\section{APÊNDICE A. TABELA DE ALÍQUOTAS DE ICMS}

\section{PORCENTUAIS DE INCIDÊNCIA DE ICMS SOBRE O PRODUTO ENTRE ESTADOS}

\begin{tabular}{|c|c|c|c|c|c|c|c|c|c|c|c|c|c|c|c|c|c|c|c|c|c|c|c|c|c|c|c|}
\hline \multirow[b]{2}{*}{ UF } & \multicolumn{27}{|c|}{ DESTINO } \\
\hline & $\mathrm{AC}$ & $\mathrm{AL}$ & AP & $\mathrm{AM}$ & $\mathrm{BA}$ & CE & $\mathrm{DF}$ & ES & GO & $\mathrm{MA}$ & MT & MS & MG & PA & PB & PR & $\mathrm{PE}$ & $\mathrm{Pl}$ & $\mathrm{RJ}$ & $\mathrm{RN}$ & RS & $\mathrm{RO}$ & $\mathrm{RR}$ & SC & SP & SE & TO \\
\hline \multirow{27}{*}{ 䎡 } & 17 & 12 & 12 & 12 & 12 & 12 & 12 & 12 & 12 & 12 & 12 & 12 & 12 & 12 & 12 & 12 & 12 & 12 & 12 & 12 & 12 & 12 & 12 & 12 & 12 & 12 & 12 \\
\hline & 12 & 17 & 12 & 12 & 12 & 12 & 12 & 12 & 12 & 12 & 12 & 12 & 12 & 12 & 12 & 12 & 12 & 12 & 12 & 12 & 12 & 12 & 12 & 12 & 12 & 12 & 12 \\
\hline & 12 & 12 & 17 & 12 & 12 & 12 & 12 & 12 & 12 & 12 & 12 & 12 & 12 & 12 & 12 & 12 & 12 & 12 & 12 & 12 & 12 & 12 & 12 & 12 & 12 & 12 & 12 \\
\hline & 12 & 12 & 12 & 17 & 12 & 12 & 12 & 12 & 12 & 12 & 12 & 12 & 12 & 12 & 12 & 12 & 12 & 12 & 12 & 12 & 12 & 12 & 12 & 12 & 12 & 12 & 12 \\
\hline & 12 & 12 & 12 & 12 & 17 & 12 & 12 & 12 & 12 & 12 & 12 & 12 & 12 & 12 & 12 & 12 & 12 & 12 & 12 & 12 & 12 & 12 & 12 & 12 & 12 & 12 & 12 \\
\hline & 12 & 12 & 12 & 12 & 12 & 17 & 12 & 12 & 12 & 12 & 12 & 12 & 12 & 12 & 12 & 12 & 12 & 12 & 12 & 12 & 12 & 12 & 12 & 12 & 12 & 12 & 12 \\
\hline & 12 & 12 & 12 & 12 & 12 & 12 & 17 & 12 & 12 & 12 & 12 & 12 & 12 & 12 & 12 & 12 & 12 & 12 & 12 & 12 & 12 & 12 & 12 & 12 & 12 & 12 & 12 \\
\hline & 12 & 12 & 12 & 12 & 12 & 12 & 12 & 17 & 12 & 12 & 12 & 12 & 12 & 12 & 12 & 12 & 12 & 12 & 12 & 12 & 12 & 12 & 12 & 12 & 12 & 12 & 12 \\
\hline & 12 & 12 & 12 & 12 & 12 & 12 & 12 & 12 & 17 & 12 & 12 & 12 & 12 & 12 & 12 & 12 & 12 & 12 & 12 & 12 & 12 & 12 & 12 & 12 & 12 & 12 & 12 \\
\hline & 12 & 12 & 12 & 12 & 12 & 12 & 12 & 12 & 12 & 17 & 12 & 12 & 12 & 12 & 12 & 12 & 12 & 12 & 12 & 12 & 12 & 12 & 12 & 12 & 12 & 12 & 12 \\
\hline & 12 & 12 & 12 & 12 & 12 & 12 & 12 & 12 & 12 & 12 & 17 & 12 & 12 & 12 & 12 & 12 & 12 & 12 & 12 & 12 & 12 & 12 & 12 & 12 & 12 & 12 & 12 \\
\hline & 12 & 12 & 12 & 12 & 12 & 12 & 12 & 12 & 12 & 12 & 12 & 17 & 12 & 12 & 12 & 12 & 12 & 12 & 12 & 12 & 12 & 12 & 12 & 12 & 12 & 12 & 12 \\
\hline & 7 & 7 & 7 & 7 & 7 & 7 & 7 & 7 & 7 & 7 & 7 & 7 & 18 & 7 & 7 & 12 & 7 & 7 & 12 & 7 & 12 & 7 & 7 & 12 & 12 & 7 & 7 \\
\hline & 12 & 12 & 12 & 12 & 12 & 12 & 12 & 12 & 12 & 12 & 12 & 12 & 12 & 17 & 12 & 12 & 12 & 12 & 12 & 12 & 12 & 12 & 12 & 12 & 12 & 12 & 12 \\
\hline & 12 & 12 & 12 & 12 & 12 & 12 & 12 & 12 & 12 & 12 & 12 & 12 & 12 & 12 & 17 & 12 & 12 & 12 & 12 & 12 & 12 & 12 & 12 & 12 & 12 & 12 & 12 \\
\hline & 7 & 7 & 7 & 7 & 7 & 7 & 7 & 7 & 7 & 7 & 7 & 7 & 12 & 7 & 7 & 18 & 7 & 7 & 12 & 7 & 12 & 7 & 7 & 12 & 12 & 7 & \\
\hline & 12 & 12 & 12 & 12 & 12 & 12 & 12 & 12 & 12 & 12 & 12 & 12 & 12 & 12 & 12 & 12 & 17 & 12 & 12 & 12 & 12 & 12 & 12 & 12 & 12 & 12 & 12 \\
\hline & 12 & 12 & 12 & 12 & 12 & 12 & 12 & 12 & 12 & 12 & 12 & 12 & 12 & 12 & 12 & 12 & 12 & 17 & 12 & 12 & 12 & 12 & 12 & 12 & 12 & 12 & 12 \\
\hline & 8 & 8 & 8 & 8 & 8 & 8 & 8 & 8 & 8 & 8 & 8 & 8 & 13 & 8 & 8 & 13 & 8 & 8 & 19 & 8 & 13 & 8 & 8 & 13 & 13 & 8 & 8 \\
\hline & 12 & 12 & 12 & 12 & 12 & 12 & 12 & 12 & 12 & 12 & 12 & 12 & 12 & 12 & 12 & 12 & 12 & 12 & 12 & 17 & 12 & 12 & 12 & 12 & 12 & 12 & 12 \\
\hline & 7 & 7 & 7 & 7 & 7 & 7 & 7 & 7 & 7 & 7 & 7 & 7 & 12 & 7 & 7 & 12 & 7 & 7 & 12 & 7 & 17 & 7 & 7 & 12 & 12 & 7 & 7 \\
\hline & 12 & 12 & 12 & 12 & 12 & 12 & 12 & 12 & 12 & 12 & 12 & 12 & 12 & 12 & 12 & 12 & 12 & 12 & 12 & 12 & 12 & 17 & 12 & 12 & 12 & 12 & 12 \\
\hline & 12 & 12 & 12 & 12 & 12 & 12 & 12 & 12 & 12 & 12 & 12 & 12 & 12 & 12 & 12 & 12 & 12 & 12 & 12 & 12 & 12 & 12 & 17 & 12 & 12 & 12 & 12 \\
\hline & 7 & 7 & 7 & 7 & 7 & 7 & 7 & 7 & 7 & 7 & 7 & 7 & 12 & 7 & 7 & 12 & 7 & 7 & 12 & 7 & 12 & 7 & 7 & 17 & 12 & 7 & 7 \\
\hline & 7 & 7 & 7 & 7 & 7 & 7 & 7 & 7 & 7 & 7 & 7 & 7 & 12 & 7 & 7 & 12 & 7 & 7 & 12 & 7 & 12 & 7 & 7 & 12 & 18 & 7 & 7 \\
\hline & 12 & 12 & 12 & 12 & 12 & 12 & 12 & 12 & 12 & 12 & 12 & 12 & 12 & 12 & 12 & 12 & 12 & 12 & 12 & 12 & 12 & 12 & 12 & 12 & 12 & 17 & 12 \\
\hline & 12 & 12 & 12 & 12 & 12 & 12 & 12 & 12 & 12 & 12 & 12 & 12 & 12 & 12 & 12 & 12 & 12 & 12 & 12 & 12 & 12 & 12 & 12 & 12 & 12 & 12 & 17 \\
\hline
\end{tabular}




\section{APÊNDICE B. TABELA DE DEMANDA POR PRODUTO E POR MERCADO}

\begin{tabular}{|c|c|c|c|c|c|}
\hline \multirow{2}{*}{ UF } & \multirow{2}{*}{ Nome da meso-região } & \multicolumn{4}{|c|}{ Demanda (toneladas) } \\
\hline & & PD_GO & PD_MG & PD_SP & Total \\
\hline$A C$ & VALE DO JURUA & 40 & 6 & 4 & 50 \\
\hline$A C$ & VALE DO ACRE & 545 & 139 & 56 & 740 \\
\hline$A L$ & SERTAO ALAGOANO & 456 & 195 & 426 & 1.077 \\
\hline AL & AGRESTE ALAGOANO & 464 & 61 & 183 & 708 \\
\hline AL & LESTE ALAGOANO & 746 & 155 & 314 & 1.215 \\
\hline AM & CENTRO AMAZONENSE & 3.943 & 1.001 & 336 & 5.280 \\
\hline AP & SUL DO AMAPA & 698 & 111 & 64 & 873 \\
\hline BA & EXTREMO OESTE BAIANO & 123 & 30 & 43 & 196 \\
\hline BA & VALE SAO-FRANCISCANO DA BAHIA & 198 & 94 & 120 & 412 \\
\hline BA & CENTRO NORTE BAIANO & 1.212 & 194 & 227 & 1.633 \\
\hline BA & NORDESTE BAIANO & 151 & 49 & 13 & 213 \\
\hline BA & METROPOLITANA DE SALVADOR & 5.466 & 1.722 & 835 & 8.023 \\
\hline BA & CENTRO SUL BAIANO & 923 & 479 & 224 & 1.626 \\
\hline$B A$ & SUL BAIANO & 716 & 237 & 122 & 1.075 \\
\hline CE & NOROESTE CEARENSE & 148 & 56 & 26 & 230 \\
\hline CE & NORTE CEARENSE & 22 & 7 & 4 & 33 \\
\hline CE & METROPOLITANA DE FORTALEZA & 2.792 & 1.152 & 867 & 4.811 \\
\hline CE & SERTOES CEARENSES & 70 & 22 & 12 & 104 \\
\hline CE & JAGUARIBE & 39 & 14 & 3 & 56 \\
\hline CE & CENTRO-SUL CEARENSE & 44 & 44 & 23 & 111 \\
\hline CE & SUL CEARENSE & 243 & 240 & 258 & 741 \\
\hline ES & NOROESTE ESPIRITO-SANTENSE & 1.646 & 1.334 & 544 & 3.524 \\
\hline ES & LITORAL NORTE ESPIRITO-SANTENS & 315 & 235 & 50 & 600 \\
\hline ES & CENTRAL ESPIRITO-SANTENSE & 4.104 & 3.164 & 566 & 7.834 \\
\hline ES & SUL ESPIRITO-SANTENSE & 164 & 122 & 22 & 308 \\
\hline GO & NOROESTE GOIANO & 3.426 & 2.381 & 251 & 6.058 \\
\hline GO & NORTE GOIANO & 12 & 4 & 1 & 17 \\
\hline GO & CENTRO GOIANO & 10.191 & 3.472 & 1.244 & 14.907 \\
\hline GO & LESTE GOIANO & 205 & 43 & 9 & 257 \\
\hline GO & SUL GOIANO & 1.078 & 1.507 & 622 & 3.207 \\
\hline MA & NORTE MARANHENSE & 510 & 175 & 81 & 766 \\
\hline MA & OESTE MARANHENSE & 557 & 164 & 444 & 1.165 \\
\hline MA & CENTRO MARANHENSE & 21 & 2 & 2 & 25 \\
\hline MA & LESTE MARANHENSE & 67 & 8 & 4 & 79 \\
\hline MA & SUL MARANHENSE & 272 & 185 & 122 & 579 \\
\hline MG & NOROESTE DE MINAS & 134 & 39 & 6 & 179 \\
\hline MG & NORTE DE MINAS & 168 & 100 & 16 & 284 \\
\hline MG & VALE DO MUCURI & 76 & 48 & 9 & 133 \\
\hline MG & TRIANGULO MINEIRO/ALTO PARANAI & 3.998 & 2.256 & 874 & 7.128 \\
\hline MG & CENTRAL MINEIRA & 150 & 53 & 7 & 210 \\
\hline MG & METROPOLITANA DE BELO HORIZONT & 12.013 & 5.357 & 894 & 18.264 \\
\hline MG & VALE DO RIO DOCE & 552 & 283 & 32 & 867 \\
\hline MG & OESTE DE MINAS & 1.265 & 380 & 45 & 1.690 \\
\hline MG & SUL/SUDOESTE DE MINAS & 4.176 & 2.184 & 832 & 7.192 \\
\hline MG & CAMPO DAS VERTENTES & 385 & 152 & 32 & 569 \\
\hline MG & ZONA DA MATA & 3.060 & 1.480 & 423 & 4.963 \\
\hline
\end{tabular}


Continuação

\begin{tabular}{|c|c|c|c|c|c|}
\hline \multirow{2}{*}{ UF } & \multirow{2}{*}{ Nome da meso-região } & \multicolumn{4}{|c|}{ Demanda (toneladas) } \\
\hline & & PD_GO & PD_MG & PD_SP & Total \\
\hline MS & PANTANAL SUL MATO-GROSSENSE & 211 & 69 & 26 & 306 \\
\hline MS & CENTRO NORTE DE MATO GROSSO DO & 1.480 & 781 & 350 & 2.611 \\
\hline MS & LESTE DE MATO GROSSO DO SUL & 1.684 & 1.330 & 396 & 3.410 \\
\hline MS & SUDOESTE DE MATO GROSSO DO SUL & 445 & 215 & 71 & 731 \\
\hline MT & NORTE MATO-GROSSENSE & 700 & 489 & 154 & 1.343 \\
\hline MT & NORDESTE MATO-GROSSENSE & 79 & 19 & 6 & 104 \\
\hline MT & SUDOESTE MATO-GROSSENSE & 205 & 70 & 26 & 301 \\
\hline MT & CENTRO-SUL MATO-GROSSENSE & 1.892 & 855 & 190 & 2.937 \\
\hline MT & SUDESTE MATO-GROSSENSE & 321 & 106 & 26 & 453 \\
\hline PA & BAIXO AMAZONAS & 170 & 55 & 38 & 263 \\
\hline PA & METROPOLITANA DE BELEM & 2.194 & 767 & 345 & 3.306 \\
\hline PA & NORDESTE PARAENSE & 22 & 8 & 3 & 33 \\
\hline PA & SUDOESTE PARAENSE & 67 & 28 & 8 & 103 \\
\hline PA & SUDESTE PARAENSE & 389 & 101 & 30 & 520 \\
\hline PB & SERTAO PARAIBANO & 128 & 99 & 58 & 285 \\
\hline PB & BORBOREMA & 9 & 16 & 1 & 26 \\
\hline PB & AGRESTE PARAIBANO & 400 & 315 & 238 & 953 \\
\hline PB & MATA PARAIBANA & 692 & 668 & 366 & 1.726 \\
\hline PE & SERTAO PERNAMBUCANO & 43 & 30 & 9 & 82 \\
\hline PE & SAO FRANCISCO PERNAMBUCANO & 229 & 128 & 112 & 469 \\
\hline PE & AGRESTE PERNAMBUCANO & 593 & 515 & 581 & 1.689 \\
\hline PE & MATA PERNAMBUCANA & 46 & 23 & 24 & 93 \\
\hline PE & METROPOLITANA DE RECIFE & 3.862 & 1.943 & 1.379 & 7.184 \\
\hline $\mathrm{Pl}$ & NORTE PIAUIENSE & 87 & 13 & 31 & 131 \\
\hline $\mathrm{PI}$ & CENTRO-NORTE PIAUIENSE & 546 & 147 & 156 & 849 \\
\hline PI & SUDOESTE PIAUIENSE & 175 & 34 & 30 & 239 \\
\hline PI & SUDESTE PIAUIENSE & 89 & 63 & 39 & 191 \\
\hline PR & NOROESTE PARANAENSE & 185 & 81 & 30 & 296 \\
\hline PR & CENTRO OCIDENTAL PARANAENSE & 61 & 45 & 5 & 111 \\
\hline PR & NORTE CENTRAL PARANAENSE & 5.463 & 2.356 & 488 & 8.307 \\
\hline PR & NORTE PIONEIRO PARANAENSE & 122 & 45 & 9 & 176 \\
\hline PR & CENTRO ORIENTAL PARANAENSE & 273 & 166 & 29 & 468 \\
\hline PR & OESTE PARANAENSE & 2.314 & 1.759 & 386 & 4.459 \\
\hline PR & SUDOESTE PARANAENSE & 523 & 231 & 120 & 874 \\
\hline PR & CENTRO-SUL PARANAENSE & 324 & 205 & 45 & 574 \\
\hline PR & SUDESTE PARANAENSE & 84 & 70 & 20 & 174 \\
\hline PR & METROPOLITANA DE CURITIBA & 6.061 & 4.129 & 631 & 10.821 \\
\hline RJ & NOROESTE FLUMINENSE & 241 & 139 & 35 & 415 \\
\hline RJ & NORTE FLUMINENSE & 867 & 545 & 95 & 1.507 \\
\hline RJ & CENTRO FLUMINENSE & 2.563 & 1.285 & 336 & 4.184 \\
\hline RJ & BAIXADAS & 437 & 387 & 44 & 868 \\
\hline RJ & SUL FLUMINENSE & 1.430 & 689 & 117 & 2.236 \\
\hline RJ & METROPOLITANA DO RIO DE JANEIR & 27.065 & 17.869 & 2.151 & 47.085 \\
\hline RN & OESTE POTIGUAR & 134 & 77 & 14 & 225 \\
\hline $\mathrm{RN}$ & CENTRAL POTIGUAR & 81 & 86 & 61 & 228 \\
\hline $\mathrm{RN}$ & AGRESTE POTIGUAR & 5 & 3 & 2 & 10 \\
\hline RN & LESTE POTIGUAR & 915 & 444 & 230 & 1.589 \\
\hline
\end{tabular}


Continuação

\begin{tabular}{|c|c|c|c|c|c|}
\hline \multirow{2}{*}{ UF } & \multirow{2}{*}{ Nome da meso-região } & \multicolumn{4}{|c|}{ Demanda (toneladas) } \\
\hline & & PD_GO & PD_MG & PD_SP & Total \\
\hline $\mathrm{RO}$ & MADEIRA-GUAPORE & 1.270 & 425 & 225 & 1.920 \\
\hline RO & LESTE RONDONIENSE & 632 & 195 & 57 & 884 \\
\hline $\mathrm{RR}$ & NORTE DE RORAIMA & 231 & 72 & 10 & 313 \\
\hline RS & NOROESTE RIO-GRANDENSE & 2.221 & 1.352 & 323 & 3.896 \\
\hline RS & NORDESTE RIO-GRANDENSE & 936 & 786 & 131 & 1.853 \\
\hline RS & CENTRO OCIDENTAL RIO-GRANDENSE & 499 & 315 & 70 & 884 \\
\hline RS & CENTRO ORIENTAL RIO-GRANDENSE & 421 & 247 & 73 & 741 \\
\hline RS & METROPOLITANA DE PORTO ALEGRE & 6.973 & 4.402 & 605 & 11.980 \\
\hline RS & SUDOESTE RIO-GRANDENSE & 1.036 & 399 & 94 & 1.529 \\
\hline RS & SUDESTE RIO-GRANDENSE & 943 & 512 & 116 & 1.571 \\
\hline SC & OESTE CATARINENSE & 1.532 & 1.200 & 218 & 2.950 \\
\hline SC & NORTE CATARINENSE & 2.052 & 998 & 202 & 3.252 \\
\hline SC & SERRANA & 1.062 & 71 & 10 & 1.143 \\
\hline SC & VALE DO ITAJAI & 1.949 & 1.210 & 226 & 3.385 \\
\hline SC & GRANDE FLORIANOPOLIS & 2.573 & 2.585 & 203 & 5.361 \\
\hline SC & SUL CATARINENSE & 809 & 526 & 76 & 1.411 \\
\hline SE & SERTAO SERGIPANO & 8 & 3 & 3 & 14 \\
\hline SE & AGRESTE SERGIPANO & 102 & 23 & 26 & 151 \\
\hline SE & LESTE SERGIPANO & 1.459 & 332 & 139 & 1.930 \\
\hline SP & SAO JOSE DO RIO PRETO & 5.187 & 1.687 & 93 & 6.967 \\
\hline SP & RIBEIRAO PRETO & 4.924 & 1.364 & 249 & 6.537 \\
\hline SP & ARACATUBA & 946 & 549 & 115 & 1.610 \\
\hline SP & BAURU & 1.851 & 895 & 140 & 2.886 \\
\hline SP & ARARAQUARA & 1.075 & 498 & 68 & 1.641 \\
\hline SP & PIRACICABA & 1.580 & 947 & 110 & 2.637 \\
\hline SP & CAMPINAS & 4.032 & 2.612 & 225 & 6.869 \\
\hline SP & PRESIDENTE PRUDENTE & 1.321 & 699 & 163 & 2.183 \\
\hline SP & MARILIA & 507 & 376 & 46 & 929 \\
\hline SP & ASSIS & 694 & 263 & 58 & 1.015 \\
\hline SP & ITAPETININGA & 916 & 418 & 53 & 1.387 \\
\hline SP & MACRO METROPOLITANA PAULISTA & 3.729 & 2.831 & 236 & 6.796 \\
\hline SP & VALE DO PARAIBA PAULISTA & 1.464 & 1.046 & 100 & 2.610 \\
\hline SP & LITORAL SUL PAULISTA & 235 & 119 & 21 & 375 \\
\hline SP & METROPOLITANA DE SAO PAULO & 50.100 & 33.114 & 3.118 & 86.332 \\
\hline TO & OCIDENTAL DO TOCANTINS & 235 & 102 & 13 & 350 \\
\hline TO & ORIENTAL DO TOCANTINS & 143 & 41 & 8 & 192 \\
\hline
\end{tabular}




\section{BIBLIOGRAFIA}

AMARAL, G.L. OLENIKE, J.E. A insuportável carga tributária empresarial brasileira. Instituto Brasileiro de Planejamento Tributário - IBPT. Curitiba, 2004.

ÁVILA, P.G.P. Estudo do processo de decisão da localização de pontos de distribuição e da competitividade logística de uma indústria de produtos de consumo de massa. 1996. Dissertação (Mestrado) - Faculdade de Economia, Administração e Contabilidade, Universidade de São Paulo.

BALLOU, R.H. Logística Empresarial. São Paulo: Atlas, 1993.

BALLOU, R.H. Business logistics management: planning, organizing and controlling the supply chain. $4^{\mathrm{a}}$ ed. Upper Saddle River: Prentice Hall, 1999.

BALlOU, R.H. Gerenciamento da Cadeia de Suprimentos. Porto Alegre. Bookman, 2001. $4^{\text {a }}$ edição.

BRANDEAU, M.L.; CHIU, S.S. An overview of representative problems in location research. Artigo de periódico. Management Science V. 35, no 6, p. 645674. Junho, 1989.

CHOPRA, S. Designing the distribution network in a supply chain. Artigo de periódico. Transportation Research Part E V.39, p.123-140. 2003.

CONSELHO NACIONAL DE POLÍTICA FAZENDÁRIA (CONFAZ). Convênio ICMS 100/97. Brasília: Ministério da Fazenda, 2004. Disponível em: < https://www.fazenda.gov.br >. Acesso em outubro de 2005.

FERRARI, R. Em busca da paz tributária. São Paulo: R. Ferrari, 1996. 
GEOFFRION, A.M. Better distribution planning with computer models. Artigo de periódico. Harvard Business Review V.54, nº 4, p. 92-99. Jul-ago, 1976.

GEOFFRION, A.M; GRAVES, G.M. Multicommodity distribution system design by Bender's decomposition. Artigo de periódico. Management Science V. 20, $\mathrm{n}^{\circ} 5$, p. 822-844. January, 1974.

GEOFFRION, A.M.; POWERS, R.F. Twenty years of strategic distribution system design: an evolutionary perspective. Artigo de periódico. Interfaces V.25, $\mathrm{n}^{\mathrm{o}}$ 5, p.105-127. Set-out, 1995.

KLOSE; A; DREXL, A. Facility location models for distribution system design. Artigo de periódico. European Journal of Operational Research V.162, p.4-29. 2005.

KOYAMA, A.F.; WEFFORT, C.C.; SESSAK, I.Jr. Direito Tributário. São Paulo: Editora Central de Concursos, 1996. $6^{\text {a }}$ edição.

LATORRACA, N. Legislação tributária: uma introdução ao planejamento tributário: atualizado de acordo com a Lei 6.404 e o Decreto 85.450. São Paulo: Atlas 1982. $8^{\mathrm{a}}$ ed.

Maiores contribuintes de impostos sobre vendas no Brasil no ano de 2004. Portal da Revista Exame. Disponível em: < https://www. portalexame.abril.com.br >. Acesso em novembro de 2005.

MARTOS, A. Projeto de redes logísticas com consideração de estoques e modais: aplicação de programação linear inteira mista à indústria petroquímica. 2000 . Dissertação (Mestrado) - Escola Politécnica, Universidade de São Paulo. São Paulo.

MELO, J.E.S. ICMS - Teoria e prática. São Paulo. Dialética, 2004. $7^{\text {a }}$ edição 
NETTO, J.S.M. Guerra fiscal entre os estados. Consultoria Legislativa da Câmara dos Deputados. Brasília, 2003.

OWEN, S.H.; DASKIN, M.S. Strategic facility location: a review. Artigo de periódico. European Journal of Operational Research V.111, p.423-447. 1998.

PANTALENA, B.G. Otimização da malha logística de uma indústria química. Trabalho de Formatura (Graduação) - Escola Politécnica, Universidade de São Paulo. São Paulo, 2004.

PIANCASTELLI, M. e PEROBELLI, F. ICMS: evolução recente e guerra fiscal. Brasília: IPEA, fevereiro de 1996 (texto de discussão n. 402).

PRADO, S. e CAVALCANTI, Carlos E.G. A Guerra Fiscal no Brasil. São Paulo: Fundap; Fapesp; Brasília: IPEA, 2000.

Regulamento do ICMS (RICMS) dos estados de Goiás e Minas

Gerais. Disponível em: $<$ https://www.fazenda.mg.gov.br $>\mathrm{e}<$ https://www.sefaz.go.gov.br >. Acesso em novembro de 2006.

RIBEIRO, N.V. Contribuição ao aperfeiçoamento de sistemas logísticos de distribuição no contexto tributário brasileiro : estudo de caso em indústria de bens de consumo. Dissertação (Mestrado) - Faculdade de Economia, Administração e Contabilidade, Universidade de São Paulo. São Paulo, 1999.

RODRIGUES JÚNIOR, M.S. A DVA como instrumento para mensuração da relação custo-benefício na concessão de incentivos fiscais: um estudo de casos. Dissertação (Mestrado) - Faculdade de Economia, Administração e Contabilidade, Universidade de São Paulo. São Paulo, 2003.

RODRIGUES, R.M. Curso de legislação tributária para administradores de empresas. São Paulo: Editora Resenha Tributária, 1978. 
SHAPIRO, J.F. Modeling the supply chain. Pacific Grove: Duxbury, 2001.

VARSANO, R. A guerra fiscal do ICMS: quem ganha e quem perde. Seminário internacional de Políticas Industriais Descentralizadas. Brasília: IPEA/CEPAL, 1996.

VIOL, A.L. O fenômeno da competição tributária: aspectos teóricos e uma análise do caso brasileiro. Monografia vencedora do IV Prêmio de Monografia do Tesouro Nacional. Brasília:1999. Disponível em <www.receita.fazenda.gov.br $>$. Acesso em outubro de 2004.

YOSHIZAKI, H.T.Y. Projeto de redes de distribuição física considerando a influência do imposto de circulação de mercadorias e serviços. 144P. Tese (Livre Docência) - Escola Politécnica, Universidade de São Paulo. São Paulo, 2002. 